University of Redlands

\title{
A Travel Network for Prehistoric Land and Water Navigation
}

\author{
A Major Individual Project submitted in partial satisfaction of the requirements \\ for the degree of Master of Science in Geographic Information Systems \\ by \\ Nicholas Reseburg \\ Mark Kumler, Ph.D., Committee Chair \\ Wesley Bernardini, Ph.D.
}

September 2013 
A Travel Network for Prehistoric Land and Water Navigation

Copyright (C) 2013

by

Nicholas Marc Reseburg 
The report of Nicholas Reseburg is approved.
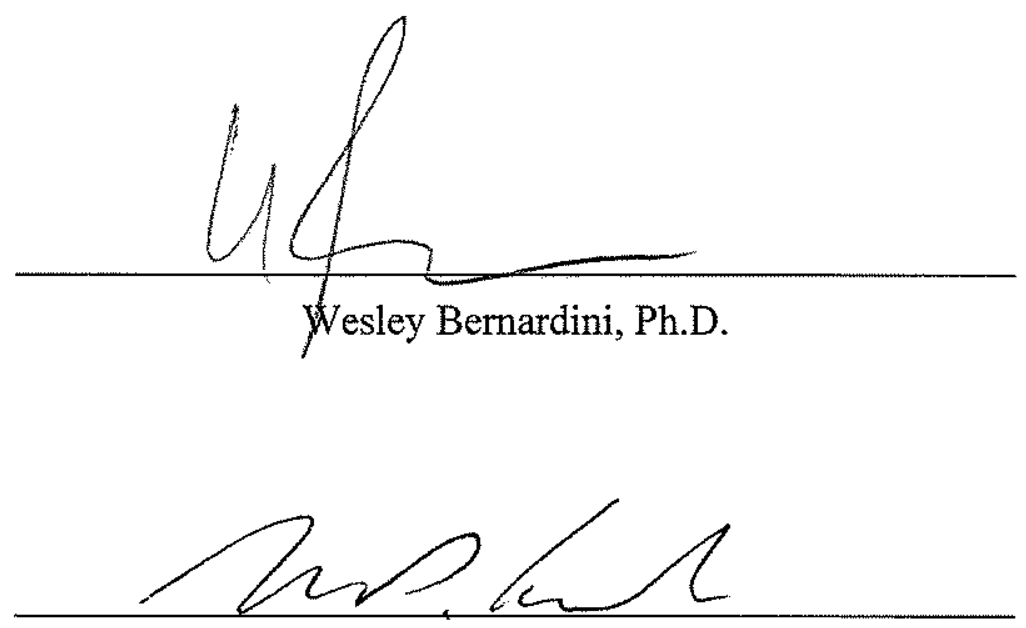

Mark Kumler, Ph.D., Committee Chair

September 2013 



\section{Acknowledgements}

I would like to thank William Hayden. While working under him, I learned countless facets and procedures about GIS and IT through observation of his work and from his direct instruction. This, without any doubt, gave me the foundation I needed to thrive in this program. I would also like to thank James Engstrom. Under his tutelage, I was introduced to what the word "Professionalism" meant and he also afforded me my general introduction to GIS. He provided me with many opportunities as well as the ultimate stepping stone which lead to my sudden and incomprehensible propulsion from white winters of Wisconsin to the sudden and direct heat of the Mojave Desert in California. Finally, I'd like to thank my cat, Pablo, for providing a calming piece of fuzz to balance my anxiety of staring at a blank computer screen, wondering how I was going to finish this program. 



\begin{abstract}
A Travel Network for Prehistoric Land and Water Navigation

by

Nicholas Reseburg

The Hopewell culture created numerous earthworks across the landscape of Southern Ohio and Illinois between $200 \mathrm{BC}$ and 400 AD. Archaeologists believe these earthworks to have been important fixtures in the Hopewell social landscape. Unfortunately, 19th and 20th century agricultural activity destroyed a large majority of the structures.

Archaeologists possess little contextual data from these activities except for brief descriptions and locations provided by early settlers. This project leverages the spatial data that remain with a set of Network Analyst tools to model prehistoric human temporal costs for both land and water navigation. This project permits archaeologists to test theories about social interaction between Hopewell earthwork centers and helps researchers gain insight into the purpose of the earthworks and the communities they
\end{abstract} organized. 



\section{Table of Contents}

Chapter 1 - Introduction ......................................................................................................... 1

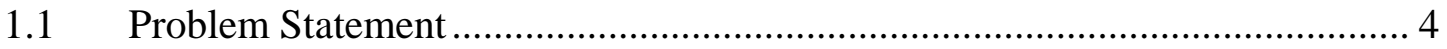

$1.2 \quad$ Functional Requirements .......................................................................

1.3 Proposed Solution ………………………………..................................

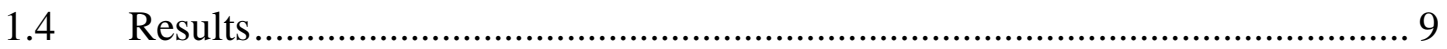

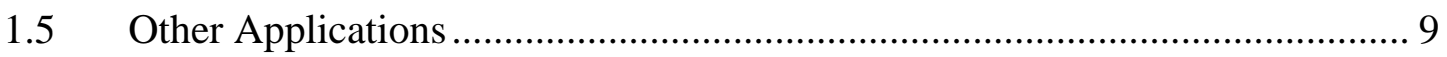

Chapter 2 - Background and Literature Review ............................................................ 11

2.1 Cost Path Analysis in Archaeology ………………........................................ 11

2.1 Network Based Analysis in Archaeology …………................................... 14

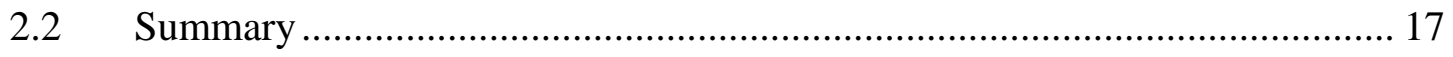

Chapter 3 - Database Design.................................................................................................... 21

3.1 Database Format and Considerations............................................................ 21

$3.2 \quad$ Data Projection....................................................................................... 23

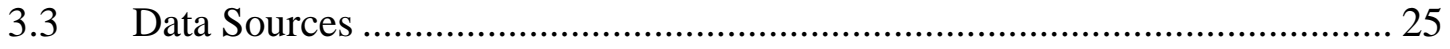

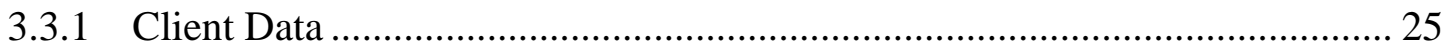

3.3.2 Modified Data from Pre-Existing Datasets ..................................................... 25

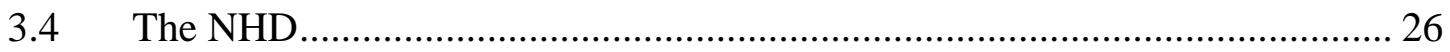

3.4.1 NHD Flowline Featureclass .................................................................. 27

Chapter 4 - Data Construction and Description ............................................................... 29

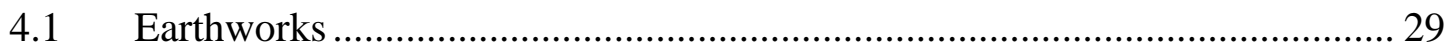

4.1.1 Earthwork Extractor Model ................................................................. 29 


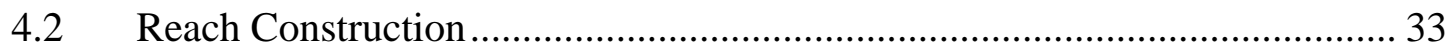

4.2.1 The "Create NHD FC For QC Model" ........................................................... 37

4.2.2 Creation of a Subregional Travel Network for Editing ................................ 42

4.2.3 Editing the subregional travel network containing intermittent reaches ........ 44

4.2.4 The "Import Perennial Reaches" Model .......................................................... 49

4.2.5 Creation of a Subregional Travel Network for Editing .................................. 51

4.2.6 Editing the Subregional Travel Network Containing Perennial Reaches ....... 51

4.2.7 The "Create Reaches_Pres" Model...............................................................52

4.2.8 The "Append Archive Reach Files" Model .................................................. 52

4.2.9 Applying Strahler Ordering to the Reaches .................................................... 53

4.2.10 The "Attribute Impedances" Model .............................................................. 54

4.2.11 Final Steps for the Reaches Feature Class ………………………............... 55

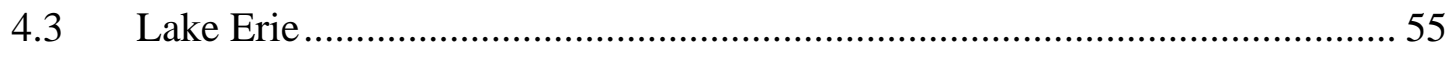

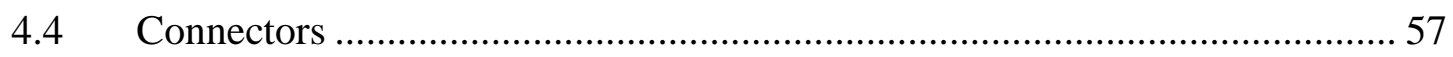

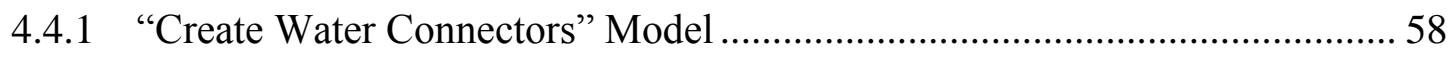

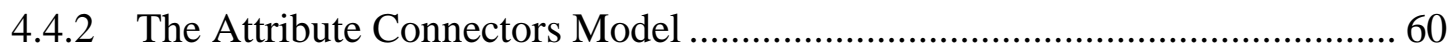

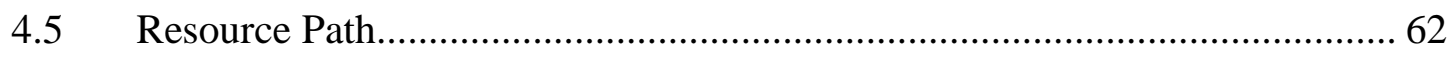

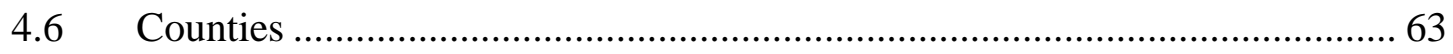

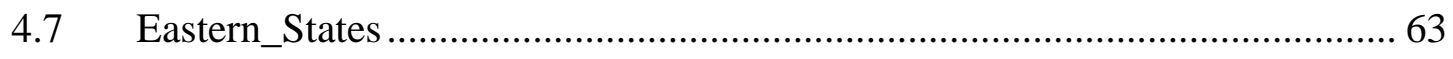

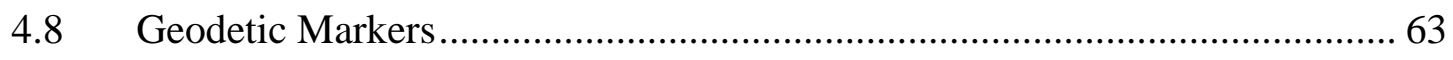

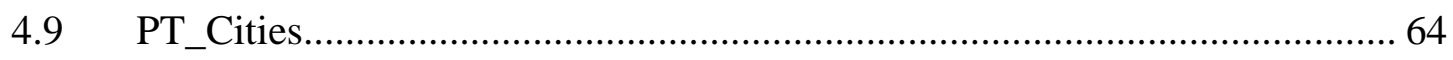

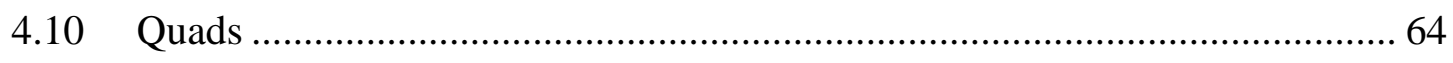

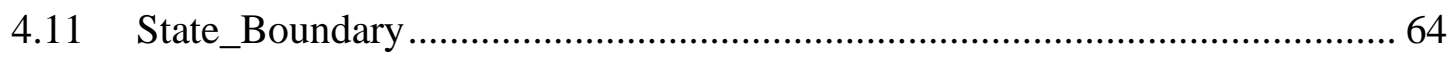




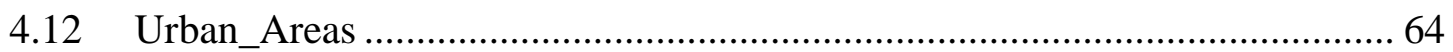

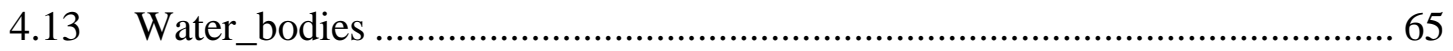

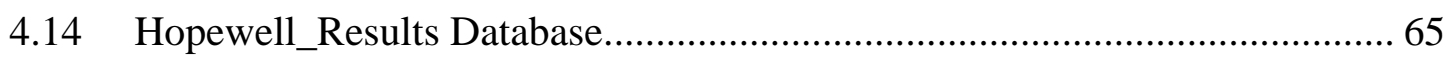

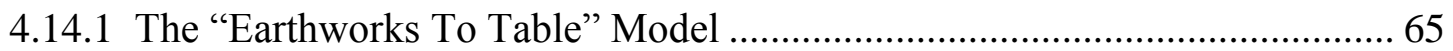

Chapter 5 - Methodology ...........................................................................69 6

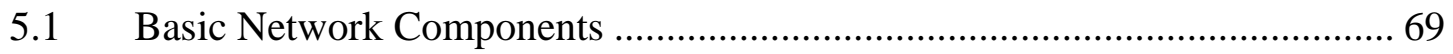

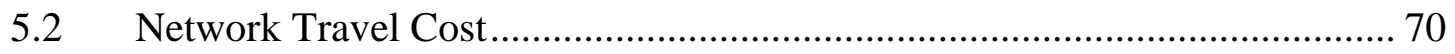

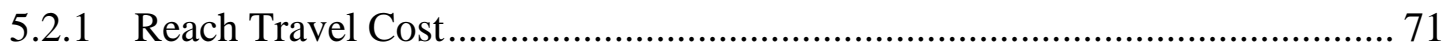

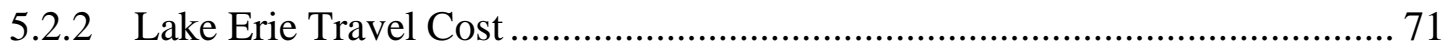

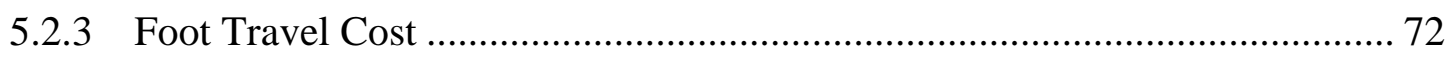

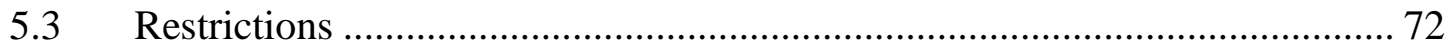

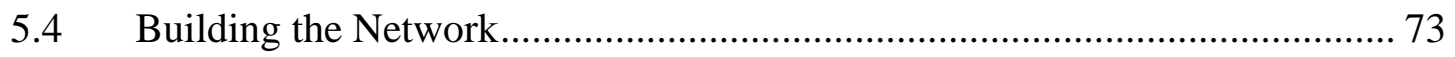

5.5 Service Area Analysis Layer ............................................................ 74

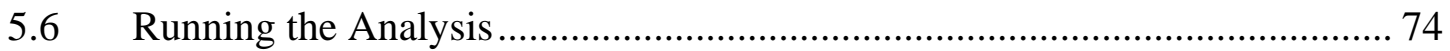

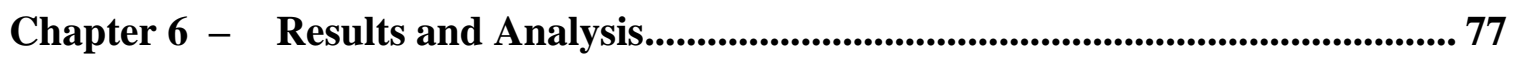

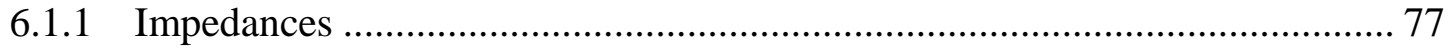

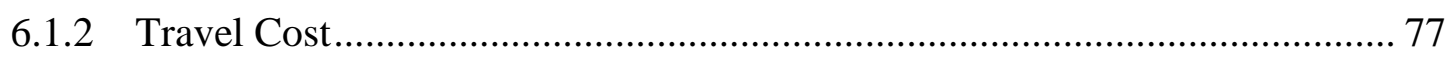

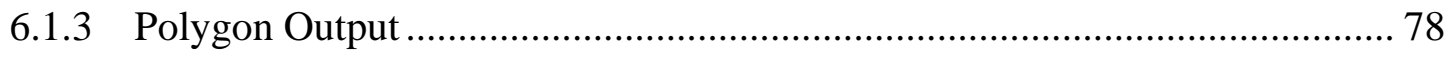

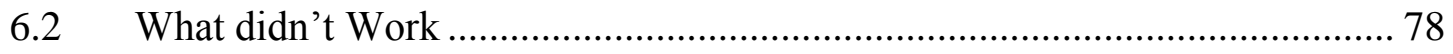

6.2.1 Physical Build Constraint of the Service Area Network ............................. 78

6.2.2 Geoprocessing/Data Construction Tools .................................................. 79

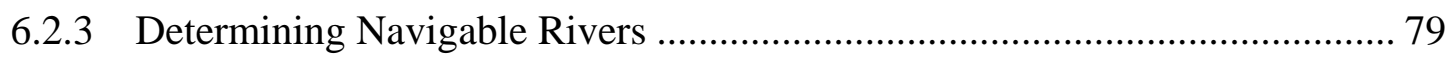

Chapter 7 - Conclusions and Future Work .......................................................... 81 


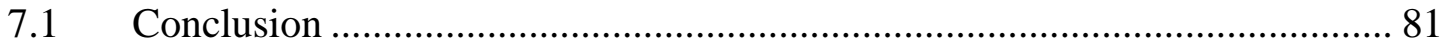

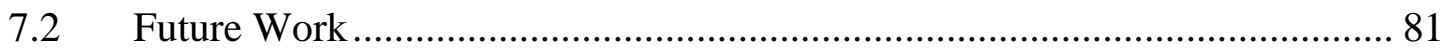

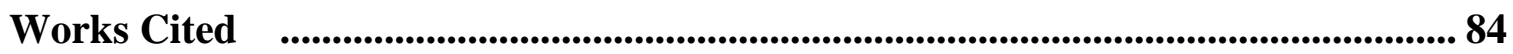




\section{Table of Figures}

Figure 1-1: An Example of a Geometric Earthwork (Bernardini 2004) .....................2

Figure 1-2 Computer Reconstruction of the Turner Geometric Earth Complex.

Photo by CERHAS University of Cincinnati........................................................... 3

Figure 1-3 Earthwork from ground level. Photo by Chris Yao ............................... 3

Figure 1-4: Left: An Illustration of the Vacant Ceremonial Center Theory. Right:

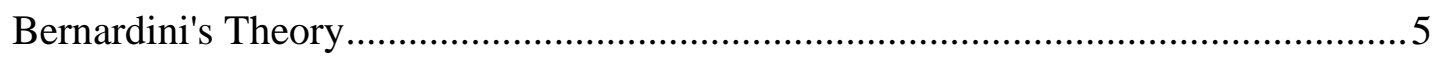

Figure 1-5: Earthwork Distribution in Ohio from Bernardini's (2004) Source Table .6

Figure 1-6: An Example of Strahler Ordering ................................................ 8

Figure 3-1 Personal Geodatabases used in project ............................................22

Figure 3-2: UTM Zones for the State of Ohio with Earthwork Distribution .............24

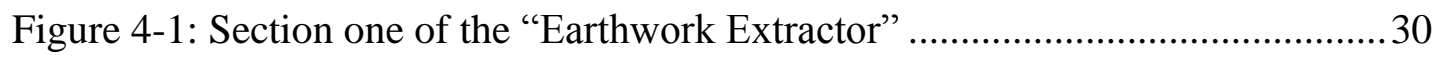

Figure 4-2: Section two of the "Earthwork Extractor" ....................................... 31

Figure 4-3: Section three of the "Earthwork Extractor" ......................................... 32

Figure 4-4: Screen shot from the NHD Viewer showing hydrologic subregions in

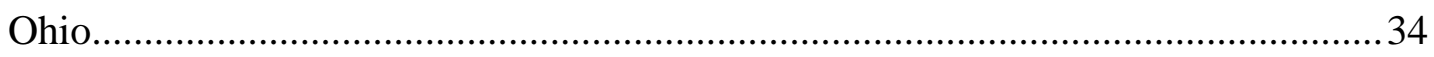

Figure 4-5: “Create NHD FC for QC” section one ................................................ 37

Figure 4-6: An example of an Artificial Path in use .............................................. 39

Figure 4-7: “Create NHD For QC section two" .............................................. 41

Figure 4-8: Examples of connectivity policies in the data................................. 43

Figure 4-9: Travel along the network using cost criteria ................................... 44

Figure 4-10: Attributes for evaluation in an Edit travel network.......................... 44

Figure 4-11: Steps of solving a network analyst service layer ........................... 45 
Figure 4-12: Results of a typical service area network solve with a disconnect ....... 46

Figure 4-13: Example of a physical error in the NHD ....................................... 47

Figure 4-14: Example of a natural disconnect in the NHD ................................. 47

Figure 4-15 A Subregion Prior to and After Removal of Intermittent Reaches........ 49

Figure 4-16: The "Import Perennial Reaches" Model.......................................... 50

Figure 4-17: The "Create Reaches_PreS" Model.................................................. 52

Figure 4-18: The "Append Archive Reach Files" Model....................................... 53

Figure 4-19: The "Attribute Impedances" model ................................................ 55

Figure 4-20: Example of a new segment added to the Lake Erie feature class ......... 57

Figure 4-21: Section one of the Create Water Connectors model .......................... 59

Figure 4-22: Section two of the "Create Water Connectors" model ........................ 59

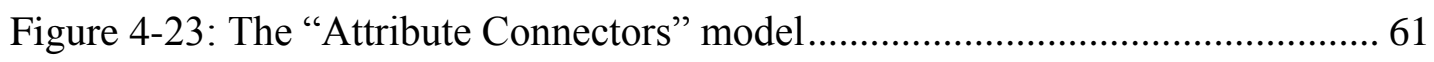

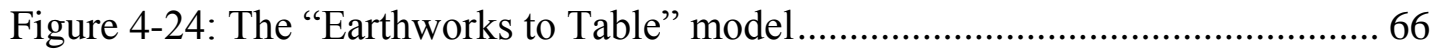

Figure 5-1: Basic Network Components and Their Interaction ............................ 69

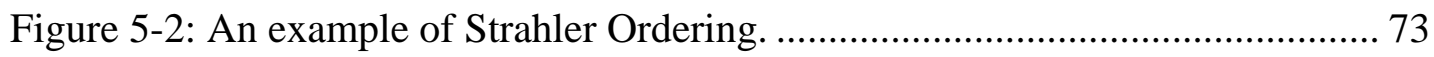

Figure 5-3: Final Network Connectivity Settings ............................................ 74 


\section{List of Tables}

Table 1. Values Represented by FTypes and their description ............................... 27

Table 2. Earthwork_DB fields used by the "Earthwork Extractor" Model ............. 30

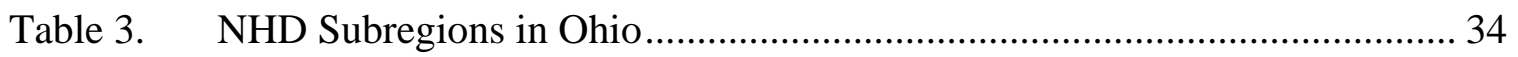

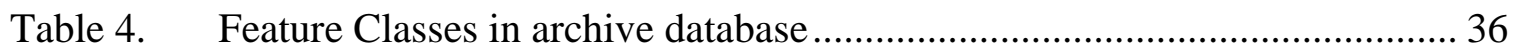

Table 5. Subtypes for the Ftype field of the NHDFlowline feature class ................... 38

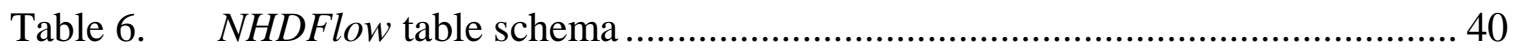

Table 7. The ComID for the NHDFlowline featureclass ........................................ 40

Table 8. Fields added by the NHD FC For $Q C$ model ........................................ 41

Table 9. The Situation and Check Code Domains ............................................... 42

Table 10. Fields added by RivEx tool to the Ohio_Reaches featureclass..................... 54

Table 11. Fields added by the "Attribute Impedances" model .................................. 55

Table 12. Fields added by the Create Water Connectors and Attribute Connectors

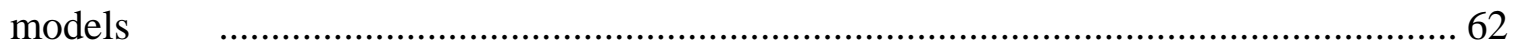

Table 13. Analysis fields added to the Earthworks to Table model .............................. 67 



\section{List of Acronyms and Definitions}

$\begin{array}{ll}\text { NHD } & \text { National Hydrography Dataset } \\ \text { USGS } & \text { United States Geological Survey } \\ \text { QTM } & \text { Universal Transverse Mercator } \\ \text { VBA } & \text { Quality Control } \\ \text { NAD } & \text { North American Datum } \\ \text { SQL } & \text { Structured Query Language } \\ \text { US } & \text { United States } \\ \text { PGDB } & \text { Personal Geodatabase } \\ \text { Esri } & \text { Environmental Systems Research Institute }\end{array}$





\section{Chapter 1 - Introduction}

Geographic Information Systems (GIS) are tools for exploring spatial relationships. Archaeology couples the spatial context of artifacts with the meaningful analysis of past cultures. GIS and archaeology are therefore natural bedmates given this tightly correlated relationship. Artifact position within a site imparts greater importance to the understanding of past life ways than the mere physical artifacts themselves. The spatial relationship of artifacts tells the story of the people who made them - how the objects were used in their lives (Renfrew and Bahn 2000). Rather than just cataloging discarded human possessions, archaeology studies how humans lived in the past. This paper documents a GIS that was built to aid in archaeological study of the Hopewell culture in what is now Ohio.

The Hopewell Culture thrived in Ohio from approximately $200 \mathrm{BC}$ to $400 \mathrm{AD}$ (Fagan 1995). They represent themselves in the archaeological record with burial mounds and elaborate artifacts found in context within these burial mounds. Physical artifacts include bear teeth, clay and stone figurines (both animal and anthropomorphic), abstract and animal representations made from sheet copper, effigy smoking pipes, and conch shells (Fagan 1995; Bernardini 2004; Carr 2006). These artifacts, in conjunction with their location within the burial mounds, allude to an elaborate ceremonial burial process. These artifacts also indicate an elaborate trade network since items such as copper and conch shells were not available locally. This well-known trade network is often called the “Hopewell Interaction Sphere” (Charles 1992).

In addition to these burial mounds, the Hopewell also constructed large geometric earthworks with earthen wall berms up to 5.2 meters in high and 15 meters wide. These 
geometric patterns (Figure 1-1, Figure 1-2, Figure 1-3) surrounded tens of acres with widths more than $300 \mathrm{~m}$ (Bernardini 2004). The Ohio landscape once possessed dozens of these earthworks. Early farming practices of 18th and 19th century settlers in the region destroyed many of these important structures (Bernardini, 2004). All that we have left of the earthworks are estimated locations and descriptions noted by early settlers in the region. In many cases, the spatial data that remain can be recorded in a GIS allowing spatial analysis to be performed on this valuable dataset.

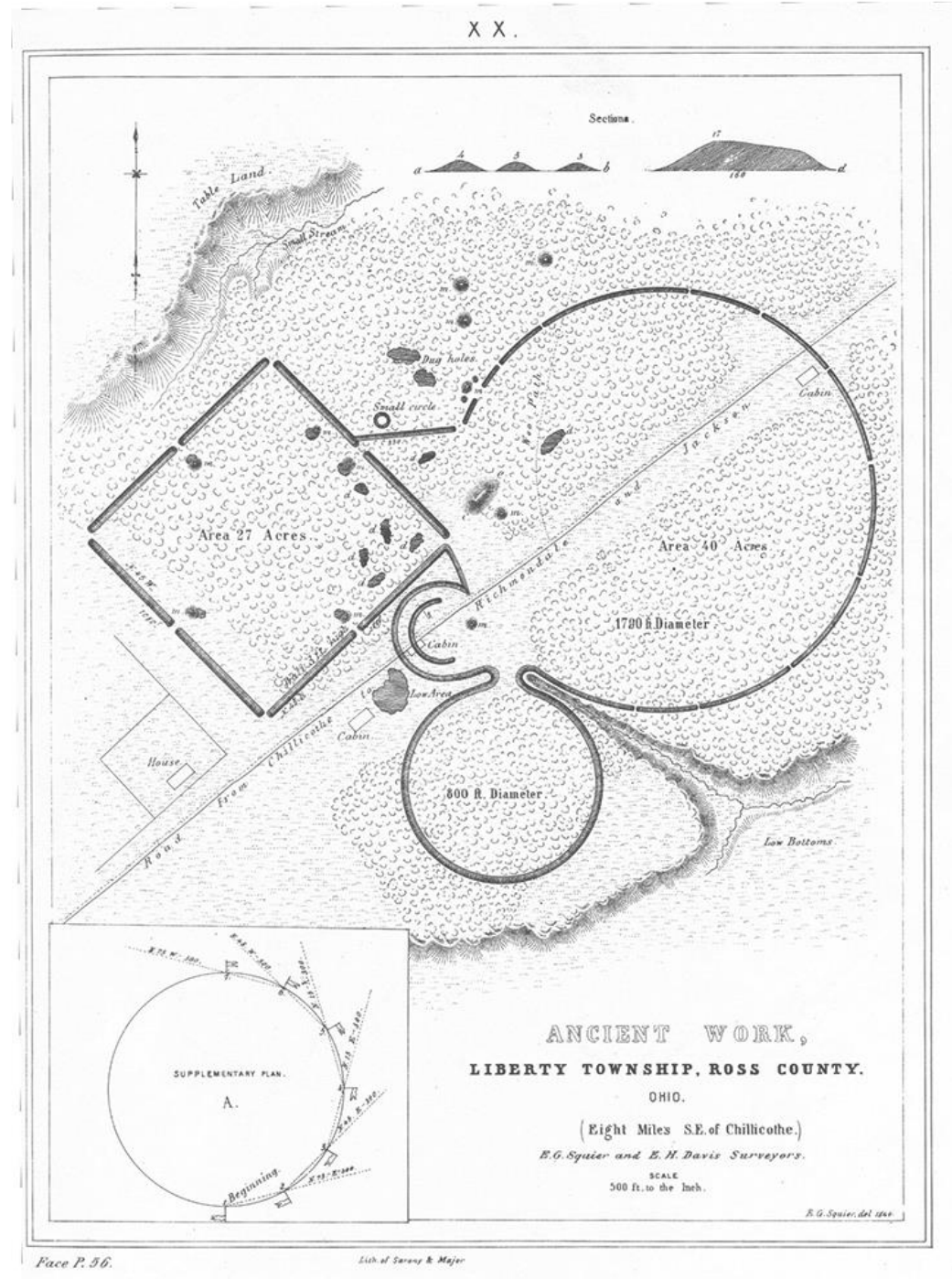

Figure 1-1: An Example of a Geometric Earthwork (Bernardini 2004) 


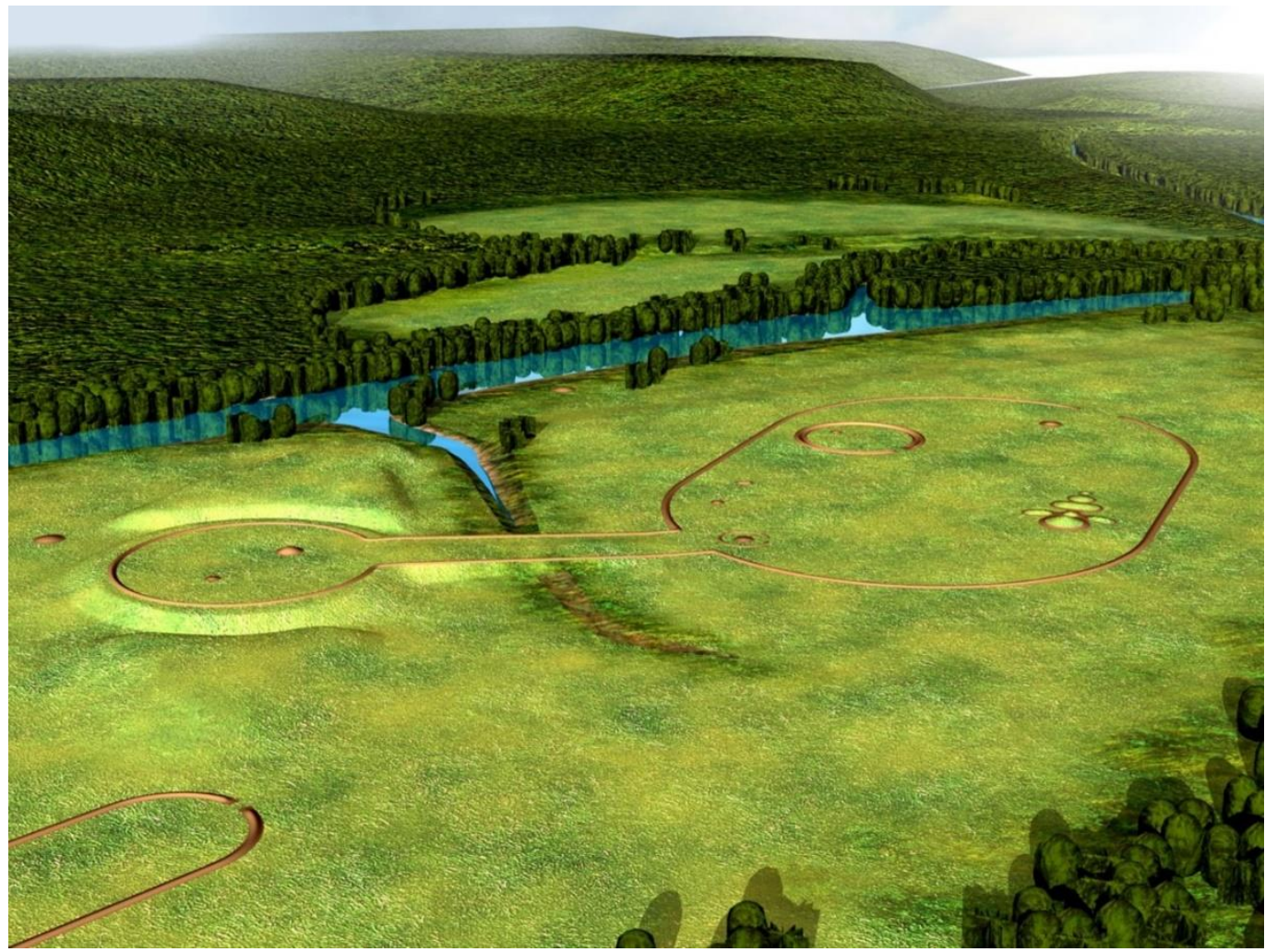

Figure 1-2 Computer Reconstruction of the Turner Geometric Earth Complex. Photo by CERHAS University of Cincinnati

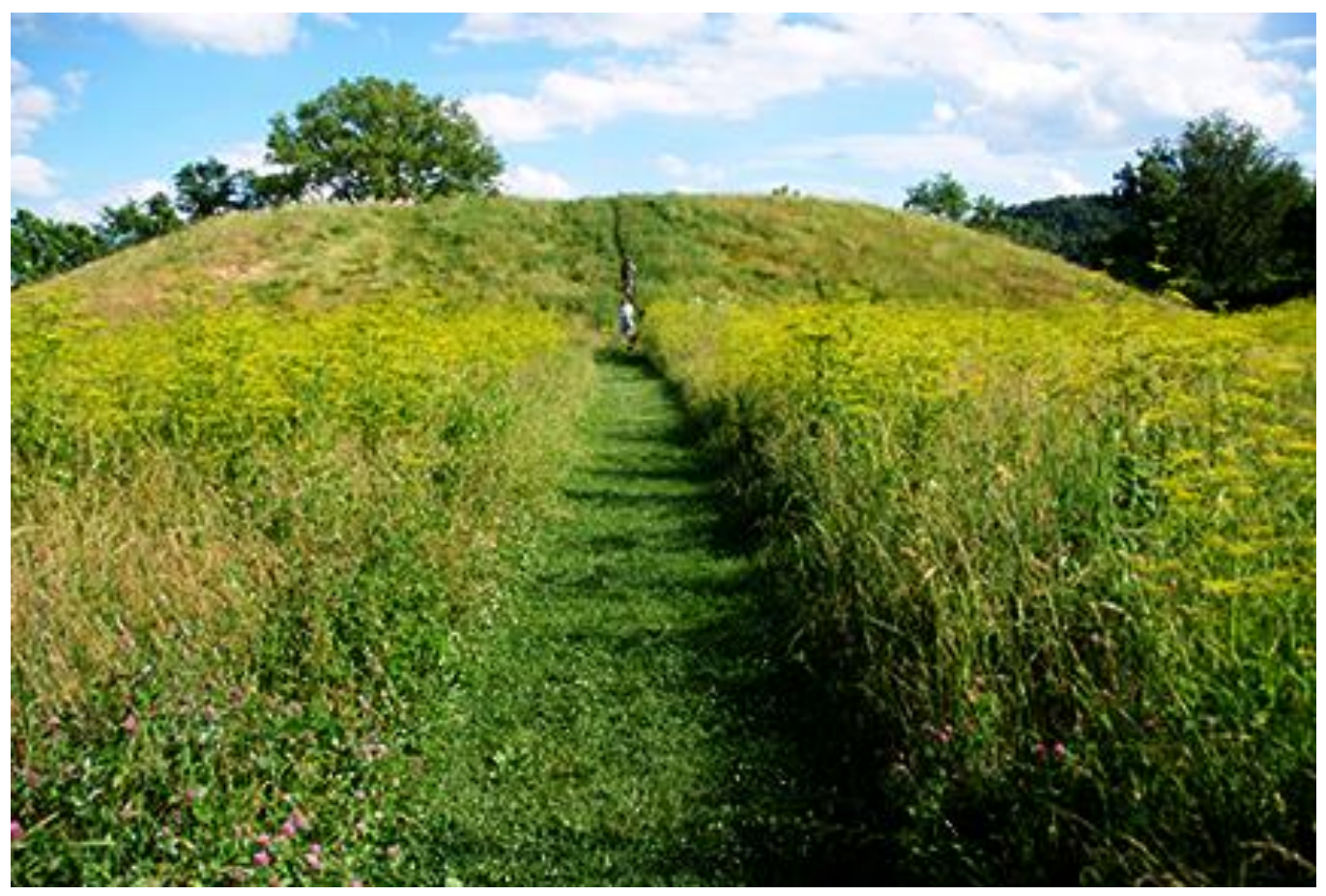

Figure 1-3 Earthwork from ground level. Photo by Chris Yao 


\subsection{Problem Statement}

Current popular Hopewell research asserts the theory of the "vacant ceremonial center". Ruby (2004) states the theory was originally proposed by Prufer (1964) and later updated by Dancey and Pacheo (1997). This theory proposes that the earthworks were built by a small local community of transitory hamlets surrounding the earthwork. The theory also theorizes that only the people living in these hamlets utilized the earthworks for ceremonial purposes (Figure 1-4).

Dr. Wesley Bernardini, an Associate Professor at the University of Redlands, is an anthropologist who specializes in archaeology. He believes that the vacant ceremonial center theory is not an adequate explanation for the earthworks. His research demonstrates that the amount of human energy involved in making an earthwork would require a much greater labor pool than could be supplied by a few dispersed hamlets surrounding each earthwork (Bernardini 2004).

He proposes instead that the earthworks were a collaboration of human effort on a much greater regional scale both in construction and utilization. He hypothesizes that the earthworks:

... may have been constructed along lines of movement rather than in centers of defended territories, and thus may not correspond in direct ways of local communities (Bernardinini 2004 II 336)

The assertion that the earthworks were regional centers for many people, rather than a few dispersed hamlets around each earthwork has significant implications to the Hopewell social landscape. This contention suggests a much greater degree of interaction among both the leaders and participants in earthwork rituals across present day Ohio. 


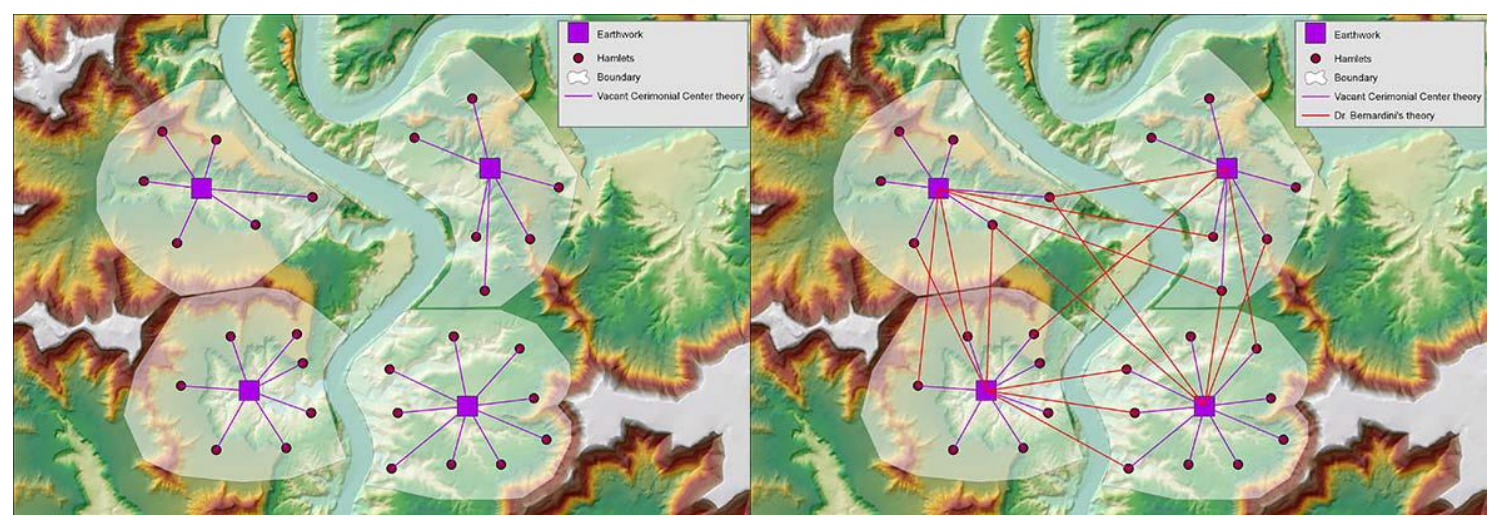

Figure 1-4: Left: An Illustration of the Vacant Ceremonial Center Theory. Right: Bernardini's Theory

Traditional archaeological survey and excavation techniques have been somewhat limited for investigating this problem. The past century of Hopewell archaeology focused mainly on burial mounds and the associated grave goods. This bias ignored habitation sites which would have produced a body of data either challenging or supporting the “vacant ceremonial center" theory. Bernardini (2004) notes that Dancey \& Ponchey (1997) have shown that as of 1997, only 91 non mortuary Hopewell sites have been recorded for the State of Ohio. Of those non-mortuary sites, many possess only marginal candidacy for residential status (Bernardini 2004). However, the few archaeological projects specifically seeking habitation sites in Ohio revealed that these sites are often deeply buried and thus difficult to locate.

Another constraint to archaeological investigation of the earthworks' purpose is farming and lumber activities. These historic and modern actions destroy the landscape, making site location even more difficult (Bernardini 2004). In light of these issues, the spatial data from the earthworks become one of the few resources from which archaeologists can wrest information on Hopewell political and societal structure from. 
As indicated earlier, early settlers destroyed the majority of known Hopewell earthworks in the 18th and 19th century. Historic records (Bernardini, 2004) are the only sources available for many of the earthworks' locations. Bernardini derived earthwork locations in modern space by consulting these and other historical accounts (Figure 1-5), compiling the most complete documented spatial locational dataset of the Hopewell geometric earthworks to date (August 2007).

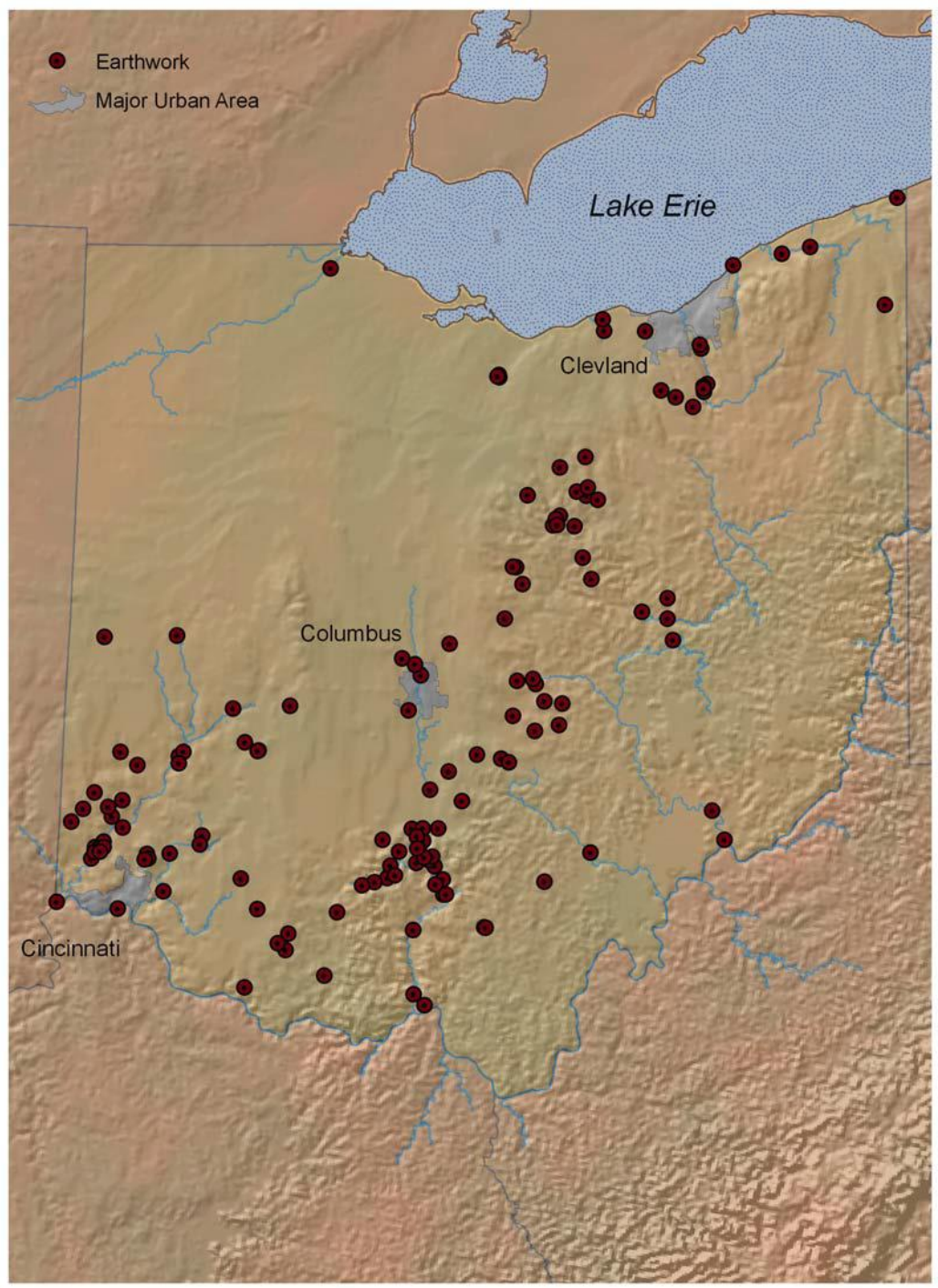

Figure 1-5: Earthwork Distribution in Ohio from Bernardini's (2004) Source Table 


\subsection{Functional Requirements}

The client requested a GIS tool that would help him support his theory using his compiled locations on the earthworks. His specific request was for a tool that would allow him to model how far a hypothetical Hopewell Indian could travel in a day from a given earthwork using Ohio's river system.

The tool was further specified to operate on a personal computer running ArcGIS $^{\text {TM }}$. The system was intended to be used by one researcher at a time to produce graphical and tabular expressions of which earthworks are within a day's travel from a given location on the network. This means that the database management system would not need to support multiple users and an Enterprise database system was not required.

\subsection{Proposed Solution}

To meet the functional requirements requested by the client, a vector-based travel network was built. This allowed the modeling of radiating travel behavior from a central source. The network was meant to model travel on a regional scale. The fastest way to travel long distances 2,200 years ago in this region was in boats along the river systems. Thus the GIS was primarily concerned with river travel.

The network consisted of hydrography data adapted from the United States Geological Survey (USGS) National Hydrography Dataset (NHD). These datasets are easily downloadable from the USGS's website (ftp://nhdftp.usgs.gov/SubRegions/). The data were formed into a travel network for the entire State of Ohio. Strahler (1957) stream orders were calculated for each reach on the network. Strahler ordering is a method of ordering rivers based on their interrelation to other rivers in the drainage 
system, giving rivers further down the system higher numbers than rivers that begin the system (Figure 1-6).

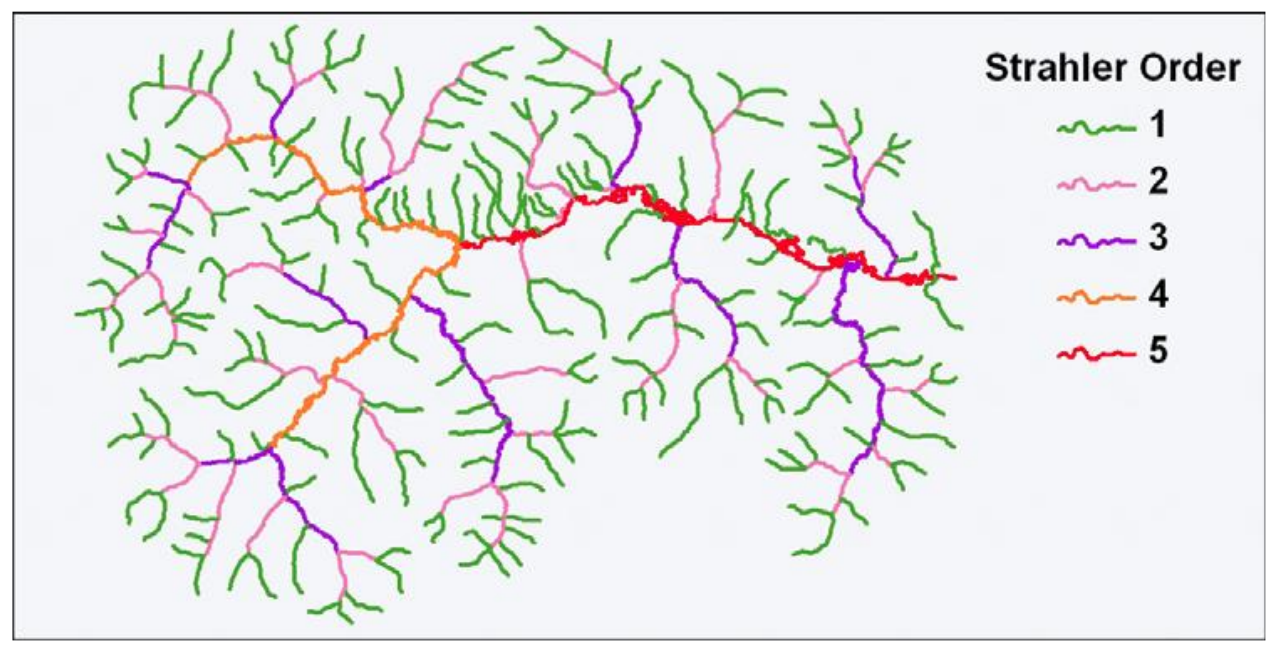

\section{Figure 1-6: An Example of Strahler Ordering}

This position can be related to water flow, as more flows near the end of the drainage system than the beginning. Being able to identify and favor rivers that have more water flow than others gives the researcher a form of control over what constitutes navigable rivers in the network when analysis is run.

Earthwork locations from the client were added as a point feature layer. The locations where the earthworks connected to the river network, as well as paths to these connectors from the earthworks, were generated by a series of models built in ModelBuilder in addition to scripts programmed in the Visual Basic for Applications (VBA) environment. A service layer analysis (which is an analysis which computes the spatial distance that can be covered in a set time, originally designed to compute the service area for delivery businesses) was then run on the network with time in hours as the major constraint and the earthworks as the facilities. River speeds, both upstream and downstream, were 
derived in kilometers per hour based on hypothetical prehistoric canoe speeds in the Northeast (Little, 1987; Brose, 1990).

\subsection{Results}

The model consistently recreated dugout canoe travel and it produced the same set of distance results when repeated after the original analysis. Distances traveled were routinely modeled greater downstream than they were upstream. Earthworks within range of other earthworks were successfully isolated and written as both standalone tables and as geographic points. These results can be used by the client in his research assessing the interconnectivity of the Hopewell earthworks.

\subsection{Other Applications}

The network model for this GIS can also be applied to other realms of analysis in archaeology. A prehistoric river transportation network has numerous applications for other types of archaeological analysis, such as trade routes and inter-site connectivity. The database design and network building process can be duplicated for other regions of the United States that contain navigable rivers. Earthwork locations can be replaced with known archaeological sites such as quarries, villages, campsites, or lithic reduction sites for other archaeological situations. 



\section{Chapter 2 - Background and Literature Review}

The importance of spatial relations in archaeological research led archaeologists to embrace GIS technology once it became economically feasible. The literature abounds with accounts of archaeologists using GIS in their research in the 1990's.

To model inter regional travel, two approaches were researched: the cost path raster-based approach, and the network vector based approach.

\subsection{Cost Path Analysis in Archaeology}

Hayden uses a quote from Hodges that nicely summarizes the early roots of traditional cost path analysis and their relevance to archaeology in his 1996 Master's Thesis:

Von Thünen's model of relationships between spatial distributions of activities and landuse around a centre galvanized [Clarke's] attention as, it did many of his contemporaries then teaching and studying at Cambridge. The essence of Von Thünen's model, published in 1826 in Der isolierte Staat, is the law of diminishing returns with distance.

Archaeologists, much impressed with Chisholm's use of it in his Land Use and Settlement (1968), adapted it to what is familiarly called site catchment analysis (Higgs and VitaFinzi, 1970, 1972). A second model used by Clarke and his contemporaries was Alfred Weber's concept of minimum energy/least-cost locations (Clarke, 1977:22-23). Hunter-Gatherer (mobile) strategies have been described using this framework until the inception of ethno-archaeology applied a cautionary brake on the use of concepts like this (Binford, 1983:202). (Hayden, 1996, Chapter II, II 19-20).

Tobler, in a technical report to the National Center for Geographical Information and Analysis (NCGIA), went into detail about how these models can be used in a GIS for a more complex surface component than could be used in these models during the early 1960s when they originated (Tobler 1993). He also gave formulas for the equations of the energetic cost computation for pedestrian travel in the models. 
Archaeologist S.H. Savage employed cost/path analysis in the early 1990's in a different way than simply calculating foot travel distance. He did his study in northeastern Georgia/southwestern South Carolina and proposed the hypothesis that Late Archaic tribal landscapes had maximum boundaries dependent on the local resources and reasonably navigable distance from them (1990). He used four test implications that he derived from his hypothesis and tested them using a GIS. Performing a cost path analysis of terrain and hydrologic data. He used two factors in his calculations: slope and terrain roughness. This least accessibility on foot stemmed from inadequate applications of existing knowledge on pedestrian travel in the field of archaeology (Machovina, 1996). He researched physiological data and sought to create a new technique for using a GIS to model human travel over rough terrain. To implement this, he laid out a physical grid simulating the cell structure of a GIS near Mound City (built by the Hopewell), Ohio, and actually walked it. He used GIS to analyze the least cost path produced by traditional methods, then fine-tuned the best method with his own calculations to fit what he saw. Then, using formulas he researched from the physiological journals, he adjusted his energetic cost formula to accommodate such factors as load carried, height of person, speed, etc. (Machovina, 1996).

In 1990 an archaeologist detailed the energetic cost of movement for humans paddling a dugout canoe (Brose, 1990). Brose provided detail, including formulas, on how to calculate metabolic rates for humans using dugout canoes in the eastern United States, where the study area happens to be for this project (Brose, 1990). His data were based on an article by Little (1987). Little went through five historical travel logs to 
determine an average speed for birchbark canoe travel both up and down stream (Little, 1987). Brose then modified Little's calculations for dugout canoe travel estimation. In 1998, Lee and Stanley published an article in the International Journal of Geographic Information Science that discussed the feasibility of uniting viewshed analysis with cost path analysis. The authors discussed how they used slope and terrain distance factors with the combination of the viewshed process. They also ran algorithms for four different types of paths: hidden, strategic, scenic, and withdrawn (Lee and Stanley, 1998). At the end of their article they suggested using vector data for decision making as opposed to the standard eight neighbor analysis algorithm.

Llobera (2000) has done much work along the lines of visualscapes, which are what Lee and Stucky (1998) demonstrated in their model incorporating a viewshed into the cost path analysis. Llobera went in to more depth and as an archaeologist applies his theories specifically to archaeology. He defined visualscape as how the GIS tries to analyze the landscape as a human walking across would see it, not from the allencompassing, all-seeing, up-above as a GIS is naturally implemented. In this 2003 article, Llobera recounted the history of visualscapes and the ways this concept of analysis has been run in the past in both urban and natural terrains. Llobera then suggested that vector data would be helpful in running a visualscape based cost path analysis (2003).

In 2002, an American named Whitley (2002) wrote an article in which he addressed some key issues about visualscapes, comparing them with the predictive models that were being made in the US at the time by such researchers as Hayden and Savage. Whitley discussed taking ideas from both these areas of research and making 
what he called spatial proxies. He defined them as follows: "Spatial proxies, simply put, are measurable spatial variables which 'stand-in' for those which are not measurable" (2002). He used an agent based GIS (in which a small program is run in the GIS which reacts to programmed environmental factors) to model human behavior using two examples. Essentially, the agents went in a landscape and made decisions. The spatial proxies were then implemented against the agents' behavior through the GIS (Whitley 2002).

In 2007, Howey (2007) wrote an article currently in press dealing with cost path regional movement of prehistoric peoples in Michigan. She used three different costs for the friction surface: water, prehistoric vegetation, and slope. This friction surface was then used to model movement from known archaeological sites to ceremonial centers in Michigan.

Balstrøm (2002) used non-visualscape methods to find a least cost path for 16 locations in a mountainous area. To accomplish this, he ran a traditional cost path friction analysis using DEM data between his locations, performing 15 least cost paths for each station. He then created a network model from the cost paths to analyze the most efficient route to take along the network to get to all 16 locations.

\subsection{Network Based Analysis in Archaeology}

Wheatley and Gillings, in a 2002 book describing GIS and its relationship with archaeology, described a network analysis as:

Network analysis is really just a geographer's term for a subset of a branch of mathematics called graph theory (see e.g. Wilson 1985 for an introduction). In network analyses, systems of lines are represented in terms of arcs, which end at 
nodes. The arcs may only be connected at the nodes. (Wheatley and Gillings, 2002I 135)

Batty noted that " the notion of describing networks within GIS - in its science as well as its software - is curiously underdeveloped." (Batty, 2005). In light of this observation, it is interesting to note that archaeologists paralleled this sentiment and carried out few movement studies using vector networks in the literature. This has been documented by Wheatley and Gillings (2002) and was still the case in 2007. There are several archaeologists, however, who use vector networks to study movement.

Bell (1985) used a vector network to study Classic period (AD 600 - 900) Mayan settlement patterns in the Valley of Mexico, in addition to Aztec patterns in the same region just prior to Spanish conquest. This analysis focused on the evolution of human settlement across a landscape rather than merely just movement across it in a single trip.

Allen (1990) created a vector network to model historic trade between the Europeans and the local Native American population for the Historic period (AD $1550-1750)$ of the state of New York. She used rivers as the major form of transport and modeled trade between known fort/trading posts and known Native American villages. She then ran the model and recorded results, such as an obvious shift in the early years from a north/south pattern to an east/west flow of trade in conjunction with the arrival of more European trading posts (Allen, 1990). In this study a vector network was used to model trade growth across a landscape. 
At the same time Allen was running her analysis, Zubrow (1990) performed a similar analysis on prehistoric New York. Zubrow, however, used a vector network derived from the New York river network that Allen used to model European settlement based on their contact with the native population and the established hydrology at the time. Specifically, known population centers were given a location and a population threshold. Hypothetical people would migrate to and from centers based on this threshold and travel routes through the hydrology of the state (Zubrow, 1990). Again, a vector network was used to analyze gradual human settlement over a terrain rather than analyzing a single trip by a human for a specific purpose, similar to Bell (1985).

Mackie explored the spatial importance of sites in his doctoral dissertation. He studied site allocation on Vancouver Island in Canada. Specifically, "analysis is applied to a network formed by transportation linkages between 238 habitation zones, created by clustering 576 archaeological sites" (Mackie, 1998). He created an allocation-location model that explored movement along this network and found that sites that were more centrally accessible were often larger in the archaeological record, indicating frequent use (Mackie, 1998). This was an example of a vector network being used to explore interconnectivity of sites on a landscape.

In 2004, Branting wrote his doctoral dissertation on creating a travel network for the Iron Age city of Kerkens Dağ in Anatolia (modern-day Turkey). He created a vector network for movement through the ancient city, then used a transport GIS already in place for the city of Cambridge. He used patterns that he found in the modern city to explore the potential traffic flows in the network he created for Kerkens Dağ (Branting 2004). While this GIS did not perform regional analysis, it was a very thorough and well 
documented use of modeling prehistoric movement of people within a vector network and is the first article in the archaeological literature to address human movement at the single trip level with a vector-based network.

\subsection{Summary}

Dr. Bernardini's problem lent itself more effectively to a network analysis approach over the traditional cost-path analysis usually performed for prehistoric regional travel quandaries. Dr. Bernardini's main tenet for a tool to model travel out from a given point in a given amount of time was an ideal problem for a travel network. Traditional cost path analysis requires travel to and from a known point. Network analysis does not have this stipulation; it allows for modeling travel from one point outward without regard for an actual destination.

Another advantage of using a travel network over conventional cost-path analysis was the nature of the earthworks spatial data itself that Dr. Bernardini compiled; specifically, the speed difference between the distances one would have to travel from the earthwork to the nearest river over land can be easily accommodated in the analysis.

The earthworks database contains estimated locations of the earthworks. Sometimes these estimates were limited to within a section of a township. Sometimes the accuracy was improved to a quarter quarter section, which had about a quarter mile by quarter mile area of uncertainty of the earthwork location. USGS Maps had an accuracy of about twelve meters according to USGS specifications. Given the discrepancies in the accuracy of the two sources, plotting a least cost path that is likely to be the same size, if not smaller, than the uncertainty of one of its destinations is not practical. Terrain data would be irrelevant to creating a friction surface as the exact location of the earthwork is 
not known within a square mile. In addition, consideration must be taken for the problem of raster representation.

Converting rivers into raster cells necessary for a cost path analysis would lose the identity of the reach into the surrounding terrain (Longley, 2005). This means a loss of resolution of the reach representation. The raster surface that would have been used for this analysis would have been USGS Digital elevation data at a resolution of $1 / 3$ arc second, which was a grid size around nine meters by nine meters. This means that a stream that is only three meters wide would regress in resolution to being shown as nine meter by nine meter blocks. Since the river system is the main mode of travel simulated in this GIS, this was not acceptable.

On the other hand, networks are concerned with point data and the connections between these points rather than absolute location of the point data (Wheatley and Gillings, 2002). This was ideally suited for Dr. Bernardini’s spatial data set of estimated locations and their connections to rivers and allowed for the original resolution be perserved.

Another advantage of the network approach was the nature of hydrologic systems. They tend to lend themselves easily to network analysis. They are naturally topologically connected rivers need to be connected in order to physically flow into each other. The resources can easily be represented in a GIS flowing to and from each other along a $1^{\text {st }}$ dimensional path, even when the actual body of water itself expands into $2^{\text {nd }}$ or $3^{\text {rd }}$ dimensional bodies in the GIS (Olivera, 2002) .

Another important facet of networks was the ability to model different costs for movement along a segment based on direction (ESRI, 2006). This easily allows for 
different rates of movement to be calculated for upstream movement and downstream movement. In addition it allows for creating different canoe speeds for Lake Erie on the northern border of Ohio. The Hopewell undoubtedly used this resource, but canoeing on a major body of water is different than canoeing on a river.

To this end, the GIS tool documented here used the vector network approach to model travel between the earthworks. The tool consisted of a multi-modal travel network containing the archaeological resources (in this case, earthworks), rivers of Ohio, and land paths from earthworks to the rivers. This network modeled dugout canoe travel between geometric earthworks in Ohio in addition to land trips from the river to the intended earthwork. The GIS allowed for the inclusion of archaeological features other than earthworks, but for the initial pilot project only earthworks were included.

Dr. Bernardini hopes to lend credence to his theory using this tool by demonstrating that the geometric earthworks of the Hopewell were within a reasonable day's travel by river of each other. This includes time for meaningful interaction at each earthwork, as well as travel to the next. 



\section{Chapter 3 - Database Design}

This project utilized two main types of spatial data to model Hopewell canoe travel: data on river locations/networks and data on Hopewell Earthwork mound locations. The federal government supplied river data and other hydrologic spatial data for the United States free of charge through the National Hydrology Dataset (NHD). The client supplied the Earthwork spatial locations in the form of Microsoft Excel tables. These two data sets required heavy modification in order to function in the GIS and to model human behavior 1,600 years ago. This chapter discusses database design, data projection, and sources for reference data in the project.

\subsection{Database Format and Considerations}

The heart of any GIS is its spatial database (Zeiler, 1999). ArcGIS currently uses a large array of spatial-database formats. These run the gamut of choices available in the database industry, from large enterprise systems such as Oracle to self-contained personal database formats such as Microsoft Access. ESRI also developed its own proprietary format, the file geodatabase, which is self-contained like Access but offers large datastorage ability similar to an enterprise system.

Ultimately, a personal geodatabase using the Microsoft 2000 Jet 4.0 engine was the best choice for this project. The personal geodatabase boasts two strong advantages over other formats: portability and ease of use. These factors contributed greatly to allowing the end user (the client), who has relatively little database training, to use the GIS system efficiently without the need for extensive training and setup. They also allow for relatively easy database maintenance. 
One major issue arose when the Access database format was used: data-storage limits. Currently, this database format offers a maximum storage size of two gigabytes (GB). A combination of four Personal Geodatabases provided all the data storage needs for this project (Figure 3.1).

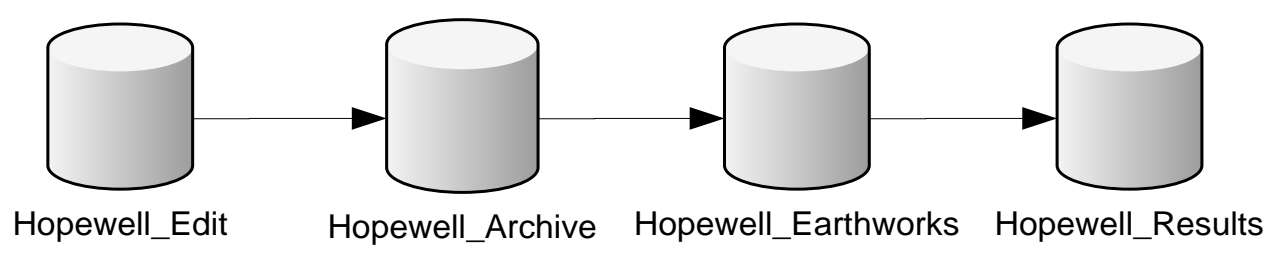

\section{Figure 3-1 Personal Geodatabases used in project}

The Hopewell_Edit database housed initial raw reach data from the NHD for construction into the network. In this database, all reaches were modified to function in the canoe-travel network. Once the edits were completed, these data sets were moved over to the Hopewell_Archive database.

The Hopewell_Archive database stored properly constructed reaches in the network. One of the overall requirements for the travel network was that it occasionally had to be rebuilt as new data became available. The rebuilding process pulled reach data from the Hopewell_Archive database.

All of the actual analysis in the GIS took place in the Hopewell_Earthworks database. It housed the travel network and relation tables, as well as reference data such as modern-day state boundaries and urban areas. In addition, the tables used for earthwork construction were stored in this database.

The Hopewell_Results database contained all the outcomes produced by the GIS. Results came in two forms: feature classes and tables. The Microsoft format of this 
personal geodatabase allowed the client to export data into Excel tables that facilitated research.

\subsection{Data Projection}

In a GIS, bytes and bits are used to represent features such as earthworks or rivers. In reality, such features exist on the Earth, which is a three-dimensional ellipsoid. The computer representation of these real-world features, however, appears on a flat screen.

In order to accommodate the shift of representation media, projections are used to relocate coordinates correctly from one to the other (Longley, 2005). Each projection has its own qualities and distortions. Geographers often use the acronym SADD to classify the types of distortion: Shape, Area, Distance, and Direction (McIntyre, 1985). Usually, only one or two of these aspects can be controlled for a given projection, making the choice of projection type crucial.

This project used the Universal Transverse Mercator (UTM) projection for all of its spatial data. Because an overall goal of the project was to measure time spent to cover specific distances in a canoe, a projection that minimized distortion of distance was preferred. The UTM projection preserves distance as much as possible, even when the distances do not fall directly on parallels (Snyder, 1987). The UTM system divides the Earth into 60 zones, each having its own meridian. This projection also allows $0.1 \%$ error in one zone (Snyder, 1987; Voxland, 1989).

Ohio covers two UTM Zones: 16 and 17 (Figure 3.2). 22\% of the earthworks analyzed fell in UTM Zone 16, whereas $78 \%$ of the analyzed earthworks fell into UTM Zone 17. The GIS could utilize only one of these projection zones. 
UTM Zone 17 showed the most promise for a correctly projected GIS. The earthworks in UTM Zone 16 populate roughly 43 miles of lateral territory outside UTM Zone 17, whereas the earthworks populate considerably more than 150 miles outside the lateral UTM Zone 16 border.

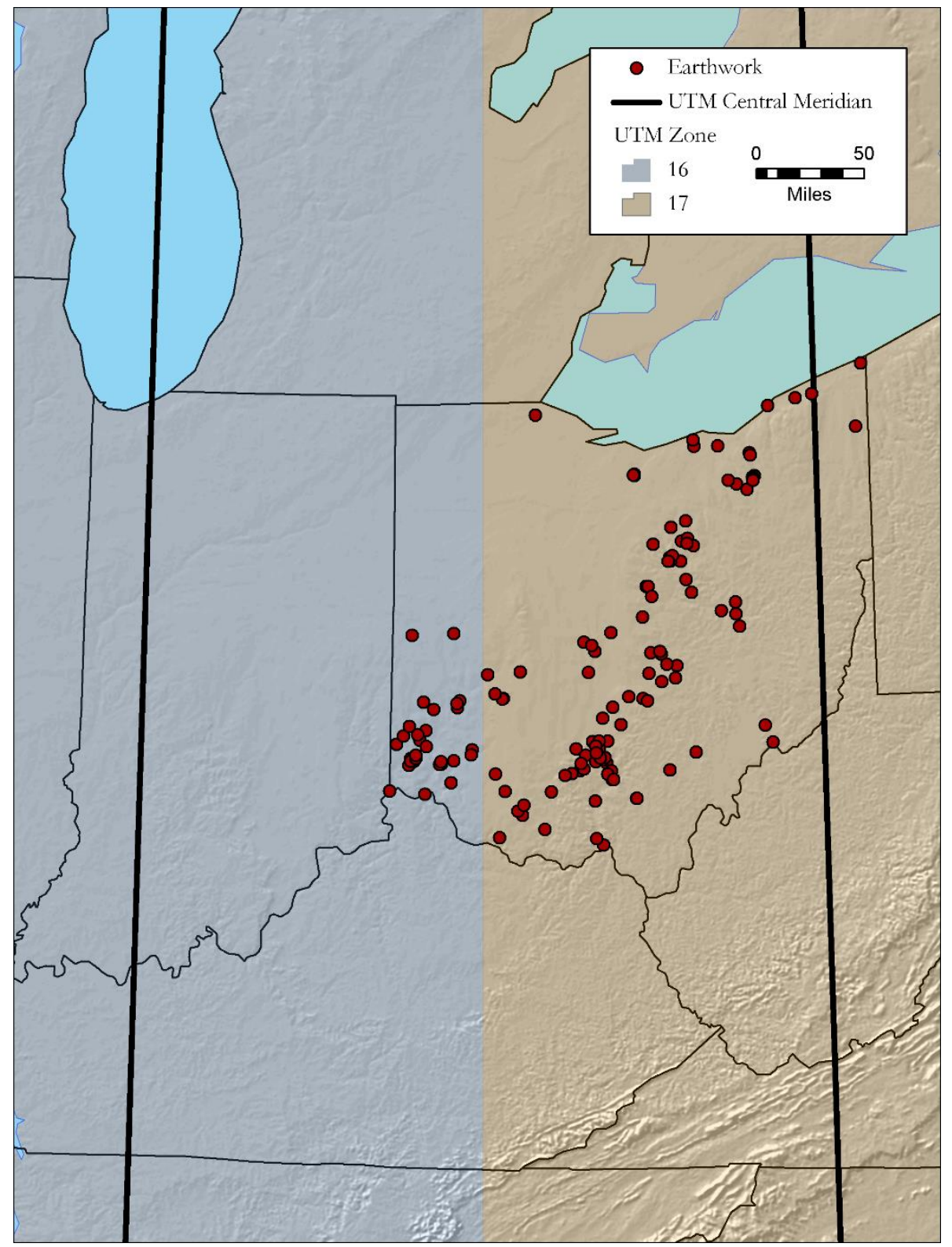

Figure 3-2: UTM Zones for the State of Ohio with Earthwork Distribution 
UTM Zone 17 was ultimately chosen because the majority of the study area falls within Zone 17.

\subsection{Data Sources}

The data used in this project were collected from various sources. Most of the data for analysis were modified from existing data or created by the client. Most of the data used for "Modern Reference points" were derived from various sources such as the Ohio Department of Natural Resources or the USGS and the data were not modified. These three sources are listed in this section. Client data and modified data discussed in sections 4.3.1 and 4.3.2 are used for actual analysis in the network while the unmodified data is used as modern reference data.

\subsubsection{Client Data}

The client provided earthwork locational data for the GIS network. These came in the form of an Excel spreadsheet file created from historical documents and interpolating destroyed earthwork locations onto modern USGS quadrangles. After locating them on the USGS quadrangle, he added the assumed coordinates to the Excel worksheet. This worksheet was then imported into the personal geodatabase in Access and the locational data read and projected to a point geometry feature class by means of the Earthwork Extractor Model (Section 4.1.1) for inclusion into the network.

\subsubsection{Modified Data from Pre-Existing Datasets}

All reach data for this project were downloaded from the NHD and provided by the USGS (http://nhd.usgs.gov/). This dataset contained U.S. hydrologic features pre-staged 
as a geometric network by sub-region, a purely administrative unit used to classify watersheds by the USGS.

In order to connect the land nodes (earthworks) to the water arcs (reaches) in the network, a connecting line feature class was created. This feature class simulated walking from the earthworks to the nearest river to start the act of canoe travel. This connector data set was derived by locating the nearest section of a reach to an earthwork and drawing a straight line to it.

\subsection{The NHD}

River travel constituted the main means of travel in this network and was the project's main focus. As mentioned above, the NHD data contained an excess of hydrologic information, so for the purpose of this project, only one element of the NHD was usedthe flowline data depicting river channels.

The NHD was designed to function as a geometric network which traces resource flow within the network (Actur \& Zeiler, 2004). The NHD allows a user to trace water flow both upstream and downstream, but does not quantify the amount of water flowing through a particular reach per second or allow for a resource in the network to make independent decisions about which way to go (Zeiler, 1999). Consequently, the NHD data had to be modified in order to model prehistoric canoe travel. These modifications are discussed in Chapter 4. 


\subsubsection{NHD Flowline Featureclass}

The NHDFlowline feature class constituted the framework of the geometric network in the NHD. It represented water flow through various reaches and water bodies in the watershed. It encoded water-flow direction in its geometry and was attributed with information about what each feature represented in the database. This project heavily used two attribute fields in the NHD flowline feature class: the FType and the FCode fields.

\subsubsection{FType}

The FType field indicated, at a low level, what each line represented in the network, e.g., stream, lake, or canal. These values helped filter out modern constructions from the NHD for use in the prehistoric network. Table 1 lists the FTypes for the NHDFlow feature class and the description.

Table 1. Values Represented by FTypes and their description

\begin{tabular}{|l|l|}
\multicolumn{1}{c|}{ Ftype } & $\begin{array}{l}\text { Description } \\
\text { Line used to show flow through a } \\
\text { large water body or river that cannot } \\
\text { be represented by a simple one- } \\
\text { dimensional line at the 1:24,000 scale }\end{array}$ \\
\hline Artificial Path & $\begin{array}{l}\text { A human-made pipe that carries } \\
\text { water }\end{array}$ \\
\hline Pipeline & The shore of an inland lake \\
\hline StreamRiver & A stream or river \\
\hline CanalDitch & A human-made canal or ditch \\
\hline & $\begin{array}{l}\text { A line used to show water flow under } \\
\text { a bridge or other visual obstruction as } \\
\text { viewed from a USGS topographic } \\
\text { map }\end{array}$ \\
\hline Connector & The shore along an ocean \\
\hline Coastline & \\
\hline
\end{tabular}




\subsubsection{FCode}

The FCode further delineated reaches by listing a specific characteristic unique to that reach. For this project, only two FCode values were critical for network construction: the code for intermittent streams and the code for perennial streams. The segregation of these two types of rivers was crucial in creating a canoe-travel network, as intermittent waterways were often not traveled by watercraft due to flow issues. 


\section{Chapter 4 - Data Construction and Description}

This section describes the various models and methods used to create data in the analysis network. It also lists the source of pre-constructed data used as reference points for the modern landscape.

\subsection{Earthworks}

The client provided the estimated earthwork locations. Since the original spreadsheet structure was modified for a better inclusion into a database, this spreadsheet was imported directly into a Microsoft Access database. The final earthworks feature class was stored in the Perennial_Travel_Network feature dataset.

\subsubsection{Earthwork Extractor Model}

In the original spreadsheet, all earthworks were plotted in their respective zones of the UTM projection with the NAD 27 datum. This convention was maintained when the spreadsheet was imported into the EarthWork_DB table.

A model called the "Earthwork Extractor" was built to pull the earthwork locations from the EarthWork_DB table and place them into the GIS as a single feature class with point geometry that is projected to UTM Zone 17 - NAD 83. Table 2 shows the specific fields used from the EarthWork_DB table for creating the resulting feature class. See Appendix A for a complete schema description of EarthWork_DB. 
Table 2. Earthwork_DB fields used by the "Earthwork Extractor" Model

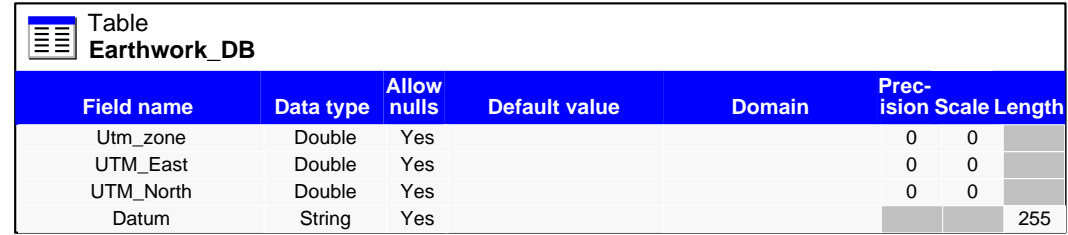

Excel table imported into Access

The UTM Zone the earthwork resides in The Easting of the earthwork in its respective zone The Northing of the earthwork in its respective zone The datum used for the UTM Zone

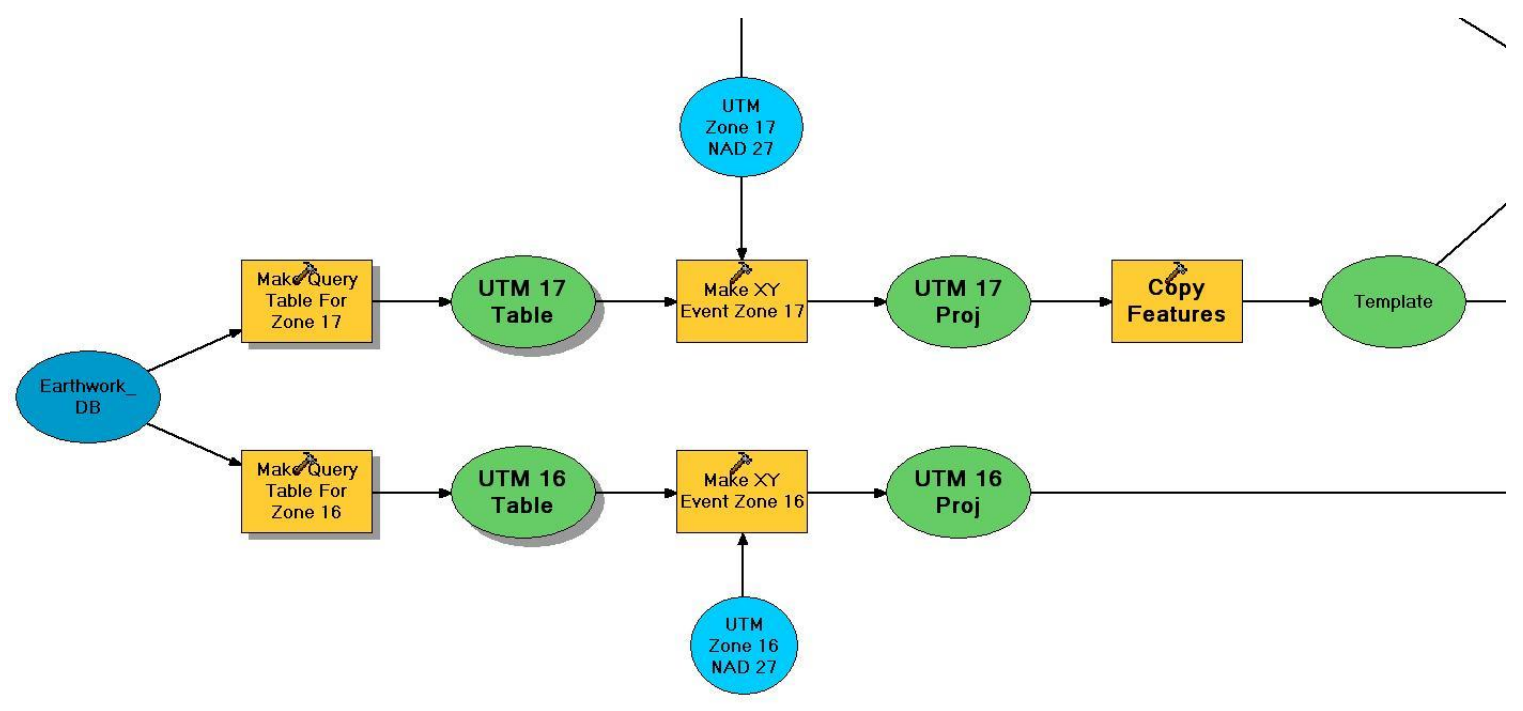

Figure 4-1: Section one of the "Earthwork Extractor"

Figure 4-1 shows the first section of the "Earthwork Extractor" model. The first step ran two SQL queries on the Earth_Works_DB table to select records for a particular UTM zone (16 or 17). The Make Query tool ran the following SQL queries on the Earth_Work_DB table:

$$
\begin{aligned}
& \text { [Utm_zone }]=16 \text { AND [UTM_East] IS NOT NULL } \\
& {[\text { Utm_zone }]=17 \text { AND [UTM_East] IS NOT NULL }}
\end{aligned}
$$

This procedure isolated all records in both zones that had a numerical value for the easting and separated the two into separate table views for projection in their respective zones. 
The EarthWork_DB table was an important work in progress. All of the earthworks mentioned in the historical records were listed in this table. However, the client had not located all of these earthworks on the modern terrain. Consequently, while there was a record for each earthwork in the table, not all of the earthworks had locational data. Their easting and northing coordinates were thus expressed as NULL values in the table. By filtering out records with NULL values in the UTM_East field, the tool assured only earthworks with locational data were projected into the travel network.

Once the records containing spatial data were selected, the Make XY Event Layer tool was run on each table view for its respective coordinate system. The tool produced a feature layer containing point locations for each earthwork selected. An additional step copied this layer to a temporary feature class. The UTM 17 feature class was used as the schema template for the final Earthworks feature class produced in the next section of the tool (see Figure 4-2).

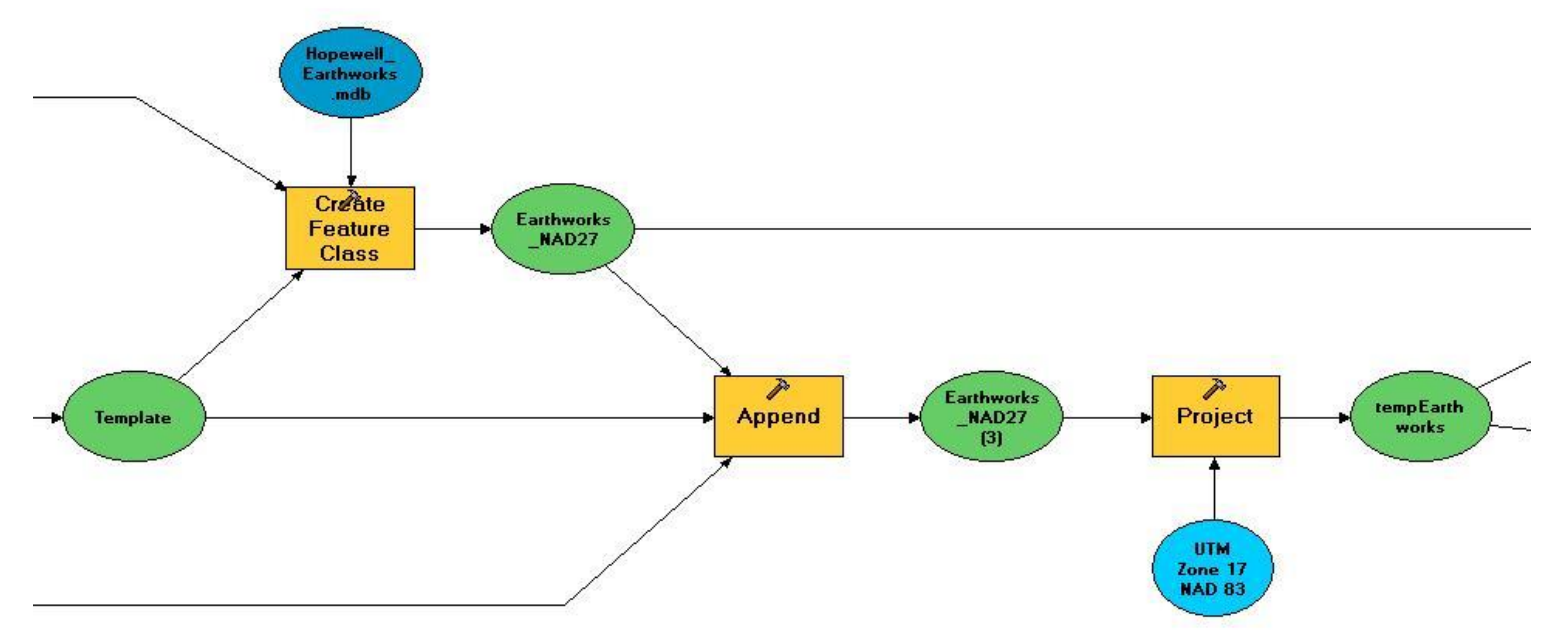

Figure 4-2: Section two of the "Earthwork Extractor" 
The "Earthwork Extractor" then took the two table views and combined them into a single feature class using the "Append" tool. First, another temporary feature class called Earthworks_NAD27 was created in UTM 17, NAD 27 with the temporary feature class used as the schema template. Both feature layers from section one of the tool, UTM 16 proj and UTM 17 proj were appended into this feature class. ModelBuilder automatically projected the UTM 16 points into UTM 17. The Earthworks_NAD27 feature class was then projected into UTM 17, NAD 83 using the "Project" tool, resulting in a feature class called tempEarthworks (see figure 4-2).

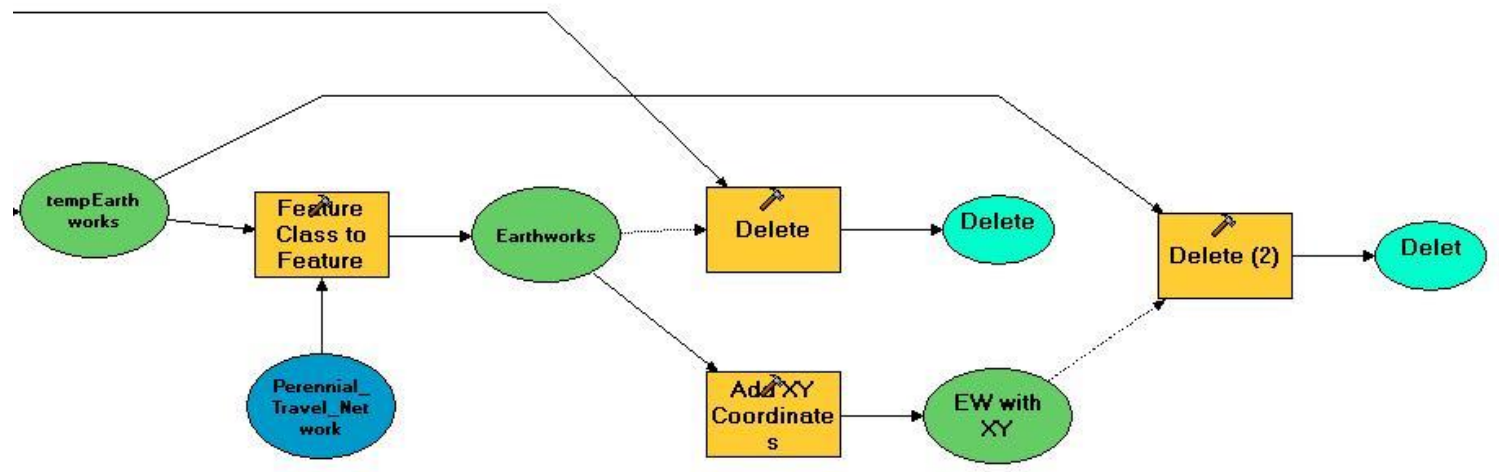

\section{Figure 4-3: Section three of the "Earthwork Extractor"}

Section three took the tempEarthworks feature class and placed it in the feature dataset of the network which is named Perennial_Travel_Network. This process used the Feature Class to Feature Class tool. Once the earthworks were in the feature dataset, the new spatial locations of each earthwork in UTM 17, NAD 83 were written to the feature class records with the $A d d X Y$ Coordinates tool. The tool created a separate POINT_X and $P O I N T \_Y$ field for this information. This resulted in the final Earthwork feature class used 
for the network. The two temporary feature classes that were used in the process are then removed with the Delete tool.

\subsection{Reach Construction}

Reaches were the main form of transportation for the network. The bulk of the data editing for this project was performed on the reaches. The Reaches feature class was stored in the Perennial_Travel_Network dataset.

The NHD is a data set representing data as it exists in this century, but was used in this project to model behavior up to 2,200 years old. This was, however, the most complete documented hydrologic data set in existence for the US for any time period. It was understood that some hydrology would have changed in two millennia. This includes such events as a river switching course over a bend or other minor changes on the regional scale. There was no significant research that indicated major hydrologic changes in the overall system in this time frame. While the data had some minor inconsistencies with the past landscape, the overall terrain has remained the same.

The first step in creating the reaches was to download data from the NHD for Ohio. This required knowing under what sub-regions Ohio fell. The NHD download viewer (USGS, 2006) was used to ascertain this information by navigating to the state of Ohio and physically looking to see what sub-regions the state falls under (see Figure 4 - 4). Using information recorded from this page, prestaged PGDBs for the area were downloaded from the NHD FTP site (USGS , 2007a). Table 3 contains a list of the subregions located in Ohio that were downloaded as PGDBs. 


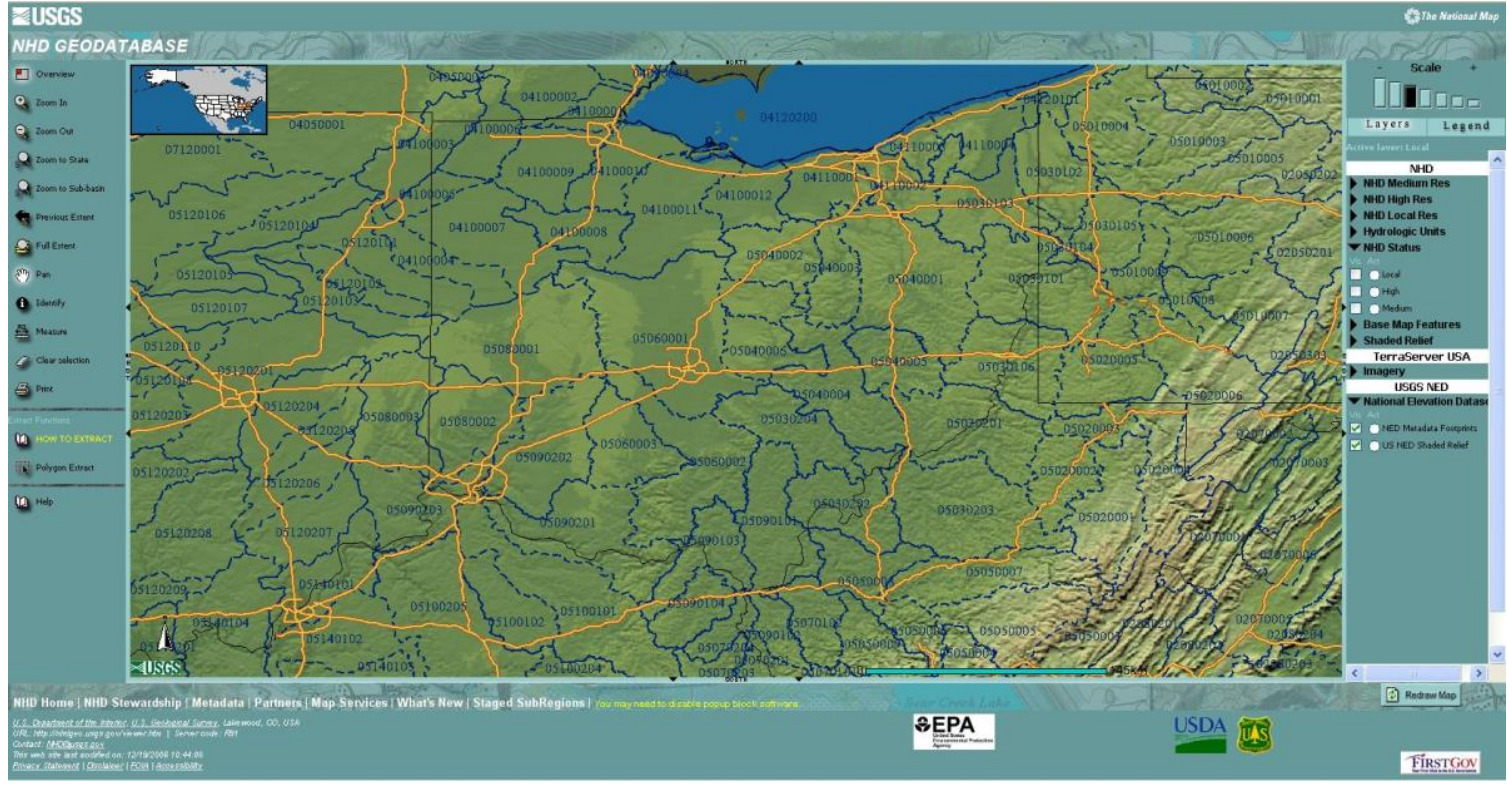

Figure 4-4: Screen shot from the NHD Viewer showing hydrologic subregions in Ohio

Table 3. NHD Subregions in Ohio

\begin{tabular}{|l|}
\multicolumn{1}{c}{$\begin{array}{c}\text { NHD } \\
\text { Subregion }\end{array}$} \\
\hline NHD4010 \\
\hline NHD0411 \\
\hline NHD0503 \\
\hline NHD0504 \\
\hline NHD0506 \\
\hline NHD0508 \\
\hline NHD0509 \\
\hline NHD0512 \\
\hline
\end{tabular}

The connectivity of the downloaded features needed to be tested. Creating a topology was considered but rejected. This was because when taking into account the topologic rules (Perencsik, 2004) applying to polylines in ArcGIS, the most applicable seemed the Must Not Have Dangles rule. 
However, given that hydrologic systems have many starting points which could be construed as dangles, this approach seemed impractical. While running this topologic rule would find errors within the NHD, it would also find every end where a stream or river started on the landscape. It would also find every artificial end where a reach stopped in one arbitrary subregion and continued in another. This could produce tens of thousands of exceptions that the operator would then have to examine to find the real errors.

Instead, a more practical approach was chosen. Rather than create a topology and validate it, the operator would exploit the very nature of the network itself. When a network is built, it creates its own topology of interconnectivity that is represented in the network dataset (Zeiler, 2001). By building a temporary network for each subregion and running a simple service area analysis for it, it was possible to locate the real connectivity errors within the network using this internal topology. Once a real connectivity error was located, it could then be repaired appropriately.

Once the subregions were downloaded, the reach data needed to be extracted for editing. Each NHD geodatabase contained a wealth of modern hydrologic data, including water monitoring points, watersheds, dams, wells, lake boundaries, swamp boundaries, and reaches, to name a few (USGS, 2000). Two additional PGDB's were used for the editing of reaches: the "Edit" PGDB and the "Archive" PGDB.

The Hopewell_Edit PGDB was the database where all of the editing of subregions happened. It contained feature datasets for each subregion used in the overall network. Within each feature dataset there were two network data sets: one for perennial reaches and one for intermittent reaches. The feature datasets also housed the feature classes that contained the subregion's reaches: one with the intermittent reaches and one without. 
The Archive PGDB contained the final versions of the subregions once they were edited (see Table 4). It has two feature datasets: intermittent and perennial. These reaches were used to build the final reach feature class for the travel network.

Table 4. Feature Classes in archive database

\begin{tabular}{|c|c|c|c|}
\hline Name & Description & Feature Dataset & Geometry \\
\hline NHD_0410_Int & Subregional Reaches & Intermittent & Polyline \\
\hline NHD_0410_Per & Subregional Reaches & Perennial & Polyline \\
\hline NHD_0411_Int & Subregional Reaches & Intermittent & Polyline \\
\hline NHD 0411 Per & Subregional Reaches & Perennial & Polyline \\
\hline NHD 0503 Int & Subregional Reaches & Intermittent & Polyline \\
\hline NHD_0503_Per & Subregional Reaches & Perennial & Polyline \\
\hline NHD_0504_Int & Subregional Reaches & Intermittent & Polyline \\
\hline NHD_0504_Per & Subregional Reaches & Perennial & Polyline \\
\hline NHD_0506_Int & Subregional Reaches & Intermittent & Polyline \\
\hline NHD_0506_Per & Subregional Reaches & Perennial & Polyline \\
\hline NHD_0508_Int & Subregional Reaches & Intermittent & Polyline \\
\hline NHD_0508_Per & Subregional Reaches & Perennial & Polyline \\
\hline NHD_0509_Int & Subregional Reaches & Intermittent & Polyline \\
\hline NHD_0509_Per & Subregional Reaches & Perennial & Polyline \\
\hline NHD_94378_Int & Subregional Reaches & Intermittent & Polyline \\
\hline NHD_94378_Per & Subregional Reaches & Perennial & Polyline \\
\hline NHD_94379_Int & Subregional Reaches & Intermittent & Polyline \\
\hline NHD_94379_Per & Subregional Reaches & Perennial & Polyline \\
\hline Ohio_Reaches & $\begin{array}{c}\text { Combined Reaches } \\
\text { with Strahler Ordering }\end{array}$ & Perennial & Polyline \\
\hline Reaches_PreS & $\begin{array}{l}\text { Combined Reaches } \\
\text { without Strahler } \\
\text { Ordering }\end{array}$ & Perennial & Polyline \\
\hline Lake_Erie & $\begin{array}{c}\text { Travel Paths on Lake } \\
\text { Erie }\end{array}$ & None & Polyline \\
\hline
\end{tabular}

In addition to the individual subregion reaches, there were two more feature classes contained in the archive PGDB: the Ohio_Reaches feature class and the Lake_Erie feature class. The Lake_Erie feature class was an archival copy of the original Lake_Erie feature class. The second feature class, Ohio_Reaches, was a combination of all the subregional feature classes combined and ordered with Strahler ordering. 


\subsubsection{The "Create NHD FC For QC Model"}

This project was interested only in the first dimensional reaches representing water flow for the network. To easily extract the reaches needed for analysis, another tool was created in ModelBuilder called "Create NHD for QC". The model selectively extracts reaches from the Flowline feature class and places them into a dataset named after the subregion in the Hopewell_Edit PGDB. Once the selected reaches were in the feature dataset, a network was created and edited.

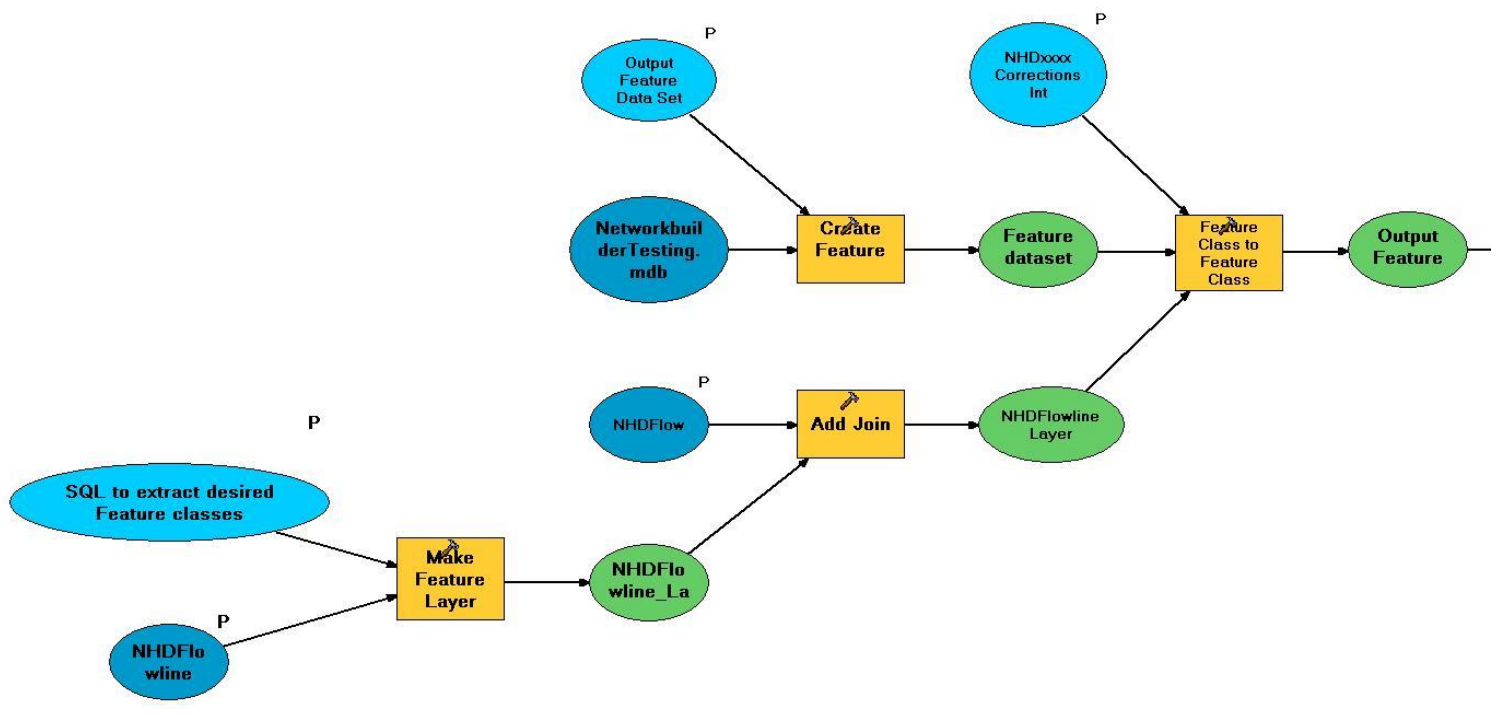

Figure 4-5: "Create NHD FC for QC" section one

The first task of the model was to extract the desired reaches into a feature layer from the NHDFlowline feature class that used the Make Feature Layer tool. The tool ran an SQL expression on [Ftype] field of the NHDFlowline feature class. This field contained a coded domain attribute which identified what type of hydrological feature a reach is (see Table 5). The tool created a feature layer from a feature set with the SQL expression:

$$
\text { [FType] }=334 \text { OR [FType }=460 \text { OR [FType] }=558 \text { OR [FType }=566
$$


This SQL expression selected the reaches in the NHD that were: Connector (334), Stream/Rivers (460), Artificialpath (558) or Coastline (334). This filtered out the modern elements of Pipeline and CanalDitch. The reaches that had codes for streams, artificial paths, and connectors were preserved and used in the initial testing of the network (Table $5)$.

\section{Table 5. Subtypes for the Ftype field of the NHDFlowline feature class}

\begin{tabular}{|c|c|c|c|c|}
\hline $\begin{array}{r}\text { Subtyp } \\
\text { Sub } \\
\text { Defaul }\end{array}$ & $\begin{array}{l}\text { HDFlowline } \\
\text { FType } \\
460\end{array}$ & \multicolumn{3}{|c|}{ List of defined default values and domains for subtypes in this class } \\
\hline $\begin{array}{l}\text { Subtype } \\
\text { Code }\end{array}$ & $\begin{array}{c}\text { Subtype } \\
\text { Description }\end{array}$ & Field name & Default value & Domain \\
\hline 558 & ArtificialPath & $\begin{array}{l}\text { Resolution } \\
\text { FlowDir } \\
\text { FCode } \\
\text { Enabled }\end{array}$ & $\begin{array}{c}0 \\
55800 \\
1\end{array}$ & $\begin{array}{c}\text { Resolution } \\
\text { HydroFlowDirections } \\
\text { ArtificialPath FCode } \\
\text { EnabledDomain }\end{array}$ \\
\hline 428 & Pipeline & $\begin{array}{l}\text { Resolution } \\
\text { FlowDir } \\
\text { FCode } \\
\text { Enabled }\end{array}$ & $\begin{array}{c}0 \\
42805 \\
1\end{array}$ & $\begin{array}{c}\text { Resolution } \\
\text { HydroFlowDirections } \\
\text { Pipeline FCode } \\
\text { EnabledDomain }\end{array}$ \\
\hline 567 & Shoreline & $\begin{array}{l}\text { Resolution } \\
\text { FlowDir } \\
\text { FCode } \\
\text { Enabled }\end{array}$ & $\begin{array}{c}0 \\
56700 \\
1\end{array}$ & $\begin{array}{c}\text { Resolution } \\
\text { HydroFlowDirections } \\
\text { Shoreline FCode } \\
\text { EnabledDomain }\end{array}$ \\
\hline 460 & StreamRiver & $\begin{array}{l}\text { Resolution } \\
\text { FlowDir } \\
\text { FCode } \\
\text { Enabled }\end{array}$ & $\begin{array}{c}0 \\
46006 \\
1\end{array}$ & $\begin{array}{c}\text { Resolution } \\
\text { HydroFlowDirections } \\
\text { StreamRiver FCode } \\
\text { EnabledDomain }\end{array}$ \\
\hline 336 & CanalDitch & $\begin{array}{l}\text { Resolution } \\
\text { FlowDir } \\
\text { FCode } \\
\text { Enabled }\end{array}$ & $\begin{array}{c}0 \\
33600 \\
1\end{array}$ & $\begin{array}{c}\text { Resolution } \\
\text { HydroFlowDirections } \\
\text { CanalDitch FCode } \\
\text { EnabledDomain }\end{array}$ \\
\hline 334 & Connector & $\begin{array}{l}\text { Resolution } \\
\text { FlowDir } \\
\text { FCode } \\
\text { Enabled }\end{array}$ & $\begin{array}{c}0 \\
33400 \\
1\end{array}$ & $\begin{array}{c}\text { Resolution } \\
\text { HydroFlowDirections } \\
\text { Connector FCode } \\
\text { EnabledDomain }\end{array}$ \\
\hline 566 & Coastline & $\begin{array}{l}\text { Resolution } \\
\text { FlowDir } \\
\text { FCode } \\
\text { Enabled } \\
\end{array}$ & $\begin{array}{c}0 \\
56600 \\
1 \\
\end{array}$ & $\begin{array}{c}\text { Resolution } \\
\text { HydroFlowDirections } \\
\text { Coastline FCode } \\
\text { EnabledDomain }\end{array}$ \\
\hline
\end{tabular}

Artificial paths (Figure 4-7) represented a conduit of flow for lakes, ponds, and reaches in the network that were too wide to be represented by a first dimension polyline (USGS, 2000). Streams could be further broken down into intermittent streams and perennial streams, a very important distinction for the network. 
The network allowed analysis only on perennial streams. Excluding intermittent streams removed some elements of seasonality, allowing for a conservative approach in the overall analysis. Perennial streams flow continuously all year, barring severe drought, and thus theoretically could be navigated at any time of year that the water is not frozen. However, intermittent streams needed to be considered when the overall physical integrity of the network was tested.

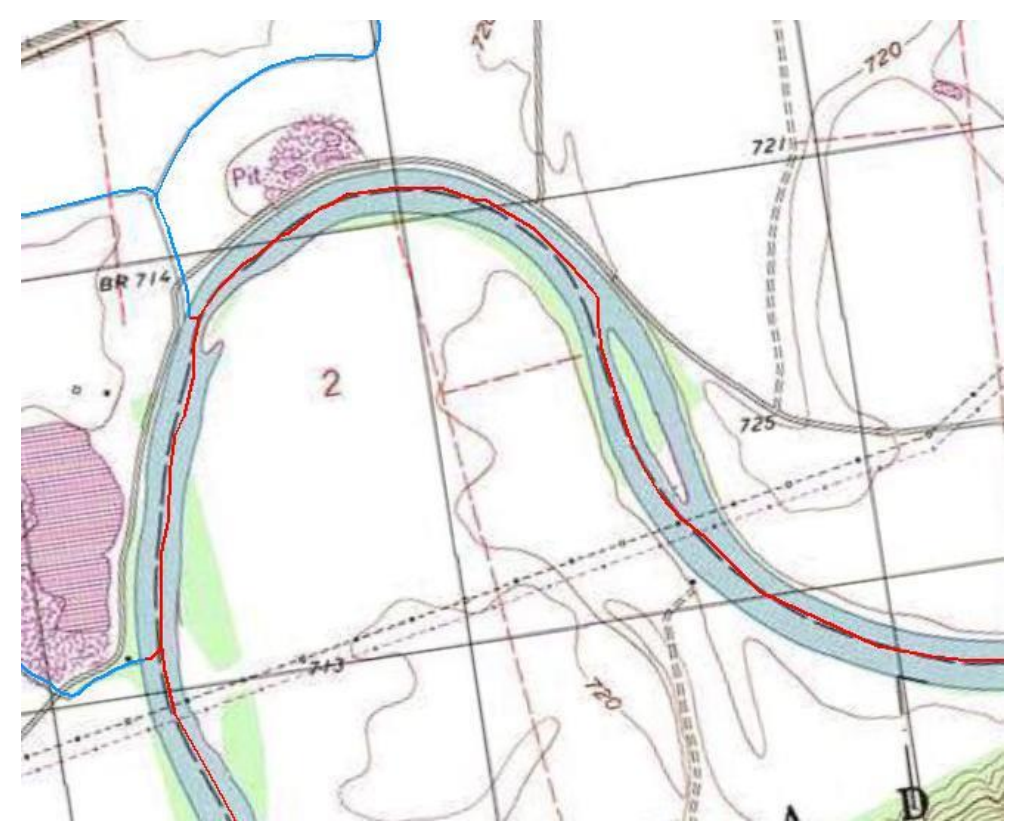

Figure 4-6: An example of an Artificial Path in use

The next step the model performed was to join the flow table for the NHD subregion to the feature layer just created. The NHDFlow table (Table 6) contained information on reach flow. It documented this with the FromComID and the ToComID fields (Table 7). The ComID field in the NHDFLowline feature class (see Table 7) was a unique number assigned to each recorded reach in the US contained in the NHD (USGS 2000). 
Table 6. NHDFlow table schema

\begin{tabular}{|c|c|c|c|c|c|c|c|}
\hline $\begin{array}{l}\text { Table } \\
\text { ENE NHDIow }\end{array}$ & & & & & & & \\
\hline Field name & Data type & $\begin{array}{l}\text { Allow } \\
\text { nulls }\end{array}$ & Default value & Domain & $\begin{array}{l}\text { Prec- } \\
\text { ision }\end{array}$ & cale & Length \\
\hline OBJECTID & Object ID & & & & & & \\
\hline FromComID & Long integer & No & & & 0 & & \\
\hline ToComID & Long integer & No & & & 0 & & \\
\hline DeltaLevel & Long integer & Yes & & & 0 & & \\
\hline Direction & Long integer & Yes & & FlowDirection & 0 & & \\
\hline ToComIDMeas & Double & Yes & & & 0 & 0 & \\
\hline
\end{tabular}

This Table Provides to from connectivity for the NHDFlowline feature class

Shows what ComID feeds into the reach Shows what ComID the reach flows into Indication of stream level assignment (empty field) Indicates how direction of the reach was encoded The distancefromt he start of the reach to the next reach

Table 7. The ComID for the NHDFlowline featureclass

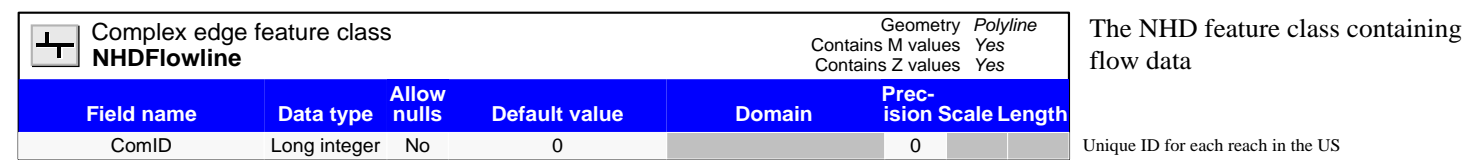

Using the "Add Join" tool, the model joined the FromComID field in the NHDFlow table to the ComID field in the feature layer formed by the Create Feature Layer tool. This was to embed flow characteristics for each reach in the resulting Reaches feature class for future use. This flow data was used later in the editing process.

The next procedure the model performed was to create an empty feature dataset to hold the resulting reaches. It then copied the feature layer to a feature class in this feature dataset. The model used the Create Feature Dataset tool and the Feature Class to Feature Class tools respectively to perform these tasks.

The next section of the model (Figure 4-7) cycled through to add fields and assign domains using multiple versions of the "Add Field" tool and the "Assign Domain To Field" tool. These fields were strictly used to track the edits made to the NHD during the editing 
phase. The model also used the "Calculate Value" tool to add the Left Alone and Natural End values to the appropriate fields (Table 8).

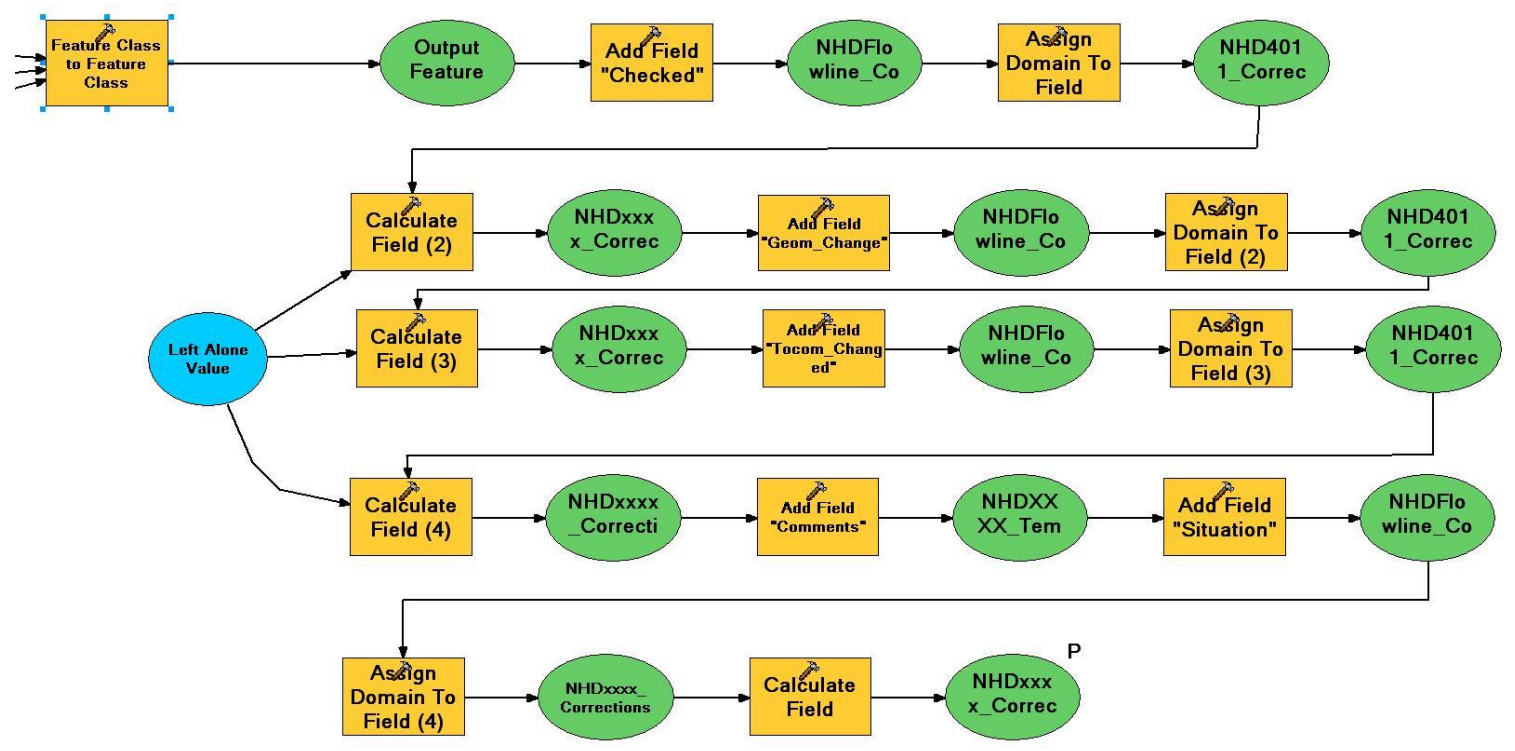

Figure 4-7: "Create NHD For QC section two"

Table 8. Fields added by the NHD FC For QC model

\begin{tabular}{|c|c|c|c|c|c|c|c|}
\hline \multicolumn{2}{|c|}{ NHDxxxx_Corrections } & & & \multicolumn{3}{|c|}{$\begin{aligned} & \text { Geometry } \text { Polyline } \\
& \text { Contains } M \text { values } \text { Yes } \\
& \text { Contains } Z \text { values } \text { Yes }\end{aligned}$} & \multirow[t]{2}{*}{$\begin{array}{l}\text { The Reaches From a SubRegion } \\
\text { Selected For Editing }\end{array}$} \\
\hline Field name & Data type & $\begin{array}{l}\text { Allow } \\
\text { nulls }\end{array}$ & Default value & Domain & $\begin{array}{l}\text { Prec- } \\
\text { ision Sc }\end{array}$ & ale Length & \\
\hline Checked & Short integer & Yes & & Check Code & 0 & & Indicates if a Reach was visited during the Editing \\
\hline Geom_Change & Short integer & Yes & & Check Code & 0 & & Indicates if the Geometery of the Reach was Edited \\
\hline Tocom_Changed & Short integer & Yes & & Check Code & 0 & & Indicates if the Tocom Feild Was Changed \\
\hline Comments & String & Yes & & & & 250 & Allows For comments From the Editor \\
\hline Situation & Short integer & Yes & & Situation & 0 & & Indicates the Situation For the Edit to the Reach \\
\hline
\end{tabular}

The Check Code domain (Table 9) was a coded value domain used to populate the majority of the fields added to track the editing changes. The domain had three states: checked, left alone, and changed. These indicated if the reach was visited during the editing process and if the reach required editing or not. The Situation Domain (Table 9) was a coded value domain that indicated the situation for reaches that required editing. These were added interactively during the editing phase. 
Table 9. The Situation and Check Code Domains

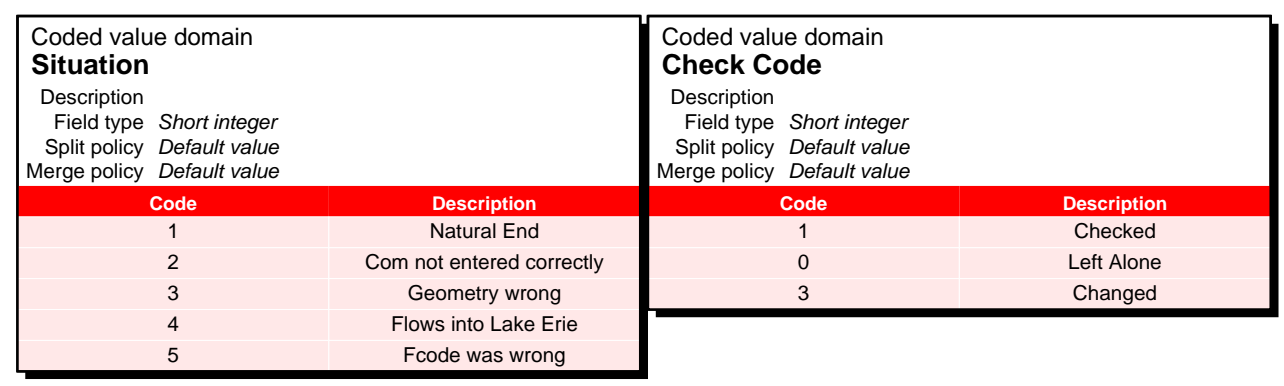

\subsubsection{Creation of a Subregional Travel Network for Editing}

Once the reaches were prepared for editing, the next step was to incorporate them into a travel network in order to test the connectivity of the NHD data in each subregion. While the data were originally designed and distributed for use in a network, it was still necessary to go through the data and do a quality assurance and quality check (QA/QC) of the data to find gaps in connectivity. Once the connectivity of the edited subregion was deemed satisfactory, the feature class was sent to the archive PGDB for inclusion in the final travel network.

The first step of a travel network creation with ESRI's Network Analyst is to create a feature dataset in a geodatabase. This was accomplished by the first part of the NHD FC For $Q C$ model. The next step was to create a Network dataset. The network was set up with the following parameters. For participating feature classes, only the subregion reach feature class created with the Create NHD FC For QC model was used. The connectivity policy of this feature class was set to "Any Vertex". The "use elevation to modify connectivity" option was left at "no". Turns were modeled in the network and the default of "Global Turns" was used. Only one cost attribute, distance, was set for the network and was read from the Length field of the feature class. 
The reason that the connectivity policy was set to "Any Vertex" is illustrated in Figure 4-8. This setting allowed for movement along the network anywhere vertices join. For example, one reach connected directly to a vertex in the middle of another reach. If the connectivity policy was set to "End Point", this would only allow for network travel where end points of reaches touch. Using the "Any Vertex" connectivity policy allows for a more realistic modeling of water flow in the GIS.
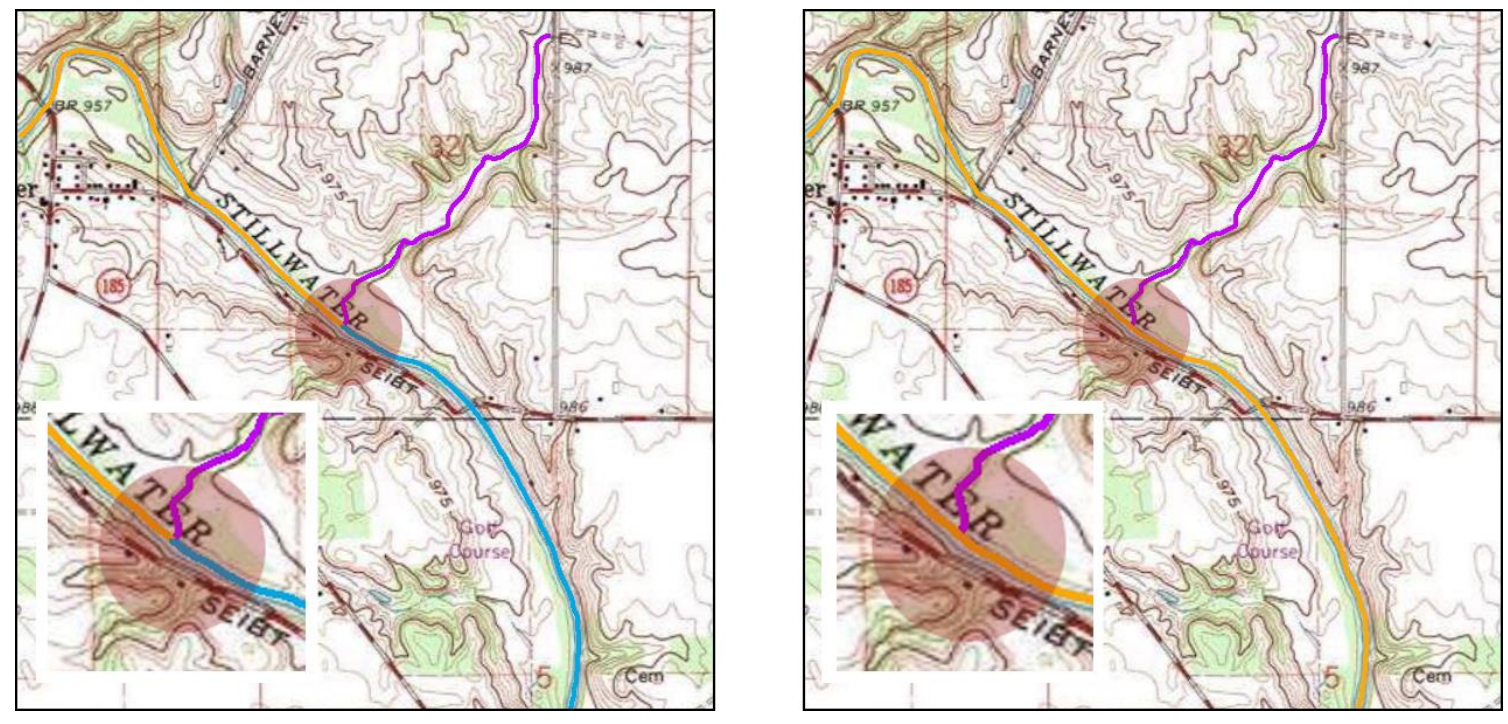

Figure 4-8: Examples of connectivity policies in the data

The purpose of the cost attribute was to give the network criteria for which to solve. Once a point was chosen to solve from, the network used the criteria from the cost attribute to move along the network given the total amounts it is told to solve for.

For example, let's say that Network Analyst was given the criteria to travel out from a point for 100 meters. When the program solves, it read the length form the field specified, in our example the Length field, and stopped after it had traveled 100 meters along the network (Figure 4-9). 


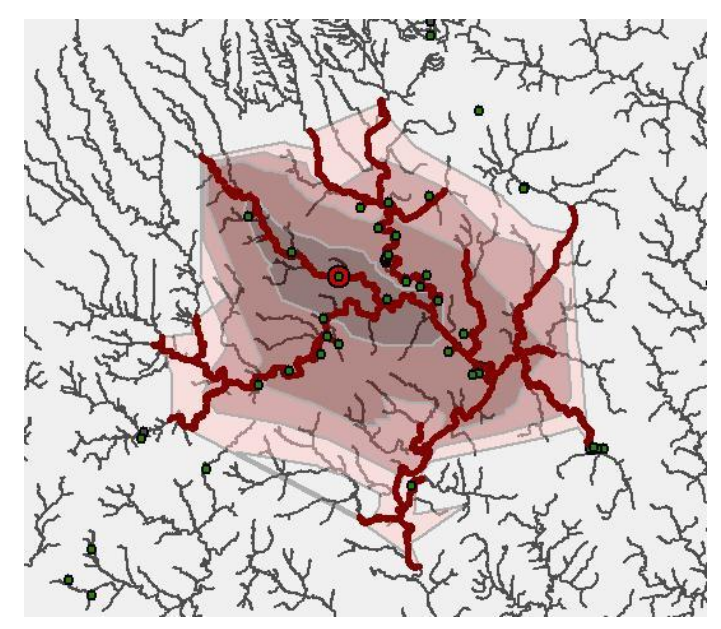

Figure 4-9: Travel along the network using cost criteria

The Subregional Test networks were attributed so that the distance in meters was the only cost and the distance information was read from the automatically generated Shape_Length field of the reaches feature class (Figure 4-10).

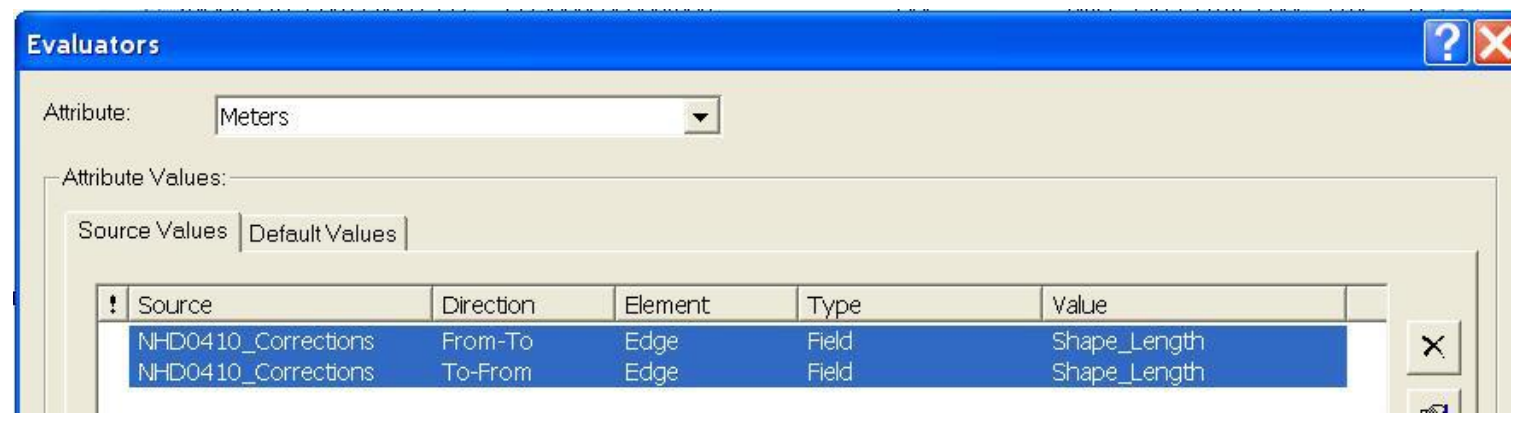

Figure 4-10: Attributes for evaluation in an Edit travel network

\subsubsection{Editing the subregional travel network containing intermittent reaches}

The next step in the editing process was to open the network dataset in ArcMap and create a service layer. A service layer is a Network Analyst specific layer that allows for distance away from a given point to be calculated. Given this criteria, the program ran along the 
network and drew a polyline that was stored in memory showing where the network was able to be traversed with the evaluator given. The three steps are shown in Figure 4-11.
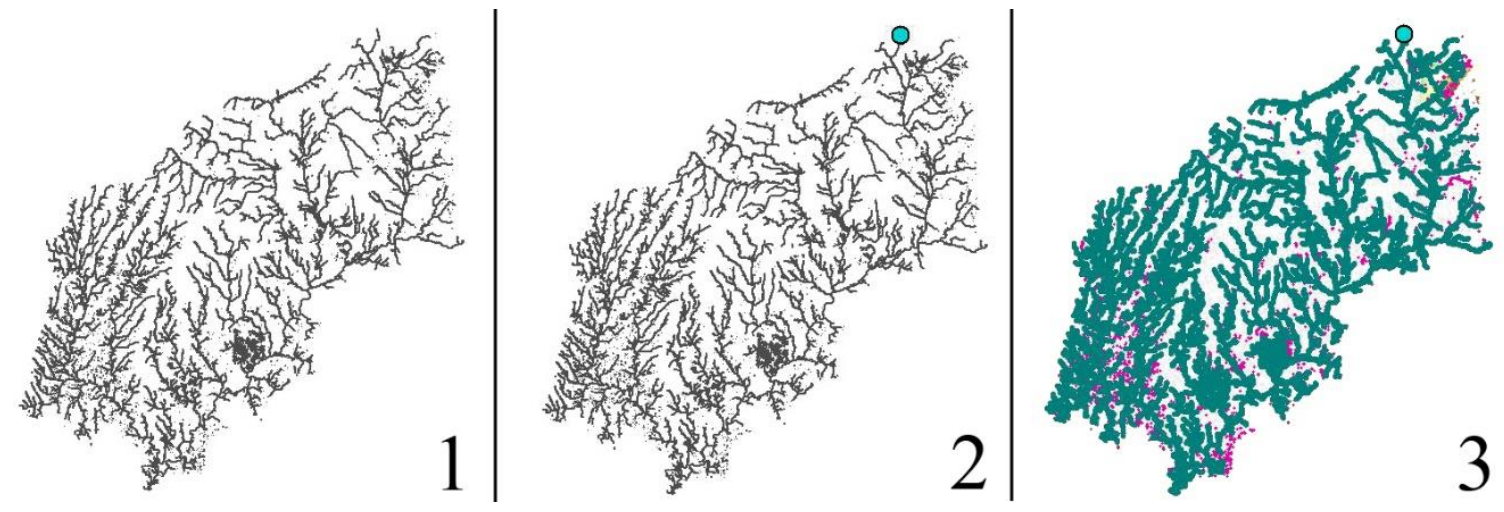

Figure 4-11: Steps of solving a network analyst service layer

First, the network set was brought into ArcMap (1). Next, a point was chosen on the network (2). Then the service area was solved for (3). After the network was solved, the human operator manually looked for disconnects. Disconnects occurred when the reaches in the network were not properly connected to each other. Once the operator found a disconnect in the network, s/he visually inspected the terrain and physically edited the disconnect if needed, then rebuilt the network and repeated the process. This subchapter describes that process.

Once the network dataset was brought into ArcMap, the next step was to create a Network Analyst service area layer. The analysis conditions for this layer were attributed with the Meters attribute as the cost. A value of 1,000,000 was entered for the break value, meaning the network would try to get 1,000,000 meters away from the point of origin. This gave ample space to test the entire subregion's connectivity. For the results settings, polygon generation was disabled and line generation was enabled. This allowed the operator to clearly see where disconnects occur. 
The next step was to graphically create an arbitrary point on the network, usually the edge. This was done with Network Analyst's Create Network Location Tool. An example of this can be seen in Figure 4-11, step 2.

The operator then solved the network by visually inspecting the data, looking for disconnects. Figure 4-12 shows an example of where the line that Network Analyst created stopped and the normal feature class underneath can be seen. It was easy for the operator to spot where the graphic lines stop at a small scale of 1:500,000. It was also generally possible to see areas where a likely disconnect occurred. At this scale, it looked like the Network Analyst generated line should continue but does not. Usually, the underlying reach from the feature class appeared flush against the graphical line. This was a sign of a likely disconnect.

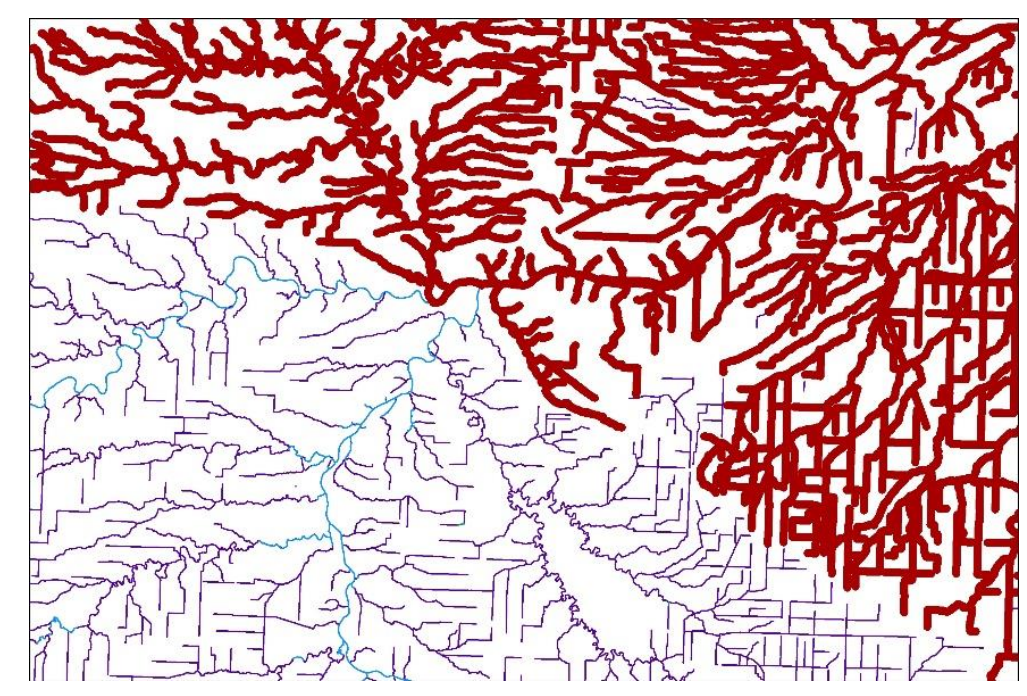

Figure 4-12: Results of a typical service area network solve with a disconnect

Once a disconnect was identified, it needed to be inspected at a larger scale. There were generally two reasons for a disconnect once inspected at a small scale: physical errors in the network (Figure 4-13), and natural disconnects of the landscape (Figure 4-14). 


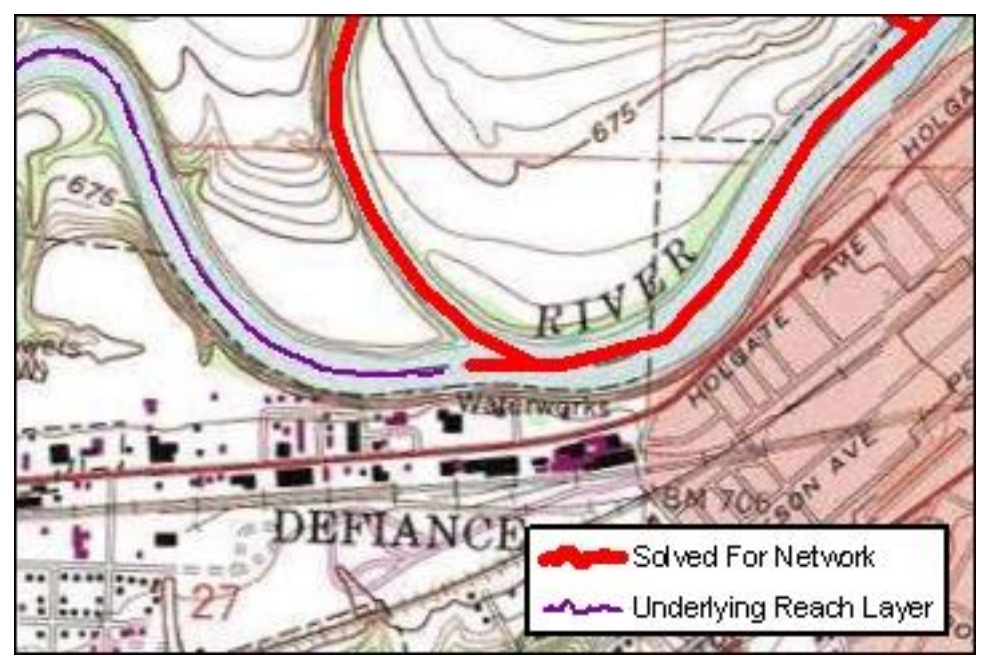

Figure 4-13: Example of a physical error in the NHD

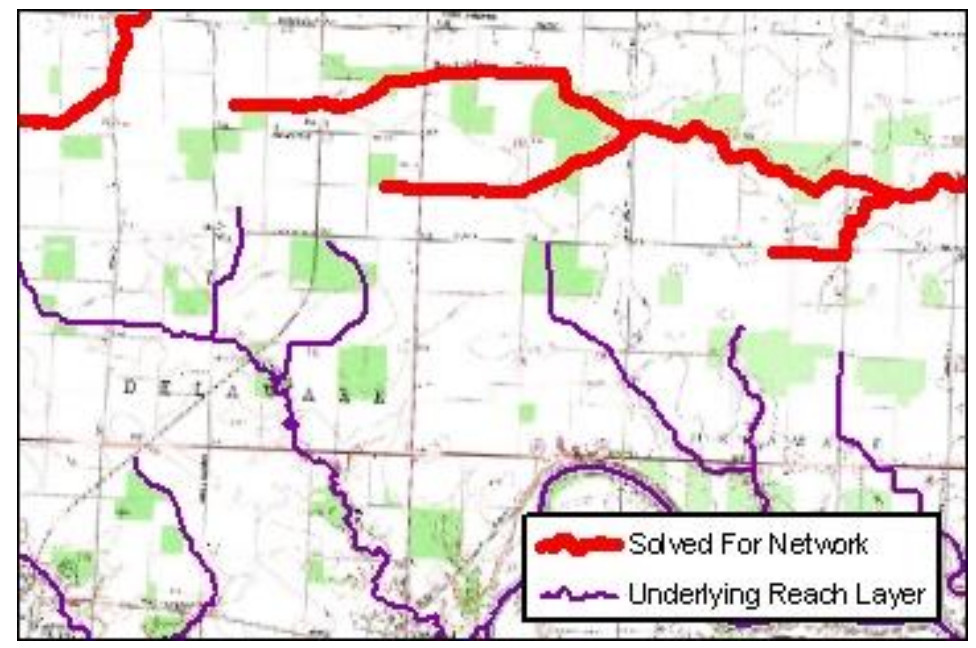

Figure 4-14: Example of a natural disconnect in the NHD

What appeared to be a disconnect at a small scale became an obvious feature of the natural topography at a large scale. This illustrated an important rule practiced during the reach editing phase; the natural topology of an area must be visually inspected and 
considered before any edits were made to a reach. The most common way that the topology was viewed was against a DRG representing a USGS Topograpic Quadrangle.. The DRGs were obtained from the Microsoft Terraserver website using the TerraServer Download Tool written by Thomas Emge and is readily available on ESRI's ArcScripts download page (Emge, 2007). Once topology was assessed and a decision to edit was made, an edit documentation process went into motion.

Table 8 (shown previously) documents the fields that were added to the original NHD reaches with section two of the "Create NHD FC For QC model". Table 9 documents the domains that these fields utilized. The first field, Checked, was edited to reflect whether the reach was visually inspected or not. In this case, the value Changed meant that some aspect of the reach was changed. Checked indicated that the reach was inspected, but a decision was made to leave its attributes and geometry alone. Left Alone indicated that the reach was never visited.

The next field that was populated was called Geom_Changed. This indicated whether the geometry of the reach needed to be edited. It used the Check domain like the Checked field and all the choices indicated the same actions. The To_Com field indicated whether the ToComID value was edited. Sometimes mistakes were found in these values as well. The Check domain was used for this field as well and the implications of the domain applied. The Comments field provided a place for the operator to enter any notes that described what was done. For example: "extended eastern edge to join adjacent reach". This field had no domain. The next field Situation used the Situation domain. This gave the operator an easy way to access the most common situations that would require editing. The default value of Natural End was used to indicate no editing had taken place. 
Once these fields were recorded, the operator returned to small scale and searched for errors. Once they satisfied that they had fixed what they could, the operator rebuilt the network and repeated the visual search over again. This process was repeated until the operator was satisfied with the entire subregion. When the operator finished the subregion with the intermittent reaches, it was imported into the intermittent feature dataset of the Archive PGDB.

\subsubsection{The "Import Perennial Reaches" Model}

Once a subregion was edited, the next step was to edit the reaches without intermittent reaches. Figure 4-15 shows an example of what a subregion looks like when this is completed.

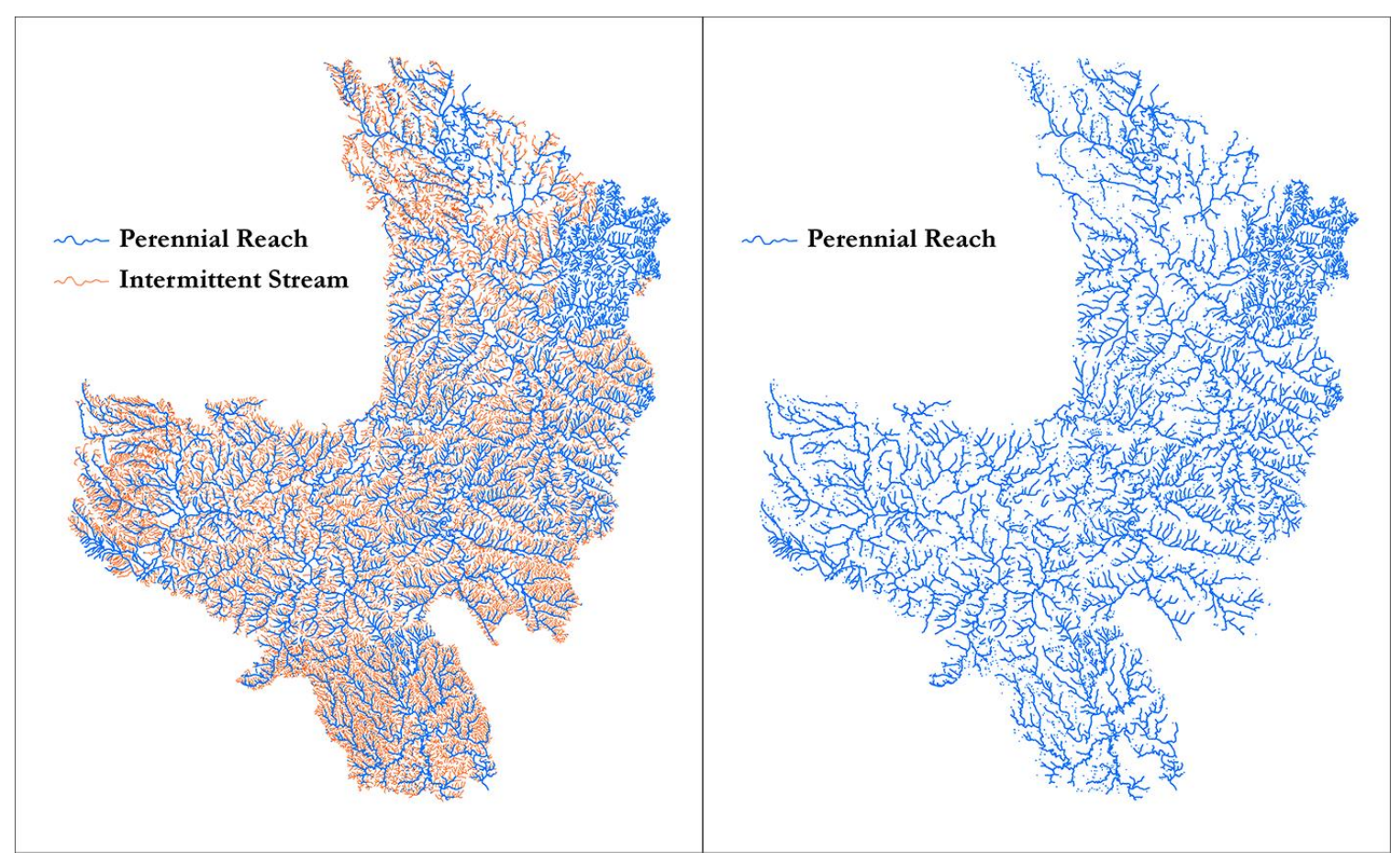

Figure 4-15 A Subregion Prior to and After Removal of Intermittent Reaches 
To accomplish the removal, the "Import Perennial Reaches" model was built (see Figure 4-16). The model took the edited intermittent reaches and ran an SQL query on the feature class, removing the intermittent features. It then placed the feature class in the same feature dataset that the original intermittent network was in. The model then assigned the editing domains that were originally assigned using the "Create NHD FC For QC" model.

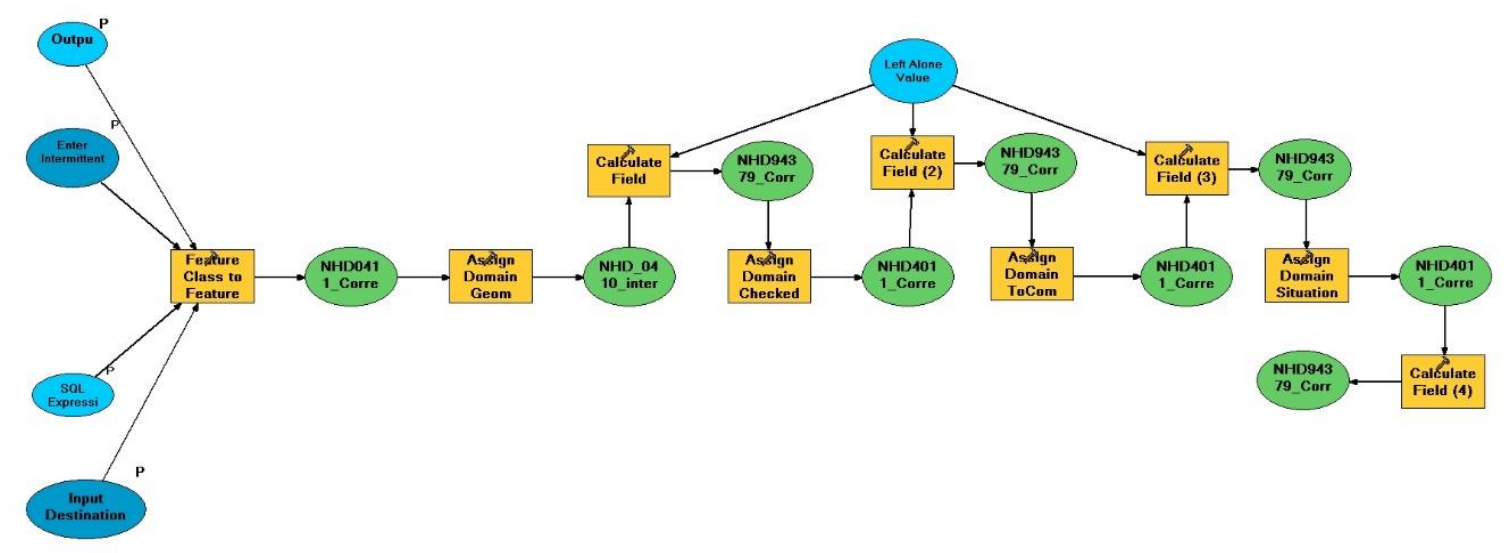

Figure 4-16: The "Import Perennial Reaches" Model

The model started out using the "Feature Class to Feature Class" tool. This tool took the original subregion feature class that was edited and ran the following query to drop the intermittent reaches: [FCode] $<>46003$. This was the code that the NHD uses to code intermittent reaches. The tool then copied these reaches into the feature dataset that the original intermittent network resided in. After this, a series of Assign Domain and Calculate Value tools went through and reassigned the edit domains that were lost when the feature class was copied and reassigned the default values. 


\subsubsection{Creation of a Subregional Travel Network for Editing}

After the operator ran the Import Perennial Reaches model, the next step was to create the travel network. A network dataset was created and the same parameters were entered, with the connection policy set to Any Vertex and a cost attribute of distance applied. The next step was to edit the network's connectivity.

\subsubsection{Editing the Subregional Travel Network Containing Perennial Reaches}

Editing the subregional travel network without the intermittent data was the next step in the process after the network was created. Again, the procedure was the same as it was for the intermittent reaches. A service area layer was solved and disconnects were visually inspected for. When one was found, the hypsography of the terrain was evaluated and edits made if needed. The network was then rebuilt and the analysis was run again. This procedure was repeated until the connectivity of the subregion was satisfactory to the operator. The operator then exported the finished edits into the Perennial feature dataset of the Archive PGDB.

The steps described for intermittent reaches were repeated for each subregion. Once all of the subregions had gone through the connectivity testing process they were ready for inclusion into the travel network. The edited subregional feature classes for both intermittent and perennial reaches were stored in a Archive PGDB as described earlier. Reach preparation for the final travel network involved the Archive and Hopewell_Earthwork PGDBs from this point on. 


\subsubsection{The "Create Reaches_Pres" Model}

After all the subregions were edited, they needed to be combined into one feature class for archival purposes and to be prepared for Strahler ordering. In order to append the subregions into a feature class, a feature class was created to append into.

The "Create Reaches_PreS" model (Figure 4-17) simply created an empty feature class in the Perennial feature dataset of the Archive PGDB. The model used the NHD_0410 feature class in the perennial feature dataset as a schema template. The Pre_S in the name stood for Pre-Strahler ordering.

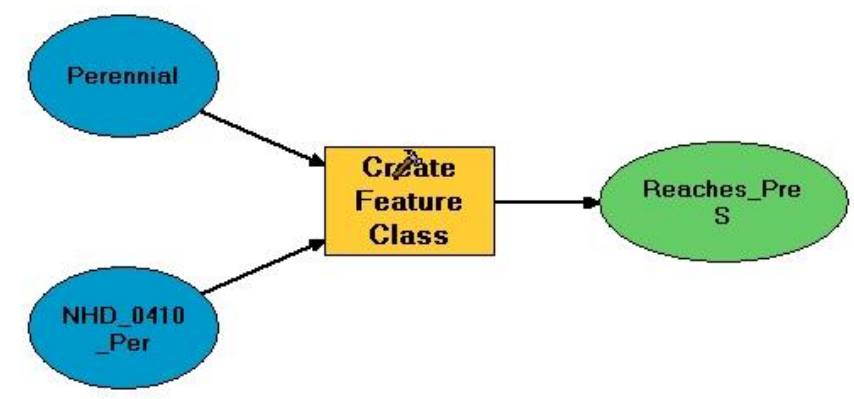

\section{Figure 4-17: The "Create Reaches_PreS" Model}

\subsubsection{The "Append Archive Reach Files" Model}

After the "Create Reaches_Pre_S" model was run, the empty feature class needed to be populated with all of the reaches from the perennial feature classes. A model was built to facilitate the process called the Append Archive Reach Files. The model took all of the perennial subregions from the Archive PGDB and combined them into one file in the Perennial feature dataset.

The model (Figure 4-18) was made up of a single instance of the Append Tool. The input was a feature class variable, which was a series of variables. These variables were made up of all of the subregional feature classes. The target feature class was the 
Reaches_PreS feature class created in Section 3.3.7. The model then iterated though each variable in the input feature class. This populated the Reaches_PreS feature class with all the reaches from the subregions. The feature class resided in the Archive PGDB for archival purposes, but it was also exported into a shapefile to allow for Strahler ordering.

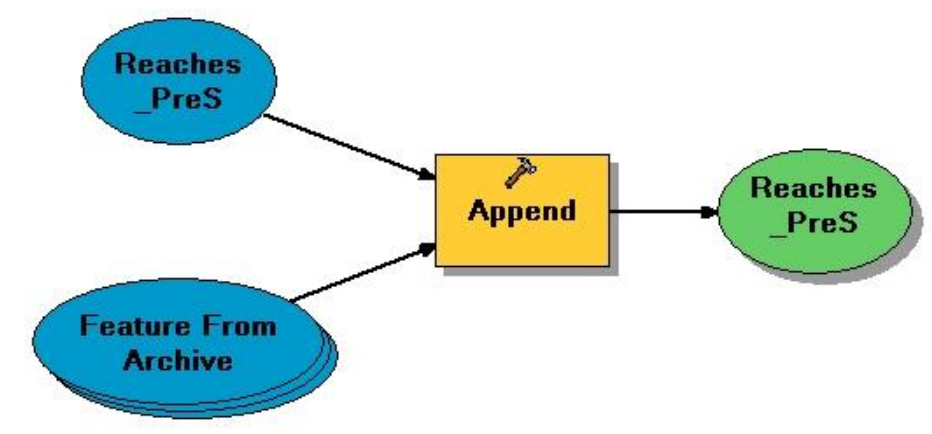

Figure 4-18: The "Append Archive Reach Files" Model

\subsubsection{Applying Strahler Ordering to the Reaches}

Strahler ordering was essential to the network. To apply Strahler ordering to the reaches, a third party tool was used called RivEx. The first step in assigning Strahler order to a reach was to export the Reaches_PreS as a shapefile. The RivEx tool works best with shapefiles as opposed to feature classes. Once the reaches were exported, the RivEx tool could be used. The RivEx tool was contained within ArcMap as a VBA script and could only be used within the .mxd document that was emailed after purchase. The .mxd document was opened in ArcMap and the reach shapefile was loaded into it.

Once the .mxd document contained a polyline shapefile, the RivEx tool became active. The tool first created an Fnode and Tnode field. This created a topology to trace the reach segment flow. After these fields were created, the tool created the Strahler ordering for the reaches. This processes added two fields to the reach shapefile: Strahler 
and Segment. The Strahler field contained the Strahler order for the reach and the Segment field contained a unique RivEX ID to the reach used to the reach. The fields added by the RivEx tool are illustrated in Table 10.

Table 10. Fields added by RivEx tool to the Ohio_Reaches featureclass

\begin{tabular}{|c|c|c|c|c|c|c|c|c|}
\hline 古 & \multicolumn{4}{|c|}{ Ohio_Reaches } & \multicolumn{3}{|c|}{$\begin{aligned} \text { Geometry } & \text { Polyline } \\
\text { Contains } \mathrm{M} \text { values } & Y e s \\
\text { Contains } \mathrm{Z} \text { values } & \text { Yes }\end{aligned}$} & \\
\hline & Field name & Data type & $\begin{array}{l}\text { Allow } \\
\text { nulls }\end{array}$ & Default value & Domain & $\begin{array}{l}\text { Prec- } \\
\text { ision } \mathrm{S}\end{array}$ & cale Length & \\
\hline & Fnode & Long integer & Yes & & & 0 & & Node that the reach flows from \\
\hline & Tnode & Long integer & Yes & & & 0 & & Node that the reach flows to \\
\hline & Strahler & Short integer & Yes & & & 0 & & Unique RivEx ID for reach \\
\hline & Segment & Long integer & Yes & & & 0 & & The reaches' Strahler order in the system \\
\hline
\end{tabular}

\subsubsection{The "Attribute Impedances" Model}

Now that each reach had a Strahler order, that information needed to be converted into a format that the network could use to properly include impedances based on this value.

In order for the network to understand Strahler orders as an impedance, seven Boolean fields needed to be added; one field for each Strahler order value present in the Ohio_Reaches feature class. If a segment has the Strahler order the field represents, a value of "1" is assigned. If not, the value is set to zero.

The "Attribute Impedances" model was essentially a series of "Add Field" and "Calculate Field" tools strung together to create and populate the fields described above. Table 11 shows the fields added by the model. To populate the fields, the Calculate Values tool ran the following VBA expression: $\operatorname{IIF}([$ Strahler $]=x, 1,0)$, where $\mathrm{x}$ equaled the Strahler value being tested. This command was called an "Immediate IF" (Perry, 1998). It looked for the value in the Strahler field and returned a "1" if the expression was true and a " 0 " if the expression was not. 


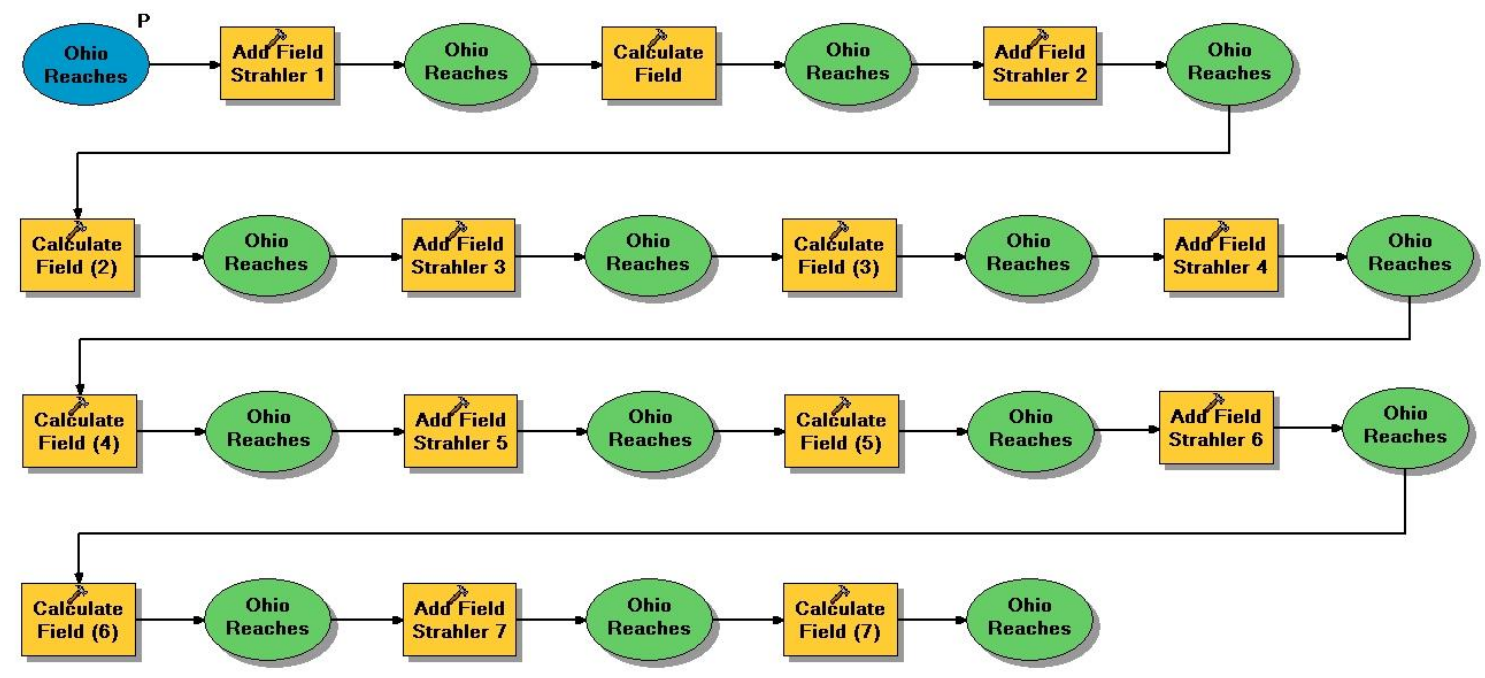

Figure 4-19: The "Attribute Impedances" model

Table 11. Fields added by the "Attribute Impedances" model

\begin{tabular}{|c|c|c|c|c|c|c|c|c|}
\hline 1 & \multicolumn{4}{|c|}{$\begin{array}{l}\text { Simple feature class } \\
\text { Ohio_Reaches }\end{array}$} & \multicolumn{3}{|c|}{$\begin{aligned} \text { Geometry } & \text { Polyline } \\
\text { Contains } M \text { values } & \text { Yes } \\
\text { Contains } Z \text { values } & Y e s\end{aligned}$} & \\
\hline & Field name & Data type & $\begin{array}{l}\text { Allow } \\
\text { nulls }\end{array}$ & Default value & Domain & $\begin{array}{l}\text { Prec- } \\
\text { ision } \mathrm{S}\end{array}$ & cale Length & \\
\hline & Restriction_1 & Short intege & Yes & & & 0 & & Indicates a Strahler order "1" reach \\
\hline & Restriction_2 & Short integer & Yes & & & 0 & & Indicates a Strahler order "2" reach \\
\hline & Restriction_3 & Short integer & Yes & & & 0 & & Indicates a Strahler order " 3 " reach \\
\hline & Restriction_4 & Short integer & Yes & & & 0 & & Indicates a Strahler order " 4 " reach \\
\hline & Restriction_5 & Short integer & Yes & & & 0 & & Indicates a Strahler order " 5 " reach \\
\hline & Restriction_6 & Short integer & Yes & & & 0 & & Indicates a Strahler order "6" reach \\
\hline & Restriction_7 & Short integer & Yes & & & 0 & & Indicates a Strahler order "7" reach \\
\hline
\end{tabular}

\subsubsection{Final Steps for the Reaches Feature Class}

Once the Ohio_Reaches feature class was in the Archive PGDB and the impedance fields calculated, they were ready for the final step. They were exported to the Perennial_Travel_Network feature dataset in the Hopewell_Earthworks PGDB. The feature class was renamed to Reaches during the process. This differentiated the archival file from the feature class participating in the transport network.

\subsection{Lake Erie}

The Lake Erie feature class represented the travel network's presence on Lake Erie. It represented a separate feature class from the reaches for two reasons: 1) it was not derived 
from the NHD, and 2) on the network, there was no upstream or downstream to Lake Erie and thus should have a single speed. The Lake Erie feature class resided in the feature data set Perennial_Travel_Network.

To create the Lake Erie feature class, the Counties layer was used as a template. Using a third party tool called ET GeoWizards (Tchoukanski, 2006), the county polygon feature class was converted into a polyline feature class. Then the polylines representing the northern portions of Ohio bordering Lake Erie were split and merged into one continuous polyline.

The next step was to download county borders for the State of Michigan, since a portion of subregion 4010 is located in Michigan. The county data were downloaded from Michigan's geographic data library (Information, 2006). The data were downloaded in shapefile format. The data were created from the Michigan DNR's MIRIS files. The MIRIS files were generated from digitized USGS Topographic 1:24,000 quadrangles.

The scale of data collection made this shapefile compatible with the data derived from the Ohio county data, which was also collected at 1:24,000 scale. The procedure for isolating the Michigan coast coincident with subregion 4010 was similar to the method used to isolate the Ohio coastline. First, the Michigan county polygon shapes were converted to polylines using the ET GeoWizard extension. The polylines forming the western coast of Michigan that resided in subregion 4010 were isolated and merged.

The resulting polyline was merged with the polyline representation of Ohio's shore. On the eastern side of Ohio, subregion 4011 stops about twenty kilometers west and nine kilometers south of the Pennsylvania/Ohio border. Consequently, the Ohio state boundary was left as the eastern border for the Lake Erie feature class. 
After the Michigan and Ohio coasts were merged, the Copy Parallel tool was used from the Editor toolbar in ArcMap to create a parallel line five meters off the coastline into Lake Erie. The operator then loaded the Ohio_Reaches feature class and manually went though and edited the Lake Erie feature class to connect to the reaches emptying into Lake Erie.

When a reach was found, the end of the reach was connected to a vertex location on the Lake Erie feature class (see Figure 4-20). This was done to assure that the Lake Erie feature class could integrate with the rest of the network using the Any Vertex connection policy for the final transport network. If no vertex existed on the Lake Erie feature class, a vertex was inserted so that the reach could be joined.

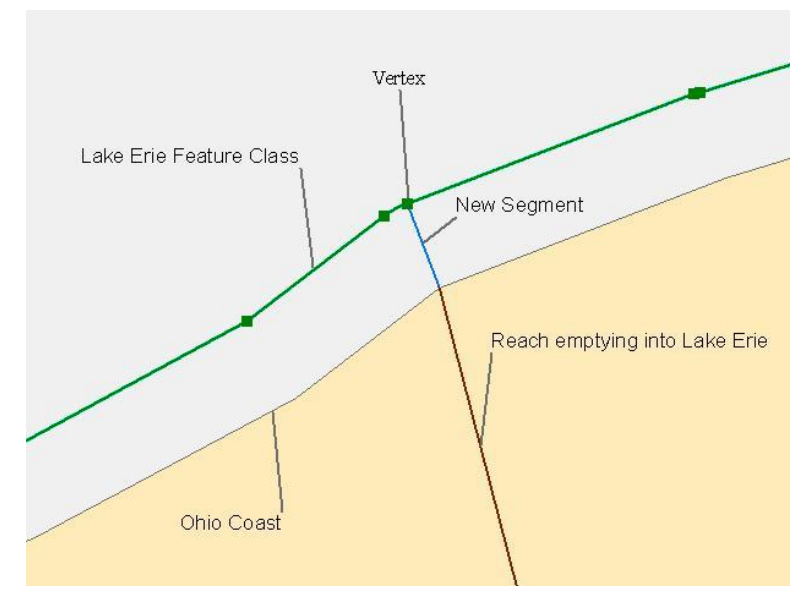

Figure 4-20: Example of a new segment added to the Lake Erie feature class

\subsection{Connectors}

The Connectors feature class was used to connect the Resource_Path feature class (Section 3.5.2) to the Reaches feature class. The Resource_Path feature class, in turn, was used to connect Earthworks feature class to the greater network. The Connectors feature class was created with the Create Water Connectors and Attribute Connectors models. The Connectors feature class needed to be rebuilt everytime the operator wanted to exclude 
earthworks from the network based on their proximity to major rivers of a given Strahler order.

\subsection{1 "Create Water Connectors" Model}

The "Create Water Connectors" model took an earthwork's location and found the nearest reach location within a user-defined search distance. This process goes through a Strahler filter that only searched selected reaches of a user-defined Strahler value. Once the near locations were found on the reaches, they were projected to a feature layer and are integrated with the Reaches feature class so that vertices occur at these locations and the connectors could participate in the network. Then it was necessary to run the “Attribute Impedance" model.

Section one of the model (Figure 4-21) used the "Select" tool to select reaches of the desired Strahler order based on the expression: [Strahler] $>=\mathrm{x}$ where $\mathrm{x}$ is the desired Strahler order. Once the reaches were selected, the Near tool was run with a user defined search radius to find the nearest reach point. When this point was found, the tool created a NEAR_X,NEAR_Y, and NEARID field in the Earthworks feature class. The tool then populated the fields with the $\mathrm{x}$ and $\mathrm{y}$ coordinates of the nearest location and the ID of the reach that contained this point. If there was no reach within the selected search radius, then a "-1" was placed in the "FID" field. 


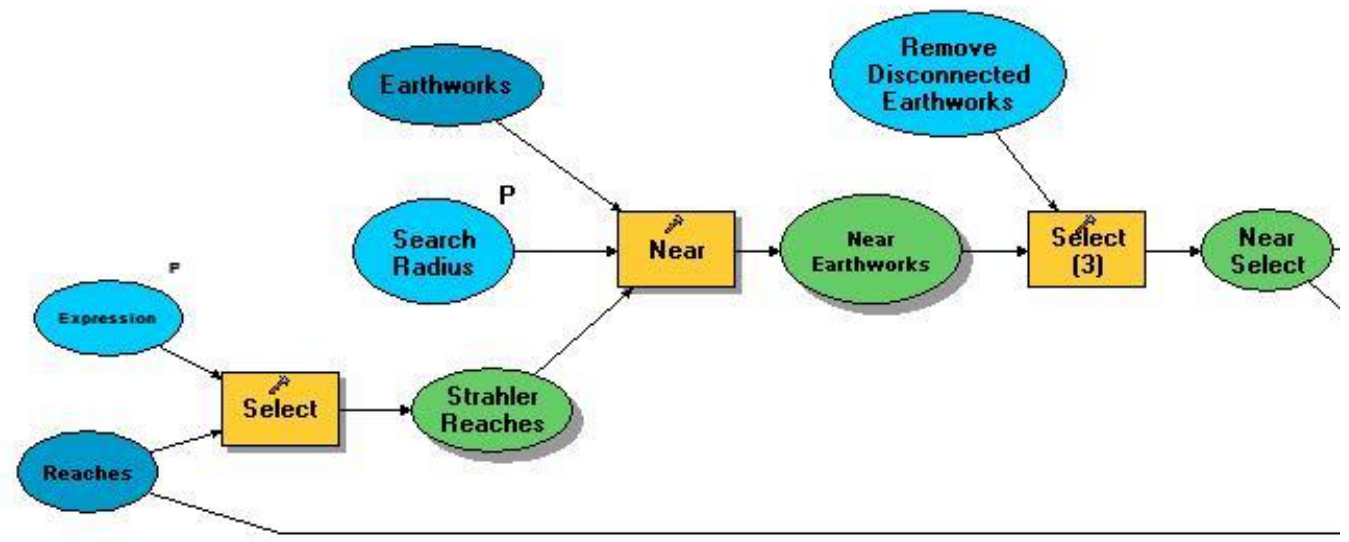

Figure 4-21: Section one of the Create Water Connectors model

The model then used the "Select" tool to filter the earthworks that did not have reaches within the near tool's search radius. It used the following SQL query on the Earthworks feature class: [NEAR_FID] $<>-1$. This removed all of the earthwork features that had a "-1" in the FID field, which indicated a negative result by the Near Tool.

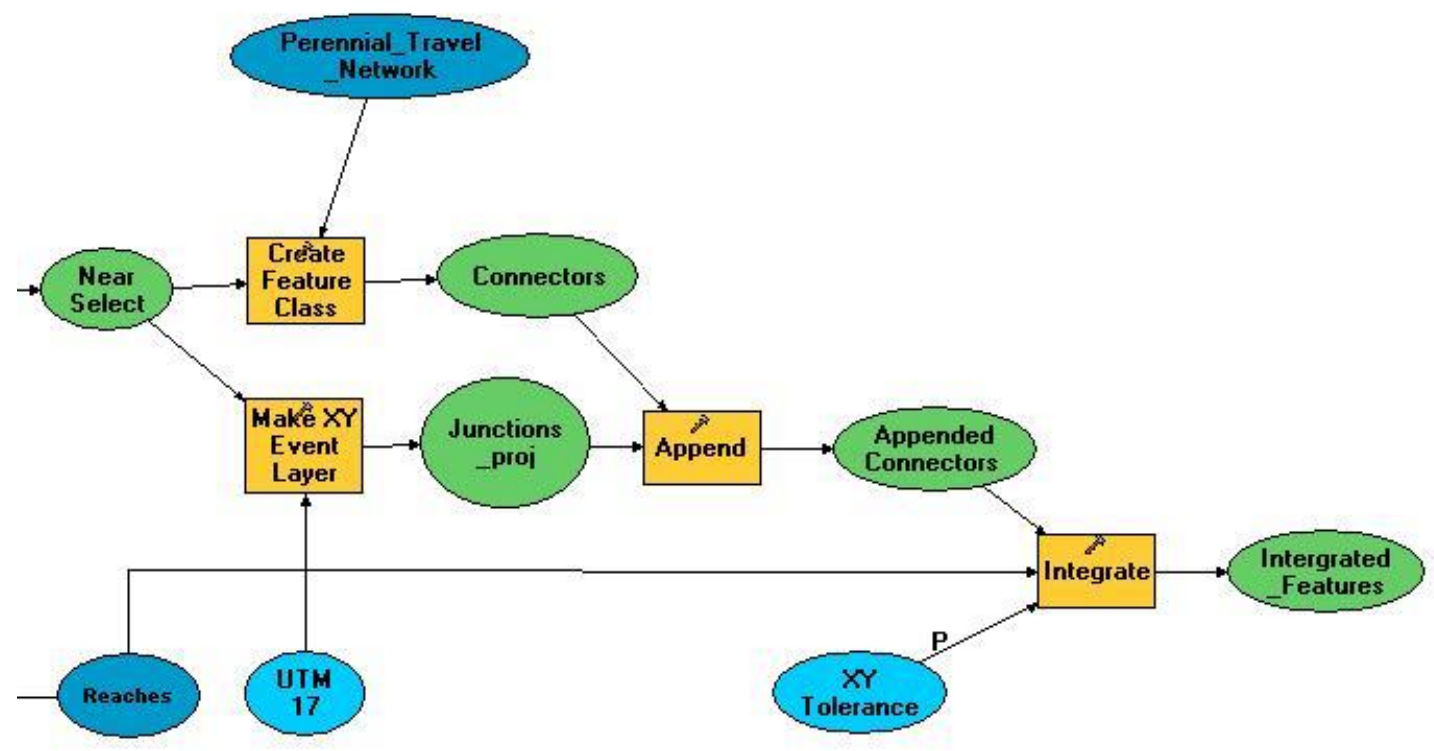

Figure 4-22: Section two of the "Create Water Connectors" model 
Section Two of the Create Water Connectors model (see Figure 4-22) took the filtered results of the second "Select" tool and ran the "Make XY Event Layer" tool to make a feature layer representing the near points on the reaches. Section Two of the model also took the result of the second Select tool and used it as a template for the Create Feature Class tool. This tool created a feature class called Connectors to append the results of the Make XY Event Layer. This step was necessary because the next tool, the Integrate tool, required two feature classes to integrate.

The "Integrate" tool took the Reaches feature class and integrated the Connectors feature classes within one meter tolerance. This produced a vertex in the Reaches feature class where the Connectors feature class was located. Again, this was done so that the connectors could connect to the reaches on the network through the Any Vertex connection policy of the network.

The Integrate tool had no outputs in the ModelBuilder environment. Consequently, the next steps for the Connectors feature class were contained in the Attribute Connectors model.

\subsubsection{The Attribute Connectors Model}

The Attribute Connectors model was immediately run after the Create Water Connectors model. This tool accomplished three goals:

1. It attributed the integrated Connectors feature class with its XY location as well as recorded the $\mathrm{X}$ and $\mathrm{Y}$ values for the earthwork that the connector serves.

2. The model created a table that would be utilized in populating the Resource_Path feature class which connected an earthwork to the connector. 
3. The model created the initial empty feature class Resource_Path that was used in the before mentioned population process

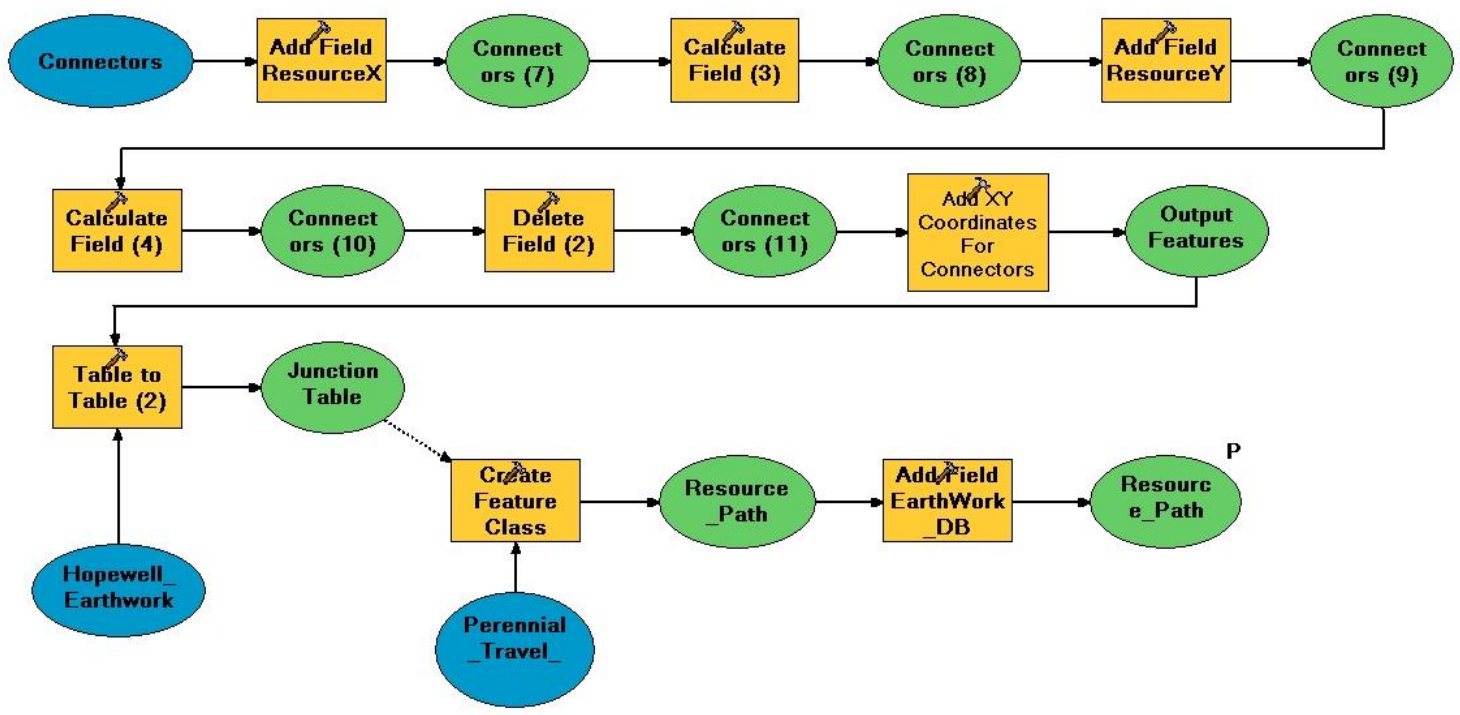

\section{Figure 4-23: The "Attribute Connectors" model}

The model began by documenting the XY coordinates for the earthwork that the connector serves. The Connectors feature class was created by running the "Near" tool in the "Create Water Connectors" model on the Earthworks feature class. The Earthworks feature class was created with the "Earthwork Extractor" model and used the "Add XY Coordinates" tool to attribute the feature class with its XY coordinates.

In order to populate the connectors with the new coordinates, this tool needed to be run again. Integrating can cause movements in the Connectors feature class depending on the XY tolerance. To keep the original earthwork XY coordinates, the model created two new fields with the Add Field tool: ResourceX and ResourceY. Two operations of the Calculate Field tool then transferred the appropriate attributes from the original fields to the new ones. This freed the $X$ and $Y$ fields to hold the XY's of the current Connectors feature class. This was accomplished by running the Add $X Y$ Coordinates tool after the 
earthwork attributes were transferred. The fields added by the Create Water Connectors and Attribute Connectors models can be seen in Table 12.

\section{Table 12. Fields added by the Create Water Connectors and Attribute Connectors models}

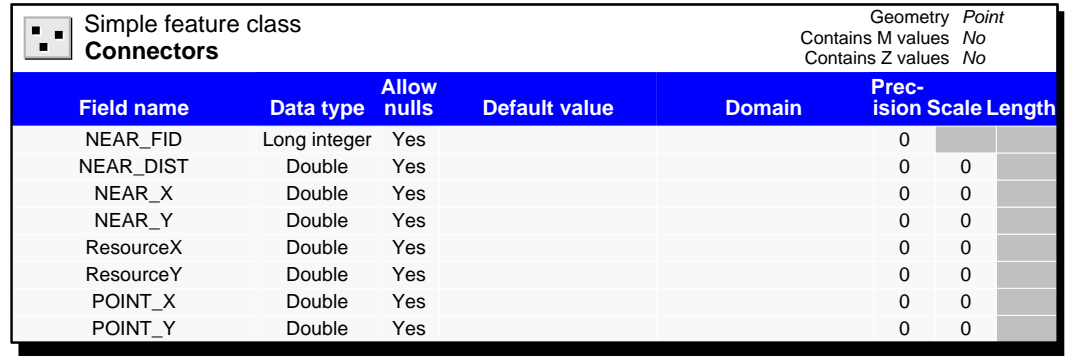

The FID of the reach the connector is located on The distance to the nearest earthwork from the connector

The original $\mathrm{X}$ coordinate of the connector

The original $\mathrm{Y}$ coordinate of the connector

The $\mathrm{X}$ coordinate of the nearest earthwork

The $\mathrm{Y}$ coordinate of the nearest earthwork

The current $\mathrm{X}$ coordinate for the connector

The current $\mathrm{Y}$ coordinate for the connector

The next part of the tool created a table to draw the Resource_Path feature class.

The "Table to Table" tool was ran on the Connectors feature class and created a table in the Hopewell_Earthworks PGDB called JunctionTable.

The last operation that the tool performs is to create an empty feature class called "Resource_Path". This empty feature class is the feature class that features were drawn to.

\subsection{Resource Path}

The Resource_Path feature class connected the earthworks over land to the reaches in the network. The initial Resource_Path feature class was created in the Attribute Connectors model (Section 3.5.2), but the feature class was empty. To draw the resource paths, this feature class needed to be brought into ArcMap along with the JunctionTable, also created by the "Attribute Connectors" model.

Once inside ArcMap, a Visual Basic for Applications (VBA) script read the resource location and connector location for each record and drew a segment from one to 
the other in the Resource_Path feature class. After running, the edits were saved and the Resource_Path were ready for inclusion in the network.

The only field that existed in the Resource_Path feature class was the EarthWork_DB field which indicated what earthwork the resource path was associated with. This field was created in the Attribute Connectors model and was attributed with the script, which read the unique EarthWork_ID field present in the JunctionTable inherited from the Connectors feature class.

\subsection{Counties}

The Counties feature class contained county borders for the State of Ohio. The source for this data set was originally downloaded from the Ohio DNR (Resources 2000) in coverage format. The coverage was imported into the Hopewell_Earthworks PGDB and projected into UTM Zone 17 NAD 83. This data was collected at a scale of 1:24,000 from DLGs.

\subsection{Eastern_States}

This dataset contained state boundaries for all US states east of the Mississippi, selected from ESRI's 2006 Data Discs and placed in the Hopewell_Earthworks PGDB. The data were meant to be used at a scale of 1:3,000,000.

\subsection{Geodetic Markers}

This feature class represents geodetic datums throughout Ohio. The National Geodetic Survey (NGS) allows the public to download the locations of NGS geodetic markers as a shapefile (NGS 1995). The data were downloaded from this site using the "Radial Search" method from the center of the state. 


\subsection{PT_Cities}

The PT_Cities feature class contained point locations for all major cities in Ohio. It was created by running an SQL query that isolated all cities in Ohio from the cities_dtl file on the ESRI 2006 Data Discs. The selection was then exported to a feature class in the Hopewell PGDB. The data was meant to represent city locations at a scale no larger than $1: 2,000,000$.

\subsection{Quads}

The Quads feature class represented the USGS Topographic 1:24,000 quadrangle boundaries for Ohio. The data was created by running the Select by Spatial Location" tool on the topoq24 feature set on the ESRI 2006 Datadiscs. This query selected all Quadrangle boundaries that intersected the Counties feature class. The results were then exported as the Quads feature class in the Hopewell_Earthworks PGDB. The data was meant to be used at a scale of 1:24,000.

\subsection{State_Boundary}

The State_Boundary feature class represented the political boundary of the State of Ohio. It was created by dissolving the Counties feature class, which was collected at a scale of 1:24,000 from DLGs.

\subsection{Urban_Areas}

The Urban_Areas feature class represented major urban area boundaries in Ohio. It was created by running an SQL query that isolated all cities in Ohio from the urban_dtl feature set on the ESRI 2006 Data Discs. The selection was then exported to a feature 
class in the Hopewell PGDB. The data was meant to represent city locations at a scale no larger than $1: 1,500,000$.

\subsection{Water_bodies}

This feature class represents all bodies of water in the State of Ohio. Modern reservoirs and the inundation areas caused by damming of rivers were filtered out with an SQL query. The feature class was created by merging all of the NHD_Waterbodies feature class from the subregions. This data is not used in the network. It was collected at a scale of 1:24,000 from USGS DLGs.

\subsection{Hopewell_Results Database}

The Hopewell_Results PGDB was the database that stored results. It contained one feature dataset named Results_Feature_Classes. The only way to populate this database was to run the Earthworks To Table model, discussed below. Since this database only returned results run by analysis, its contents varied on the numbers of analyses run.

\subsubsection{The "Earthworks To Table" Model}

This model (Figure 4-24) was run after a service area analysis was performed. It took the resulting area polygons produced in the analysis and wrote the coincident earthworks inside them to a table in the database. It also wrote a feature class containing the earthworks to the feature dataset. The model was set up so that these two files have the same name, the feature class and the table which shared the same name with the suffix “_". 


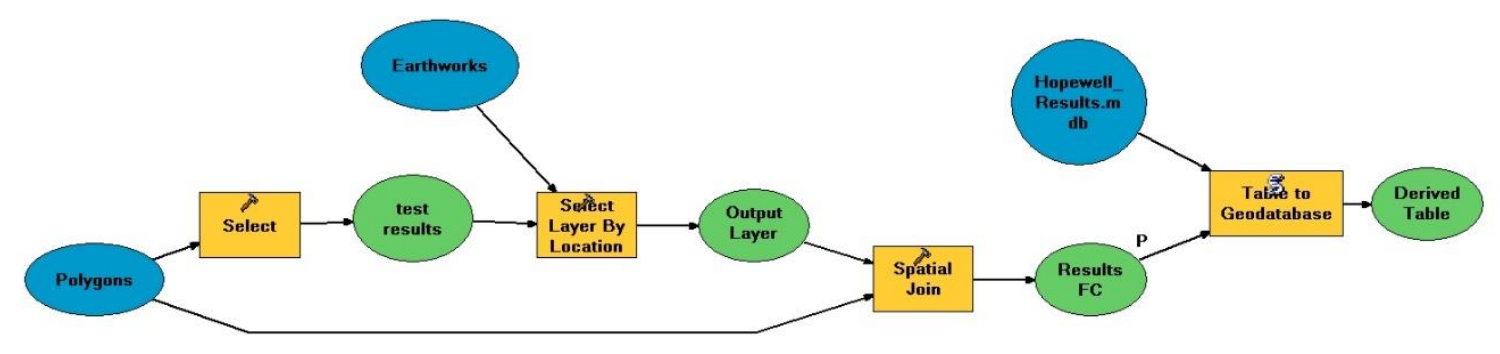

\section{Figure 4-24: The "Earthworks to Table" model}

The model started out by using the "Select" tool to select out the polygon coverage of travel area created by the Service Area analysis. Once this was selected, the "Select By Location" tool selected all the earthworks that intersected the polygon; next, the "Spatial Join" tool joined the attributes of the travel area polygons with the attributes of the earthworks that resided inside of them. The resulting feature class was written to the Results_Feature_Classes dataset. The "Table to Geodatabase" tool then took the feature class and wrote its attributes to a table in the database. Since there was already an object with the name of the table (the feature class) the tool automatically added the "_ 1 " suffix to the feature class.

The model added several fields to the original Earthworks feature class attribute table (Table 13). These fields were written to both the results table and the resulting feature class. The Join_Count field indicated how many spatial joins the record represented. The Facility_ID field represented the Service Area ID for an earthwork. This number was largely dependent on analysis at the time and meant little once the analysis session was closed. The "Name" field gave the unique earthwork id for the record and the time break it was in. This field is the most important as it showed from what destination earthwork the analysis was started from and gives the general time 
window it was in. FromBreak gave the time window immediately before the one the earthwork was located. The ToBreak gave the time window in the analysis directly after the one the earthwork was located in.

Table 13. Analysis fields added to the Earthworks to Table model

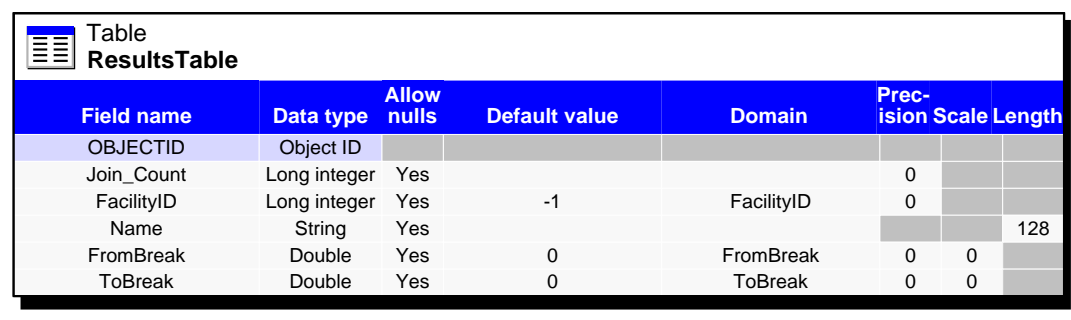

Tabular output of earthworks reachable in the specified distance

Indicates the number of joins th result represents The analysis facility that the travel area belongs to Indicates the name of the earthwork
Indicates the time window before the one the travel area represents

Indicates the time window after the one the travel area 



\section{Chapter 5 - Methodology}

The methodology of this project was based on running a service layer analysis using ESRI's Network Analyst Extension. The analysis settings were set, the earthworks were selected to test travel from, and the analysis was then run. After the analysis was completed, the operator then ran a model that wrote the results into a point feature class and table in the Hopewell_Results PGDB. This chapter documents the steps taken to perform the final analysis on the network data set.

\subsection{Basic Network Components}

The network consisted of four basic components: earthworks, resource or land, paths, connectors, and reaches. To illustrate how the components work together, Figure 5-1 traces movement from one earthwork to another in the network.

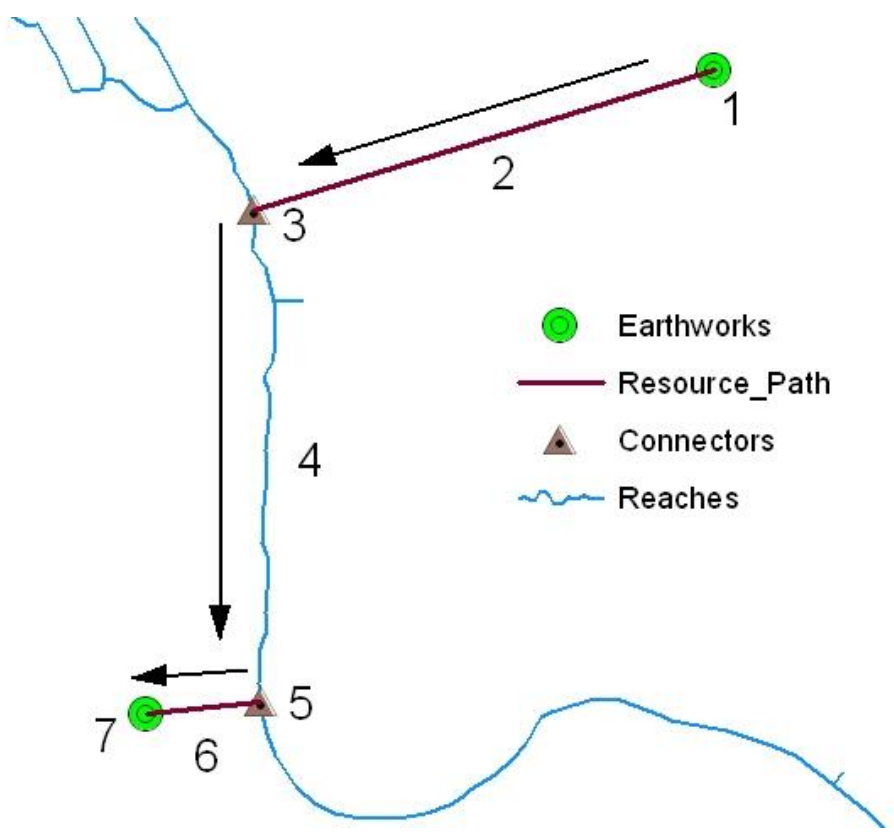

Figure 5-1: Basic Network Components and Their Interaction 
The Lake_Erie feature class was another component to the network, in addition to these four basic components. This feature class was created to deal with navigation on the lake. This feature class acted like a reach in that it afforded water travel. However, the travel cost was determined to be different for canoes on the lake than along reaches.

There was a noticeable lack of discussion about any type modeling of portages in the network throughout Chapter Three. This was due to the nature of the dugout canoe that the Hopewell would have used. These craft were essentially large hollowed out logs. Several roughly seven meter long craft, at least one of which was made of white oak, have been recovered from a small kettle lake in Ohio. Portaging these large craft would have been impractical and undesirable (Brose, 1990). Consequently, portaging was not factored into this model.

\subsection{Network Travel Cost}

The network needed to have a cost to measure travel on the network. Hours were chosen as an acceptable unit for cost since the network was built to measure travel within a day. This cost still had length at its basis, however. Hours were calculated by entering an hourly rate in meters per hour. Given this rate, the network calculated how much distance could be covered in a given time.

This rate can be changed for directional movement across a line. This property was used to model both upstream and downstream travel in the network. The NHD was created in such a way that lines were drawn directionally with reach flow. It is possible for two feature classes to have different travel costs in the same network. This allowed the network to model different movement rates for foot travel as opposed to dugout canoe 
travel. The next two subsections discuss travel costs in the network for the linear feature classes participating in the network.

\subsubsection{Reach Travel Cost}

The reach speed for the network was determined from an article published by Brose (1990) in which he investigated the relative value of goods in Hopewell trade networks based on energetic transportation cost. The article gave a value of 76 kilometers per day downstream and 30 kilometers per day upstream. Given a 10 hour travel day, this worked out to 7.6 kilometers per hour downstream or roughly five miles per hour. and three kilometers per hour upstream, or roughly two miles per hour upstream.

\subsubsection{Lake Erie Travel Cost}

Lake Erie needed to be modeled separately from the reaches because there is no real upstream or downstream flow in the lake. However, there are a host of other factors to consider. Elizabeth Little writes:

Particular problems arise quickly on the Great Lake, such as high winds, great waves, and "set-up" and seiche, which are waves not necessarily associated with local winds (Bonnécamps, 1900; Croghan, 1904; Galinée, 1917; O'Callaghan, 1853 - 1887:5:730; Phillips and McCulloch, 1972:36; Tonti, 1917). Because of these dangers, canoeists on big lakes must keep close to shore and safety (Morse, 1962: 28-29), and historic lake travel times were more variable than travel times on rivers (Bonnécamps, 1900) (Little, 1997, II 57-58).

With conditions such as these, it was difficult to pick a suitable rate of speed for Lake Erie. For this model, a rate of 5.7 kilometers per hour (roughly 3.5 miles per hour) was chosen as the constant Lake Erie speed. This number was derived from averaging the upstream three kilometers per hour speed with the downstream speed of 7.6 kilometers per hour. 


\subsubsection{Foot Travel Cost}

The foot travel speed over land for the network was decided from an article by Balstrøm (2002), in which he investigated rain gauge paths in a mountainous terrain. Balstrøm gave a rate of about 4.5 kilometers per hour for a pedestrian walking over terrain between $0-12 \%$ slope. This was the rate given for foot travel across land in the network.

\subsection{Restrictions}

The NHD data set used for the reaches contained all the hydrology for the US. This included small streams and rivers which were too small to allow passage with a dugout canoe. This presented the problem of discerning traversable and non-traversable reaches in the network. One method of discerning navigable reaches was to look at the reaches' streamflow. Streamflow is how much water passes through a given point in a stream per minute (USGS, 2005). This gives an idea of stream size and how much water is in a stream, which is directly related to whether or not a boat can float and navigate a river.

The downloadable NHD data did not contain streamflow data in the data set. The USGS does have stream flow stations set up at select rivers across the US. However the current data are sparse and these stations were not a solution to the problem. Instead, this project classified the NHD data using Strahler order to approximate stream flow. This classification system gave an indication of general water flow capacity, with rank increasing alongside flow. The more streams that flow into a central stream, the larger the central stream would have to be to take in the additional amount of water and so a sequential number can be assigned (see Figure 5-2).

Where a stream starts, an order of one is assigned to it. When two ones merge into a stream, that length of stream is given a two. If three ones flow into a stream, that 
number still retains a two. Only when two twos flow into a stream does it become a three. The pattern continues on in this manner (Strahler, 1957). The travel network utilized Strahler ordering to connect or disconnect streams from consideration in the travel network at the researcher's leisure.

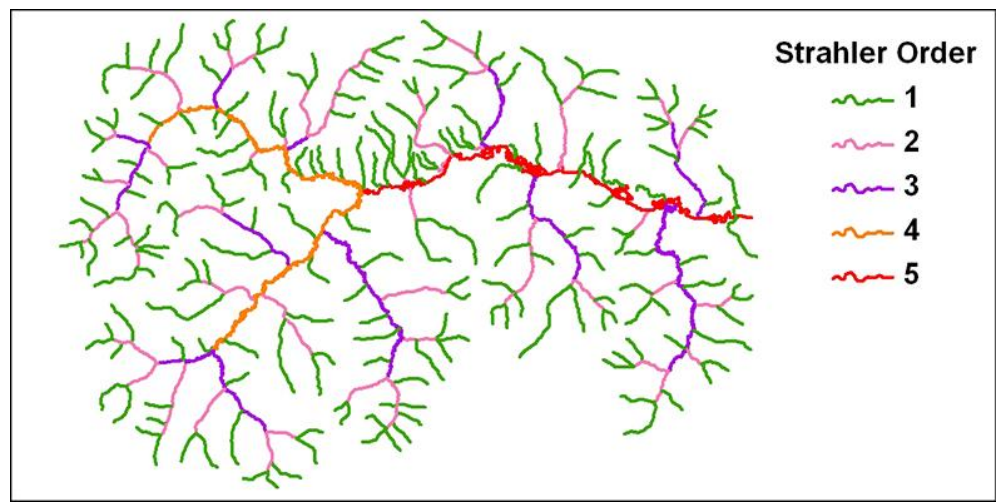

Figure 5-2: An example of Strahler Ordering.

\subsection{Building the Network}

The next step was to build the network out of the above components. The five components discussed in section 5.1 made up the spatial framework of the network, representing the actual space that can be traversed. Section 5.2 discussed the costs used to travel through the network. Section 5.3 discussed restrictions placed on the network given the Strahler stream order and the operator's discretion. The same procedure was used to create the final network with a few exceptions.

One exception to the process was inclusion of participating elements and the connectivity settings. Rather than just one feature class participating, the five feature classes discussed in section 5.1 were used to build the network.

Connectivity changed significantly. While the connectivity policy was kept to Any Vertex, another column of connectivity was added. Reaches were set to connect only to connectors. Connectors were set to connect to reaches and Resource_paths. 
Resource_paths were set to connect to earthworks and the land paths. The connectivity settings for the network can be seen in Figure 5-3.

\begin{tabular}{|c|c|c|c|c|}
\hline \multicolumn{4}{|l|}{ Network Dataset Properties } & $? \times$ \\
\hline \multirow{2}{*}{\multicolumn{5}{|c|}{ General| Sources Connectivity |Elevation | Turns |Attributes | Directions }} \\
\hline & & & & \\
\hline Source & Connectivity Policy & & 2 & \\
\hline LakeErie & Any vertex & $\square$ & $\nabla$ & \\
\hline Reaches & Any vertex & $\square \nabla$ & $\nabla$ & \\
\hline Resource_Path & Any vertex & $\nabla$ & $\square$ & \\
\hline Connectors & Honor & $\nabla$ & $\nabla$ & \\
\hline Earthworks & Honor & $\nabla$ & $\square$ & \\
\hline
\end{tabular}

\section{Figure 5-3: Final Network Connectivity Settings}

The last change between building the final network and the edit networks involved the travel cost. For the edit networks, distance was used as the cost. For the final network, the costs discussed in section 5.2 were used for each linear element of the network.

\subsection{Service Area Analysis Layer}

"Service areas model accessibility along the network and facilities..." (ESRI, 2006).

The Service Area analysis started from a chosen facility or facilities in the network and modeled the accessibility out based on the travel cost. Service Area analysis was originally designed to find the serviceable areas for facilities such as hospitals, police stations, and fire stations in modern street networks (ESRI, 2006). However, this project utilized it to find the service areas of the earthworks.

\subsection{Running the Analysis}

To run the actual network analysis, the GIS used ESRI's Network Analyst extension. A Service Area analysis layer was created and selected earthworks were loaded into the 
layer as facilities. The travel cost for the network was set to a time travel cost whose values were discussed in section 5.3. The Network analyst extension allowed for multiple times to be entered; these multiple times were called Breaks. For example, it was possible to create travel areas for different hourly travel ranges. It was then necessary to set up the restrictions for navigable rivers.

Once these settings were initiated, it was a matter of solving the network by a Service Area analysis. At this point, the results were graphical. The travel area polygons contained attributes about what facility (earthwork) it came from and what break range it was in, but these data only existed in memory and would cease to exist once the analysis .mxd was closed.

To make these data permanent, the operator ran the "Earthwork To Table" model to write the results to a table and a separate feature class. This table could then be easily exported to an Excel table per the client's request. 



\section{Chapter 6 - Results and Analysis}

Initial results were promising for the project and showed signs that this tool would be useful to the client. The project modeled dugout canoe movement in a consistent manner, results were easily duplicated in different model runs with the same behavior. Over all this tool is useful for the client. The main feature that works is the customizability of the project to allow for various "what if" scenarios with what navigable rivers to choose or what earthworks one would want to build the network with.

The Esri Network Analyst Service area analysis showed itself to be the best way to accomplish the goal of the project, though there was one drawback to using this type of analysis. Both are discussed below.

\subsection{What Worked}

\subsubsection{Impedances}

The service area analysis allowed parts of the network to be considered "off limits" for an analysis run. This was useful because the NHD data used to construct the stream portion of the network contained all hydrology for the area, including streams that were not ideal for navigation but essential to the makeup of river systems. By using Strahler ordering to code these streams, they were able to be "filtered out" by the network and represent a more accurate environment that the canoes would travel.

\subsubsection{Travel Cost}

The service area analysis's ability to easily assign cost of traveling the network, in the project's case distance that can be covered in X amount of time, was another useful 
feature. The ability to assign each segment in the network different costs worked exceptionally well for the land vs. stream component of the network.

\subsubsection{Polygon Output}

The ability to create a polygon that encapsulated the total travel area of an analysis run was critical to making sense of the results of each analysis output. The polygon resulting from the analysis could easily be used to find all intersecting earthworks and facilitated the ability to summarize reachable earthworks in table form as well as extract a point file of the earthwork locations for further study.

\subsection{What didn't Work}

\subsubsection{Physical Build Constraint of the Service Area Network}

There was a major feature of the network service area analysis that was not a perfect fit with this project. That was the rigidness of the network once it was created. Once lines were in place in a finished network, they could not be modified without rebuilding the whole network. The reason this was not optimal for this project had to deal with the earthworks themselves. As mentioned above, not all streams were navigable that were present in the network and a decision had to be made of which Strahler order streams to

filter out. While the ability to dynamically choose the streams in the service area analysis is useful, the problem lies with the land paths generated by the tool to the nearest stream point. When the land paths are generated, they must be included in the network beforehand. When new earthworks are added and their paths to the nearest stream landing location calculated, a Strahler order must be decided at this stage where the path from the earthwork to the river is drawn. Once it is decided, it cannot be changed without rebuilding the network. This then could lead to a situation where the land paths 
for an earthwork lead to a smaller Strahler order stream than was chosen as navigable by a service area run. For this reason, a new network dataset would have to be built for each minimum Strahler order in order to ensure a connection to the network. Fortunately, a series of geoprocessing models was created that make building a new network dataset relatively easily, accomplishing the task with just a few clicks.

\subsubsection{Geoprocessing/Data Construction Tools}

Most of the data construction and network building for this project was done through a series of geoprocessing models and a Visual Basic for Applications (VBA) script that automated repetitive tasks. While all of these tools worked, they needed to be broken into smaller pieces for them to work. This led to a series of steps the user has to go through before the data is ready. What might have worked better for this would be the creation of a program that linked all of these steps together and the entire suite of operations accomplished by filling out all the options on just one form and clicking "go" button. This would require using a .Net or Java programming language. This would be an advantage over the VBA script which is used to draw the paths from earthwork to stream, as Esri has hinted that they will discontinue support for VBA in future releases.

\subsubsection{Determining Navigable Rivers}

For this project, Strahler Order of streams was used to give a general classification for what streams were considered navigable. While Strahler order is a good relative estimate for estimating flow, it does lack hard numbers. For example, a Strahler order two stream in a watershed may be perfectly navigable, but a Strahler order two stream in another watershed may not be. This is because Strahler order doesn't measure the area drained by a stream, but rather how many branches flow into it. This means that to determine an 
effective Strahler order to use, one must have some familiarity with the area being studied or do some research prior to running the model. At the current time, there is no easily accessible good flow data that have hard numbers that would be useful in determining river navigability. 


\section{Chapter 7 - Conclusions and Future Work}

\subsection{Conclusion}

This project sought to test the feasibility of prehistoric peoples' ability to visit Hopewell Geometric Earthworks within socially and culturally meaningful timescales. Given the paucity of earthworks currently left on the landscape, earthwork locations need to be frequently updateable as current historical and archaeological research progresses and adds new information to our canon of known locations. Additionally, the framework to test movement across this ancient landscape needed to be dynamic enough to incorporate potential newly discovered barriers in travel such as water flow in high flow/dry seasons and potential physical barriers that may have existed on the ancient client to test various "what if" scenarios. The tool accomplished these goals. It consistently produced the same results when given the same information. The main benefit of this tool lay in its ability to automate the network creation process and the ability to filter out different streams to represent different waterflow scenarios.

\subsection{Future Work}

Several components of this tool would benefit from further development. The automated data building of the network would benefit from a redesign where all components are run from a central location such as a form that is accessed from one button or tool bar in the ArcMap interface. This program would be an add-in to the ArcMap interface and would need to be programmed in .Net or Java. 
Another area that could be developed would be a method to locate natural barriers such as waterfalls. A method could be developed that looks at the slope along each reach and if the slope goes up strikingly, this very well could indicate a waterfall in the hydrology. A point restriction could be then added at this point to indicate an unpassable reach.

To solve for round trip distances, a new cost could be added to the network dataset as a formula that adds both the upstream and downstream costs together, indicating a round trip time for each reach.

River navigability determination in the system could be could be improved as follows:

- The USGS released the NHD+ dataset in 2007 through a private vendor. This dataset contains data on flows at over 1.5 million sites. This flow data could be used to identify rivers that were likely navigable in prehistoric times.

- Another approach that might be more accurate than using Strahler order to approximate flow would involve using precipitation data and drainage area for a reach. Oregon State University ran a site called PRISM (2007) that averaged rainfall for the $20^{\text {th }}$ century across the United States. A method could be developed to approximate navigable conditions based on how much area a reach drains in the watershed in addition to the average rainfall in the area drained. Additionally, the PRISM site offered rainfall data by year. The data could be analyzed to find wet or dry years and modeled accordingly.

- Use USGS Gauge data and precipitation data for a watershed to create a flow ratio based off of the area of watershed drained above the gauge over the 
average precipitation. This ratio could then be used to estimate flow in reaches that do not have a USGS gauge in the watershed. 


\section{Works Cited}

Allen, K. M. S. (1990). Modeling early historic trade in the eastern Great Lakes using geographic information systems. Interpreting Space: GIS and archaeology. Allen, K.M.S., Green, S.W., Zubrow, E.B. London, Taylor \& Francis: 319-329.

Arctur, D., \& Zeiler, M. (2004). Designing geodatabases : case studies in GIS data modeling. Redlands, Calif., ESRI Press.

Balstrøm, T. (2002). "On identifying the most time-saving walking route in a trackless mountainous terrain." Geografisk Tidsskrift, Danish Journal of Geography 102: 51-58.

Batty, M. (2005). Approaches to Modeling in GIS: Spatial Representation and Temporal Dynamics. GIS, spatial analysis, and modeling. D. J. Maguire, Batty, Michael, Goodchild, Michael F., Redlands, Calif., ESRI Press: 480 p.

Bell, T. L., \& Church, R.L. (1985). "Location-Allocation Modeling in Archaeological Settlement Pattern Research: Some Preliminary Applications." World Archaeology 16(3): pp. 354-371. 
Bernardini, W. (2004). "Hopewell Geometric Earthworks: a case study in the referential and experiential meaning of the monuments." Journal of Anthropological Archaeology 23(3): 331-356.

Branting, S. (2004). Iron Age Pedestrians at Kerkenes Dağ: An archaeological GIS-T approach to movement and transportation. Department of Anthropology. Buffalo, State University of New York. Doctor of Philosophy: 167.

Brose, D. S. (1990). "Toward a Model of Exchange Values For The Eastern Woodlands." Midcontinental Journal of Archaeology 15(1): 100 - 136.

Carr, C., \& Case, T. (2006). The Gathering of Hopewell. Gathering Hopewell: Society, Ritual, and Ritual Interaction. New York, Springer: 19-50.

Charles, D. K. (1992). "Woodland Demographic and Social Dynamics in the American Midwest: Analysis of a burial Mound Survey." World Archaeology 24(2): 159 - 173.

Dancey, W., \& Pacheo, P. (1997). A community model of Hopewell settlement. Ohio Hopewell Community Organization. W. Dancey, Pacheo, P. Kent, Kent State University Press: p. 3-40. 
Emge, T. (2007). "TerraServer Download for ArcGIS 9.2." Retrieved February 23rd, 2007, from http://arcscripts.esri.com/details.asp?dbid=14816.

ESRI. (2006). "Linear Modeling With Networks." Retrieved February 15th, 2007, from http://edndoc.esri.com/arcobjects/9.2/CPP_VB6_VBA_VCPP_Doc/shared/working_arcg is/work_networks/Networks_MOW2_draft.pdf.

Fagan, B. M. (1995). Ancient North America : the archaeology of a continent. New York, N.Y., Thames and Hudson.

Gleyzer, A., Denisyukm M.R., Alon, S., \& Yigal (2004). "A Fast Recursive GIS Algorithm for Computing Strahler Stream Order in Braided and Nonbraided Networks." Journal of the American Water Resources Association 40(4): 937-946.

Hayden, W. E. (1996). A Landscape based regional analysis of settlement patterns in the San Joaquin Hills, Orange County, California. Anthropology. Fullerton, California State University. Master of Arts: 77.

Hill, J. B. (2006). Human ecology in the Wadi al-Hasa : land use and abandonment through the Holocene. Tucson, University of Arizona Press. 
Hornby, D. (2007). "RivEx - a vector river network processing tool for ArcGIS 9."

Retrieved April 15th, 2007, from http://www.rivex.co.uk/.

Howey, M. C. L. (2007). "Using multi-criteria cost surface analysis to explore past regional landscapes: a case study of ritual activity and social interaction in Michigan, AD 1200 - 1600." Journal of Archaeological Science 34(11): 1830 - 1846.

Kennedy, M., \& Kopp, S. (2000). Understanding Map Projections. Redlands, CA., ESRI Press.

Lee, J., \& Stucky, D. (1998). "On applying viewshed analysis for determining least-cost paths on Digital Elevation Models." International Journal of Geographical Information Science 12(8): 891-905.

Little, E. A. (1987). "Inland Waterways in the Northeast." Midcontinental Journal of Archaeology 12(1): pp 55-76.

Llobera, M. (2000). Understanding Movement: a pilot model towards the sociology of movement. Beyond the map : archaeology and spatial technologies. G. R. Lock. Amsterdam, IOS Press ; Ohmsha [distributor]: 65-84. 
Llobera, M. (2003). "Extending GIS-based visual analysis: the concept of visualscapes." International Journal of Geographical Information Science 17(1): 25-48.

Longley, P., Goodchild, M. F., Maguire, D.J., \& Rhind, D.W. (2005). Geographical information systems and science. Chichester ; Hoboken, NJ, Wiley.

Machovina, J. (1996). Modeling of pedestrian mobility across a natural landscape using a geographic information system. Columbus, University of Ohio. M.A.: 93.

Mackie, Q. (1998). The Archaeology of Fjordland Archipelagos: mobility networks, social practice, and the built enviornment. Archaeology. Southampton, University of Southampton. (Doctoral dissertation): 228.

Maidment, D. R. (2002). Arc hydro : GIS for water resources. Redlands, Calif., ESRI Press.

McIntyre, M. P. (1985). Physical geography. New York, Wiley.

Olivera, F., Maidment, D., \& Honeycutt, D. (2002). Hydro networks. Arc Hydro: GIS for water resources. D. Maidment. Redlands, ESRI Press: pp. 33 - 53. 
Prufer, O. H. (1964). The Hopewell Complex of Ohio. Hopewellian Studies. J. Caldwell, Hall, J., Caldwell, J., Hall, R. Springfield, Illinois State Museum, Scientific Papers. 12: $35-83$.

Renfrew, C., \& Bahn P.G. (2000). Archaeology : theories, methods, and practice. New York, Thames and Hudson.

Ruby, B. J., Carr, C., \& Charles, D. K. (2004). Community Organizations in the Scioto, Mann, and Havanna Regions. Gathering Hopewell - Society, Ritual, and Ritual

Interaction. C. Carr, Case, D. Troy. New York, Springer: 119-176.

Savage, S. H. (1990). Modeling the Late Archaic social landscape. Interpreting space :

GIS and archaeology. K. M. S. Allen, S. W. Green and E. B. W. Zubrow. London ; New York, Taylor \& Francis: 330-355.

Snyder, J. P., \& P. M. Voxland (1989). An album of map projections. Denver, CO, U.S. G.P.O.

Tobler, W. (1993). Three Presentations on geographical analysis and modeling. Santa Barbara, National Center for Geographic Information and Analysis: 24. 
Turnbaugh, W. A. (1999). Understanding physical anthropology and archaeology. Belmont, CA, West/Wadsworth.

USGS. (2000). "The National Hydrologic Dataset: Concepts and contents." Retrieved October 16th, 2006, from http://nhd.usgs.gov/chapter1/index.html.

USGS. (2006). "NHD Geodatabase." Retrieved October 3rd, 2007, from http://nhdgeo.usgs.gov/viewer.htm.

USGS. (2007a). "ftp://nhdftp.usgs.gov/SubRegions/." Retrieved October 5th, 2006, from ftp://nhdftp.usgs.gov/SubRegions.

USGS. (2007b). "USGS: National Hydrography Dataset." Retrieved January 23rd, 2007, from http://nhd.usgs.gov/.

Wheatley, D., \& Gillings, M. (2002). Spatial technology and archaeology : the archaeological applications of GIS. New York, Taylor \& Francis.

Whitley, T. B. (2002). "Spatial Variables as Proxies for Modeling Cognition and Decision-Making in Archaeological Settings: A Theoretical Perspective." Retrieved 
October 22nd, 2006, from http://www.brockington.org/research/papers/TAG2002-

Whitley.pdf.

Zeiler, M. (1999). Modeling our world : the ESRI guide to geodatabase design. Redlands, CA, ESRI Press.

Zeiler, M. (2001). Exploring ArcObjects Vol II - Geographic Data Management. Redlands, CA, ESRI Press.

Zubrow, E. B. W. (1990). Modelling and prediction with geographic information systems: a demographic example from prehistoric and histroic New York. Interpreting space: GIS and archaeology. K. M. S. Allen, S. W. Green and E. B. W. Zubrow. London, New York, Taylor \& Francis; 307-318. 


\section{Appendix A. Important but Extraneous Information}

Put information and/or data here that are extraneous to your document. All of the content

and the formatting of the Appendices should be discussed with and agreed upon by

your committee chair. 